Cahiers $d u$ MONDE RUSSE

\section{Cahiers du monde russe}

Russie - Empire russe - Union soviétique et États indépendants

42/2-4 | 2001

La police politique en Union soviétique, 1918-1953

\title{
Wie Dder terror "Gross" wurde: Massenmord und Lagerhaft nach Befehl 00447
}

\section{Rolf BINNER et Marc JUNGE}

\section{OpenEdition}

Journals

Édition électronique

URL : https://journals.openedition.org/monderusse/8470

DOI : $10.4000 /$ monderusse. 8470

ISSN : $1777-5388$

Éditeur

Éditions de l'EHESS

\section{Édition imprimée}

Date de publication : 1 avril 2001

Pagination : 557-614

ISBN : 2-7132-1398-3

ISSN : $1252-6576$

Référence électronique

Rolf BINNER et Marc JUNGE, "Wie Dder terror "Gross" wurde: Massenmord und Lagerhaft nach Befehl 00447 », Cahiers du monde russe [En ligne], 42/2-4 | 2001, mis en ligne le 01 janvier 2007, consulté le 02 septembre 2022. URL : http://journals.openedition.org/monderusse/8470; DOI : https://doi.org/10.4000/monderusse.8470 
chercher : repérer : avancer

Cet article est disponible en ligne à l'adresse :

http://www.cairn.info/article.php?ID REVUE=CMR\&ID NUMPUBLIE=CMR 422\&ID ARTICLE=CMR 4220557

\section{Wie Dder terror "Gross" wurde: Massenmord und Lagerhaft nach Befehl 00447}

par Rolf BINNER et Marc JUNGE

\section{Editions de l'EHESS | Cahiers du monde russe}

2001/2-3-4 - Vol 42

ISSN 1252-6576 | ISBN 2713213983 | pages 557 à 614

Pour citer cet article :

-BINNER R. et JUNGE M., Wie Dder terror "Gross” wurde: Massenmord und Lagerhaft nach Befehl 00447, Cahiers du monde russe $2001 / 2-3-4$, Vol 42, p. 557-614.

Distribution électronique Cairn pour les Editions de l'EHESS.

(C) Editions de l'EHESS. Tous droits réservés pour tous pays.

La reproduction ou représentation de cet article, notamment par photocopie, n'est autorisée que dans les limites des conditions générales d'utilisation du site ou, le cas échéant, des conditions générales de la licence souscrite par votre établissement. Toute autre reproduction ou représentation, en tout ou partie, sous quelque forme et de quelque manière que ce soit, est interdite sauf accord préalable et écrit de l'éditeur, en dehors des cas prévus par la législation en vigueur en France. Il est précisé que son stockage dans une base de données est également interdit. 


\section{WIE DER TERROR “GROSS” WURDE: MASSENMORD UND LAGERHAFT NACH BEFEHL 00447}

Mehr als 750.000 Menschen wurden getötet oder in Lager eingewiesen. Dennoch gab es über diese monströse Operation, die vom höchsten Gremium der Kommunistischen Partei der Sowjetunion, dem Politbüro, befohlen und unter seiner Kontrolle durchgeführt wurde, bis zur Archivrevolution in Rußland nur rudimentäre und fragmentarische Informationen. Der Entscheidungsprozeß im Politbüro, die Planung der Aktion durch die Geheimpolizei und ihre flächendeckende Durchführung geschahen unter strikter Beachtung aller Regeln der Geheimhaltung, so daß kein offizielles Schriftstück bekannt wurde, in dem auch nur Spuren der Aktion zu finden waren. Das blieb so bis zum Ende der Sowjetunion. In den Erinnerungen von Zeitzeugen finden sich bisweilen bruchstückhafte Nachrichten über die Operation. So wird in der Memoirenliteratur öfters über Trojki berichtet: "Most prisoners were sentenced [1937-1938], in their own absence, by NKVD judicial comittees - either the so-called troika, a committee of three which met in the provincial cities, or by a "special NKVD council' in Moscow." ${ }^{1}$ Ein sowjetischer Strafverteidiger, der im November 1939 im Prozeß gegen zwei Untersuchungsführer des Staatssicherheitsdienstes vor dem Militärtribunal des Militärbezirks Kalinin auftrat, berichtet von seinen vergeblichen Nachforschungen, in den Gesetzessammlungen, Verordnungen der Regierung und der juristischen Spezialliteratur auch nur eine Zeile über die rechtliche Grundlage und die Funktion der Dreiergremien in Erfahrung zu bringen. ${ }^{2}$ Obwohl also die Existenz der Trojki, der zentralen Terroragenturen des Stalinismus, seit fast einem halben Jahrhundert bekannt war, blieb der Kenntnisstand bis 1989 nahezu unverändert

1. Vgl.F. Beck, W. Godin, Russian purge and the extraction of confession, New York, 1951, S. 75.

2. B. G. Men'šagin, Vospominanija. Smolensk... Katyn'... Vladimirskaja tjurma..., Paris, 1988, S. 60ff. 
dürftig. ${ }^{3}$ Dadurch stieß jeder Versuch, über "die hinreißende Geschichte dieses Organs zu schreiben", ${ }^{4}$ auf allergrößte Schwierigkeiten. Es schien, als hätten diese "Erschießungskommissionen" mit den Menschen - uns sind keine Gulagerinnerungen bekannt, deren Autoren von den Trojki verurteilt wurden und die Lager überlebten - auch alle Spuren ihrer eigenen Tätigkeit beseitigt.

Eine Ausnahme in der Erinnerungsliteratur bilden die Publikationen von Abdurachman G. Avtorchanov, ${ }^{5}$ der die Geschichte der Trojki der Jahre 1937-1938 in einen breiten Kontext stellte: 1937 habe der NKVD einen ungeheuerlichen Plan vorgelegt, in dem den Gebieten, Regionen und Republiken der Sowjetunion Sollziffern für Massenhinrichtungen vorgegeben wurden. Eine detaillierte "table of specification" habe sieben Repressionskategorien festgelegt. Da die Zahl der geplanten Hinrichtungen in die Millionen ging, "there was no way of dealing with them through normal legal channels. It was therefore decided to set op a special tribunal under the Central NKVD and extraordinary three-man tribunals in republics, oblasts, and districts to try in absentia persons held under arrest." Auch wenn Avtorchanovs Bericht die für das Genre "Sowjetmemoiren" kennzeichnenden Verzerrungen, Übertreibungen und Lücken aufweist, dürfte außer Zweifel stehen, daß seine Skizze zentrale Aspekte des größten Repressionsprojekts der Jahre 1937-1938 getreu wiedergibt. ${ }^{7}$ Vor allem der sehr detaillierte Feindkatalog liest sich wie die offizielle Liste der Volksfeinde, allerdings fehlt bei ihm die Kategorie der Kriminellen. Avtorchanov bescheinigt dem zögerlichen Entstalinisierer Chruščev, alles getan zu haben, "damit die Außenwelt nichts über sie [die Trojki] erfahre". Denn die Todesurteile hätten neben den NKVD-Repräsentanten auch die regionalen Parteisekretäre wie Chruščev selbst unterschrieben. ${ }^{8} 1989$ veröffent-

3. Vgl. dazu Žak Rossi [Jacques Rossi], Spravočnik po GULagu. Istoričeskij slovar' sovetskich penitentarnych institucij i terminov, svjazannych s prinuditel'nym trudom, London, 1987, S. 412 mit Verweisen.

4. A. Solschenizyn, Der Archipel GULAG, Bd 1, Reinbek, 1983, S. 267. Auch Solschenizyn muß der von ihm selbst beschriebenen Anonymität der Trojki Tribut zollen, denn er läßt ihre Geschichte noch vor 1937 in die der "OSO", eines anderen außergerichtlichen Organs (vgl. unten), übergehen.

5. Der 1908 geborene Autor studierte 1933-1937 am Institut der Roten Professur in Moskau, arbeitete im Gebietskomitee der VKP(b) der Autonomen Sowjetrepublik der Čečenen und Ingušen und leitete deren Parteiverlag. Zwischen 1937 und 1942 wurde er zweimal verhaftet und wieder freigelassen. 1943 wurde er nach Deutschland deportiert, wo er nach 1945 blieb und für das Münchener Institut zur Erforschung der UdSSR arbeitete.

6. A. Avtorkhanov, Stalin and the Soviet Communist Party. A study in the technology of power, München, 1959, S. 219-221.

7. In seinen Erinnerungen gibt Avtorchanov an, er habe 1937 in Groznyj im Gebietskomitee der Partei entsprechende von Stalin, Ežov und Vyšinskij unterzeichnete "Instruktionen" gesehen, vgl. A. Avtorkhanov, Memuary, Frankfurt, 1984, S. 546-547.

8. Ebenda, S. 546. In der 1990-1992 veröffentlichten Version der Memoiren erwähnt Chruščev die Trojki, will jedoch den Anschein erwecken, als wären an ihnen nur die Sicherheitsorgane beteiligt gewesen. "Diese Leute [die Lagerhäftlinge] verhaftete die Staatssicherheit, die Untersuchung führte ebenfalls die Staatssicherheit und die Staatssicherheit fällte auch die Urteile. Die 'Trojki', die bei der Staatssicherheit errichtet wurden, machten, was sie wollten." "Memuary Nikity Sergeeviča Chruščeva", Voprosy istorii, 2-3, 1992, S. 94. 
lichte die führende Zeitschrift der historiographischen glasnost', Izvestija $C K$ KPSS, den viel zitierten Artikel "Über die außergerichtlichen Organe" von der Oktoberrevolution bis zum 1. September 1953. Als Autoren sind Staatsanwaltschaft und KGB der Sowjetunion genannt. Hier wird zum erstenmal auf eine am 30. Juli 1937 ergangene Direktive des NKVD hingewiesen, die "bei der Durchführung der Massenoperationen" von kardinaler Bedeutung gewesen sei: Das Dokument habe festgelegt, welche Bevölkerungsgruppen von außergerichtlichen Organen (Trojki) abgeurteilt werden sollten, und Zusammensetzung sowie Strafkompetenz dieser Tribunale geregelt. 1992 wurde dieses Dokument, "prikaz 00447" - die beiden Nullen signalisieren die höchste Geheimhaltungsstufe - mit kleinen Auslassungen in der Tageszeitung Trud veröffentlicht, und zwar im Zuge der Vorbereitung des Prozesses gegen die KPdSU. "One of the most chilling documents in modern history" 10 hat der amerikanische Historiker Getty den Befehl genannt. Nach diesem Schlüsseltext zum Großen Terror wurden weitere Dokumente zu dieser Operation publiziert und Archivmaterialien zugänglich gemacht - z. B. die Politbüroakten -, so daß heute Entschlußbildung, Planung, Ingangsetzung, Durchführung und Beendigung der größten Repressionskampagne des Großen Terrors in groben Umrissen dokumentiert sind. Wahrscheinlich gibt es in der an ungeheuerlichen Staatsverbrechen reichen Geschichte des 20. Jahrhunderts keine andere Verfolgungsmaßnahme dieser Größenordnung, über die so viele dokumentarische Belege vorliegen: zudem Dokumente einer besonderen Qualität, da sie das höchste Machtorgan des Regimes, das Politbüro, und die faktisch höchsten Repräsentanten von Partei und Staat, Stalin und Molotov, als Urheber und Initiatoren des massenhaften Mordens und der Lagereinweisungen denunzieren. ${ }^{11}$ Probleme, wie sie die Holocaustforschung kennt, die seit Jahrzehnten vergeblich nach Hitlers Befehl zur "Endlösung der Judenfrage" sucht, ${ }^{12}$ hat die neuere Stalinismusforschung nicht, obwohl auch in der Sowjetunion mehrfach systematisch Archivmaterialien vernichtet wurden. ${ }^{13}$

9. “O vnesudebnych organach”, Izvestija CK KPSS, 10, 1989, S. 80-82.

10. J. Arch Getty, Oleg V. Naumov, The road to terror. Stalin and the self-destruction of the Bolsheviks, 1932-1939, New Haven, 1999, S. 471.

11. Die von Getty und Naumov vorgelegte Quellensammlung enthält zahlreiche von Stalin unterzeichnete Mordbefehle, darunter einige in Faksimile. Vgl. auch die bisher nicht publizierten 383 Listen, auf denen 44.000 Angehörige der sowjetischen politischen, militärischen, wirtschaftlichen und intellektuellen Elite zum Tode (39.000) oder zu Haftstrafen von 8 bis 25 Jahren (5.000) verurteilt wurden. 372 bzw. 362 dieser Listen tragen die Unterschriften von Molotov und Stalin. "Massovye repressii opravdany byt' ne mogut", Vestnik, 1, 1995, S. 124.

12. Vgl. Ch. Gerlach, Krieg, Ernährung, Völkermord. Forschungen zur deutschen Vernichtungspolitik im Zweiten Weltkrieg, Hamburg, 1998. Nach Joachim Fest ist ein einziger, von Hitler unterzeichneter Mordbefehl überliefert: Der im Oktober 1939 unterschriebene Auftrag zur Tötung von “unheilbar Kranken”, vgl. Der Spiegel, 43, 1999, S. 192.

13. Vgl. A. Graziosi, "The new Soviet archival sources. Hypotheses for a critical assessment", Cahiers du Monde russe, 40, 1-2, 1999, S. 30-31 und O. Hlevnjuk, "L'historien et le document. Remarques sur l'utilisation des archives", ebenda, S. 110-111. N. S. Chruščev gilt heute als der größte Quellenvernichter. 
Unsere Publikation ist in zwei Teile aufgeteilt. Teil eins ist eine, angesichts des Forschungsstandes, noch immer provisorische Übersicht über Genese, Bestimmungen und Durchführung von Befehl 00447 zwischen August 1937 und November 1938. Die beigefügte Tabelle wurde anhand der Politbüroakten, anderer Quellenpublikationen und Angaben in der Literatur erstellt. Einen Anspruch auf Vollständigkeit können die kalten Zahlen dieser Buchhaltung des Grauens nicht erheben, da die Festlegung der regionalen Repressionsziffern nicht in jedem Falle über Politbürobeschluß erfolgte. ${ }^{14}$ Trotzdem dürfte die Tabelle die chronologische Abfolge bzw. die Schübe und die regionale Streuung der Terrormaßnahmen illustrieren. Da die regionalen Opferziffern häufig nicht mit den entsprechenden Bevölkerungsstatistiken korrelieren (vgl. Repressionsgrad), läge es nahe, strukturelle Faktoren (ökonomische, sozialdemographische dazu die geographische Lage) und situative (Einstellung der lokalen Machthaber) näher zu untersuchen. Im folgenden Band der Cahiers erscheint Teil zwei unserer Publikation. Er enthält eine Analyse der wichtigsten Zielgruppen des Befehls 00447 und eine abschließende Auswertung der gesamten Publikation.

Wir danken herzlich Wladislaw Hedeler (Berlin), Paul Hagenloh (Austin/Texas), Barry McLoughlin (Wien), Gábor Rittersporn (Berlin), David Shearer (Newark/ Delaware), Stephen Wheatcroft (Melbourne) und Jaroslav Leont'ev (Moskau), die uns großzügig Materialien und ihre unpublizierten Arbeiten zur Verfügung gestellt haben. Ganz besonders hervorheben möchten wir die freundliche Unterstützung durch Jurij Markovin (Memorial-Jaroslavl’') und Michail Erin, Dekan der historischen Fakultät der Staatlichen Universität Jaroslavl'.

Auch der Familie S. G. Račinskijs möchten wir für ihr Vertrauen und die Erlaubnis danken, seine persönliche Akte beim NKVD einsehen zu dürfen. Nicht Zuletzt gebührt Emely Nobis ein großes Lob für die Datenautobahn Amsterdam Bochum.

\section{Der Mordbefehl}

\section{Auftakt}

Einen viel zitierten Satz aus Jewgenia Ginsburgs Memoiren ${ }^{15}$ variierend, darf man heute sagen, daß das Jahr 1937 doch nicht am 1. Dezember 1934, dem Tag der Ermordung Kirovs, begann. Viel eher bietet sich der 2. Juli 1937 als Auftakt des annus horribilis an. An diesem Tag beschloß das Politbüro der VKP(b), landesweit die genannte Operation durchzuführen. Der Politbürobeschluß vom

14. Zuden Konnten wir nur einen Teil der als “osobaja papka” qualifizierten Politbürobesclüsse einsehen.

15. "Das Jahr 1937 begann, genaugenommen, schon Ende 1934. Genauer gesagt - am ersten Dezember 1934.” Vgl. J. Ginsburg, Marschroute eines Lebens, München, 1989, S. 9. 
2. Juli $1937^{16}$ macht zwei Bevölkerungsgruppen zur Zielscheibe repressiver Maßnahmen, die bei Anbruch des neuen Terrorzyklus im August 1936 von der sowjetischen Propaganda noch nicht vorrangig als Regimefeinde stigmatisiert worden waren. Das höchste Parteigremium forderte die Parteisekretäre auf, mit Hilfe der Dienststellen des NKVD die in den letzten Jahren aus der Verbannung zurückgekehrten ehemaligen Kulaken und Kriminellen in den Gebieten (oblasti), Regionen (krai) und Republiken zu registrieren. Denn diese seien als Hauptanstifter zahlreicher Verbrechen und Diversionsakte in Landwirtschaft und Industrie identifiziert worden. Nach dem Grad ihrer Gefährlichkeit für den Sowjetstaat seien beide Gruppen in die Kategorien 1 (Erschießung) und 2 (Verbannung) einzuordnen. Das Ergebnis dieser Erhebungen sollte innerhalb von fünf Tagen an die Moskauer Zentrale gemeldet werden. In einem für die Durchführung der Operation folgenreichen Punkt legte sich das Politbüro bereits fest: Zur endgültigen Entscheidung über Leben oder Tod der registrierten ehemaligen Kulaken und Kriminellen befahl das Politbüro, außergerichtliche Organe einzurichten, denen in der Regel der jeweilige NKVD-Chef, Erste Parteisekretär und Oberste Staatsanwalt angehören sollten. Vorschläge aus der Provinz zur personellen Besetzung dieser Schnellgerichte sollten ebenfalls innerhalb von fünf Tagen an das Zentralkomitee gerichtet werden.

Der Politbürobeschluß setzte den von R. Hilberg beschriebenen und seiner bahnbrechenden Studie über die Vernichtung der europäischen Juden als Ordnungsprinzip zugrundeliegenden Mechanismus der Definition, Registrierung, Konzentration und Vernichtung bzw. Lagereinweisung der Opferkategorien in Gang. ${ }^{17}$ Bei der Erfassung konnten die Dienststellen des NKVD auf bei ihnen geführte Listen "verdächtiger antisowjetischer Elemente" - im NKVD-Jargon "antisovetčiki" genannt - zurückgreifen. Diese wurden seit Anfang der zwanziger Jahren auch anhand von Agentenmeldungen immer wieder aktualisiert. Der Kazaner Historiker A. F. Stepanov hat, gestützt auf Untersuchungen in lokalen Archiven Tatarstans, den umfassenden Feindkatalog dieser Proskriptionslisten rekonstruiert: Neben ehemaligen Kulaken sind registriert: Angehörige der zarischen Administration, ehemalige Weißgardisten, Teilnehmer an Bauernaufständen im Bürgerkrieg, Remigranten, in die Sowjetunion geflohene Politemigranten, aus deutscher und österreichischer Gefangenschaft entlassene Kriegsgefangene des Ersten Weltkriegs, Mitglieder antibolschewistischer politischer Parteien, lišency (Personen, denen das Wahlrecht entzogen worden war), aus der VKP(b) Ausgeschlossene usw. ${ }^{18}$ Daten über ugolovniki (Kriminelle) waren bei den lokalen Polizeibehörden (URKM - Upravlenie Raboče-Krest'janskoi Milicii) des Volkskommissariats des Inneren gesammelt. ${ }^{19}$ Bis zum 11. Juli 1937 lagen dem Politbüro aus

16. P51/94 Ob antisovetskich elementach, in: Rossijskij Gosudarstvennyj Archiv Social'noPolitičeskoj Istorii (RGASPI), f. 17, op. 162, d. 21, 1. 89. Erstmals veröffentlicht in: "Rasstrel po raznarjadke, ili Kak eto delali bol’ševiki”, Trud, 4. Juni 1992, S. 1, 4.

17. R. Hilberg, Die Vernichtung der europäischen Juden, Bd 1-3, Frankfurt, 1990.

18. A. F. Stepanov, Rasstrel po limitu. Iz istorii političeskich repressij $v$ TASSR $v$ gody "ežovščiny", Kazan, 1999, S. 8, 34 FN 12. 
den meisten der 64 angeschriebenen administrativen Einheiten die angeforderten Angaben zur Vernichtung und Verbannung von Kulaken und Kriminellen sowie die Empfehlungen für die personelle Besetzung der Trojki vor. Soweit bisher bekannt, hat das Politbüro die aus der Provinz vorgeschlagenen Repressionsziffern kaum modifiziert. (Vgl. Tabelle). Auch nicht im Falle von Stadt und Gebiet Moskau, von wo geradezu ungeheure Erschießungs- und Verbannungsziffern am 10. Juli 1937 angefordert wurden. Nicht weniger als 8.500 Personen sollten erschossen und 32.805 verbannt werden. ${ }^{20}$ Der Gebietssekretär beabsichtigte offensichtlich, die Operation im Gebiet Moskau vorrangig als Feldzug gegen die Kriminalität zu führen (Relation Kulaken: Kriminelle ca. 1:4). Der gleiche Gebietssekretär, der auch als Mitglied der Trojka vorgesehen war, konnte sich 20 Jahre später an nichts mehr erinnern, versuchte aber auf dem ZK-Plenum vom Juni 1957 mit windigen Argumenten nachzuweisen, daß die ganze Operation gegen Kulaken und Kriminelle von Kaganovič, Molotov und Malenkov initiiert worden sei. ${ }^{21}$ Die Rede ist von N.S. Chruščev. Einige Antworten aus der Provinz, in denen die Repressionskategorien aufgeschlüsselt sind, lassen andere Prioritäten erkennen: In Territorien, aus denen bzw. in die 1930-1933 eine hohe Anzahl Kulakenfamilien deportiert worden war (West-Sibirische Region, Gor'kij, Sverdlovsk, Azov-Černomorskij), sind die Exkulaken das primäre Repressionsziel. Das Politbüro akzeptierte aber auch "Sonderwünsche" und Initiativen aus der Provinz, die über die im Beschluß vom 2. Juli 1937 vorgegebenen Zielgruppen und Strafmaßnahmen weit hinausgingen: Es billigte die Anfrage der Azerbajdžanischen SSR, Mitglieder konterrevolutionärer Aufständischenorganisationen zum Tode zu verurteilen bzw. in die Verbannung zu schicken sowie Familienangehörige von Bandenmitgliedern in die Lager des NKVD einzuweisen; der Trojka im Fernen Osten gestatte es, Lagerinsassen, die sich feindlich betätigten, zu verurteilen, der Trojka des Gebiets Orenburg erlaubte es, Familienangehörige von verurteilten Kulaken und Kriminellen zu verbannen. Der Trojka Turkmenistans genehmigte das Politbüro, Mitglieder einer konterrevolutionären nationalistischen Organisation, die ihre Gefängnisstrafen verbüßt hatten, sowie islamische Geistliche "und dergleichen mehr" zu verfolgen. Auch die Anfrage der Kazachischen SSR, die Repression "auf Kulaken in Sonderansiedlungen auszuweiten", wurde gebilligt. ${ }^{22}$ Auch gegen das Ersuchen der Uzbekischen Republik, neben Kulaken und Kriminellen "nationalistische Terroristen"

19. Vgl. N. Petrov, "Die Rolle der Organe der Staatssicherheit (OGPU-NKVD) in der UdSSR", in: D. Dahlmann, G. Hirschfeld (Hrsg.), Lager, Zwangsarbeit, Vertreibung und Deportation. Dimensionen der Massenverbrechen in der Sowjetunion und in Deutschland 1933 bis 1945, Essen, 1999, S. 187-205, hier S. 192. Daneben waren die Exkulaken auch in den Listen der lišency bei den Rayonsowjets registriert.

20. Vgl. Tabelle Nr. 40/Moskau. Der Brief ist publiziert in: "Rasstrel po raznarjadke...", art. cit., S. 1.

21. Vgl. die Diskussion über die Rolle von Kaganovič, Molotov, Malenkov und Chruščev im Großen Terror auf dem Juni-Plenum des Zentralkomitees im Jahre 1957, in: Molotov, Malenkov, Kaganovič. 1957. Stenogramma ijun'skogo plenuma CK KPSS i drugie dokumenty. Sost.: N. Kovaleva, A. Korotkin u.a., Moskau, 1998, S. 68-69, 159-204, 488-489.

22. RGASPI, f. 17, op. 162, d. 21, 11. 95-99. 
abzuurteilen, ${ }^{23}$ hatte das Politbüro keine Einwände. Haben diese "schöpferischen" Initiativen aus der Provinz das Politbüro und die NKVD-Zentrale bewogen, die Liste der zu verfolgenden Feinde auszuweiten?

In den Instruktionen der Leningrader NKVD-Leitung werden die lokalen Dienststellen bereits am 16. Juli angewiesen, nicht nur nach Exkulaken und Kriminellen zu fahnden, sondern auch "nach den anderen feindlichen Elementen, die aktive, subversive antisowjetische Arbeit verrichten." Daß eine Operation gegen interne Feinde der Sowjetunion, die "dem aktiver auftretenden konterrevolutionären Element den entscheidenden Schlag" versetzen wollte (so der Chef des Leningrader UNKVD Zakovskij am 22. Juli 1937), sich nicht auf Repressalien gegen Exkulaken und Kriminelle beschränken konnte, impliziert die stalinistische Vorstellung vom Universum der die Sowjetunion bedrohenden internen Feinde: Dieses wird als geschlossene, vereinte Gegenwelt gesehen, in der alle "antisovetčiki" sich zu einer großen Koalition zusammengefunden haben: "Die Trotzkisten, Zinov'evisten, Bucharinisten, Rykovisten, die bourgeoisen Nationalisten, die Men'ševiki, die Sozialrevolutionäre, die weißgardistischen Generäle." 24 "Zu einer schmutzigen, bluttriefenden Masse hat sich der konterrevolutionäre Abschaum der Trotzkisten, Rechten, Sozialrevolutionäre, professionellen Spione, Weißgardisten und flüchtigen Kulaken vereinigt." 25

Wahrscheinlich haben Ežov und sein Stellvertreter Michail P. Frinovskij das Führungspersonal der regionalen Verwaltungen des NKVD, das sie am 16. Juli 1937 in Moskau zusammengerufen hatten, bereits im Sinne dieses erweiterten Feindbildes instruiert. ${ }^{26}$ Spätestens hier wurde diesen auch mitgeteilt, daß die Moskauer Zentrale in Kürze einen Plan mit detaillierten Anweisungen zur Durchführung der Aktion vorlegen werde.

Auch auf der Republik-, Gebiets- und Regionsebene des NKVD wurden in der zweiten Julihälfte Besprechungen und Konferenzen einberufen, um die Leiter der Stadt- und Rayonabteilungen auf ihre Aufgaben bei der Aktion vorzubereiten. ${ }^{27}$ In Novosibirsk skizzierte der NKVD-Chef der westsibirischen Region Sergej N. Mironov am 25. Juli bereits die Umrisse der geplanten Massenoperation: Er verpflichtete seine Zuhörer zu absolutem Stillschweigen über die Operation, vor allem über die Repressionsquoten ("Staatsgeheimnis"), unterrichtet sie, daß die von der Verfassung garantierten Prärogativen der Staantswaltschaft (Verhaftung an ihre Zustimmung gebunden, Artikel 127 der neuen Verfassung) suspendiert seien und gibt Anweisungen, wie das Ermittlungsverfahren zu vereinfachen sei (Gegenüber-

23. Ebenda, 1.99.

24. Izvestija, 20.12.1937, S. 1.

25. N. Rabič, "Gnilaja i opasnaja teorija prevraščenija klassovych vragov v ručnych", Bol'švik, 7, 1. April 1937, S. 55.

26. Vgl. dazu das auf der Hamburger Arbeitstagung "Stalinistischer Terror, Massenrepressalien, Gulag" (21.-22. Februar 1998) gehaltene Referat von N. Petrov, "Tod nach Plansoll: Der operative NKWD-Befehl Nr. 00447", S. 3.

27. Für das Gebiet Omsk vgl. das Interview mit dem an der Operation 00447 beteiligten NKVD-Funktionär von Tjumen', der auch 1998 seine Anonymität nicht preisgeben wollte, in: R. Gol'dberg, "Slovo i delo po-sovetski. Poslednyj iz NKVD", Rodina, 9, 1998, S. 85-87. 
stellungen nur bei Gruppenverfahren, bei Geständnis genüge ein Verhörprotokoll). Um nicht in die Situation zu kommen, "daß unsere Quote aufgebraucht ist", empfiehlt Mironov, sofort Verhaftungen in großem Maßstab durchzuführen ("Sie müssen bis zum 28. Juli 11.000 Personen verhaften"), bis zu 20.000 ingesamt, um eine "Reserve" zu haben bei der Aufteilung nach Kategorien.28 Wichtigstes Ziel der Kampagne sei, “den organisierten Untergrund zu entlarven.” Den Chefs der Sicherheitspolizei seiner Region empfiehlt er, nach ihrer Rückkehr abgelegene ErschieBungs-und Beerdigungsplätze auszuwählen. ${ }^{29}$ Moralische Skrupel an der Mordoperation scheinen die Čekisten nicht gekannt zu haben, im Bericht eines Teilnehmers an der Versammlung heißt es, daß Mironovs Referat mit "stürmischer Zustimmung" aufgenommen worden sei. ${ }^{30}$ Dieser Eindruck deckt sich mit Aussagen 1938-1939 verhafteter NKVD-Kader, die keinen Zweifel an der Legitimität der Kampagne aufkommen ließen. ${ }^{31}$

Am 30. Juli 1937 legte Frinovskij dem Leiter des Sekretariats des Generalsekretärs Poskrybyšev den 15 Seiten langen Befehl "Über die Operation zur Repression ehemaliger Kulaken, Krimineller und anderer antisowjetischer Elemente" vor. Ežovs Stellvertreter war maßgeblich an der Ausarbeitung des Projekts beteiligt gewesen und hatte Stalin sowie andere Politbüromitglieder über den Fortgang der Planung auf dem laufenden gehalten bzw. von ihnen Instruktionen eingeholt. Darauf verweist, daß Frinovskij im Juli 1937 dreimal im Besucherbuch von Stalins Kremlkabinet notiert steht. ${ }^{32}$ Frinovskij wurde dann auch die allgemeine Leitung der Operation übertragen.

Am 31. Juli wurde der Operationsplan vom Politbüro gebilligt ${ }^{33}$ und noch am selben Tag als Prikaz (Befehl) 00447 den NKVD-Leitern der Republiken, Regionen und Gebiete zugestellt.

\section{Befehl 00447}

Der Text des Dokuments wurde 1992 in Trud (4. Juni 1992) unter dem Titel "Rasstrel po raznarjadke, ili Kak eto delali bol'ševiki" (Erschießung nach Kontingenten oder Wie haben die Bol'ševiki das erledigt) erstmals publiziert, allerdings mit Aus-

28. Mironov geht von der Annahme aus, daß die beantragte und vom Politbüro gebilligte Erschießungsquote für Westsibirien (10.800) endgültig sei.

29. Von Mironovs Rede ist ein Stenogramm überliefert. Auszüge daraus sind publiziert in: Bol ljudskaja. Kniga pamjati Tomičej, repressirovannych v 30-40-e i načale 50-ch godov, Tom 5. Sost. V. N. Ujmanov, Tomsk, 1999, S. 102-103, 110-111.

30. S. A. Papkov, Stalinskij terror v Sibiri 1928-1941, Novosibirsk, 1997, S. 211

31. G. Stankovskaja, "Kak delali "vragov naroda", in: Gody terrora. Kniga pamjati žertv političeskich repressii. Sost. A. B. Suslov, N. Gaševa, Perm', 1998, S. 92-108, S. 107: "Ich bin absolut davon überzeugt, daß die Augustkampagne zur Verhaftung der Kulaken richtig war."

32. "Posetiteli Kremlevskogo Kabineta I. V. Stalina”, Istoričeskij archiv, 4, 1995, S. 58-62.

33. RGASPI, f. 17, op. 162, d. 21,1.161. 
lassungen. Danach folgten zahlreiche Texteditionen, die fast immer auf dieser unvollständigen Ausgabe beruhten. Ohne Kürzungen erschien der Prikaz 1996 im Gedenkbuch für die Opfer der politischen Repression des Gebiets Ul'janovsk ${ }^{34}$ und 2000 in einem Dokumentenband über den GULAG. ${ }^{35}$

Eine kurze Analyse der wichtigsten Punkte dieses Dokuments, das für mehr als ein Jahr der Geschichte der Sowjetunion seinen Stempel aufdrückte. In der Präambel wird hervorgehoben, daß die Aktion nicht mehr und nicht weniger als die endgültige Lösung des Problems der internen Feinde der Sowjetunion anstrebt: "Vor den Sicherheitsorganen steht die Aufgabe, diese ganze Bande antisowjetischer Elemente ohne die geringste Schonung zu zerschlagen [...] und schließlich ihrem niederträchtigen, zersetzenden Treiben [...] ein für allemal ein Ende zu setzen.” Das war keine leere Rhetorik. In den "Organen" interpretierte man die Direktive als Appell zum letzen Gefecht, "zur direkten physischen Liquidierung der ganzen Konterrevolution". ${ }^{36}$ Und selbst der in der Gefängniszelle isolierte Bucharin glaubte im Dezember 1937 zu erkennen, daß sich im Lande "Großes" ereignete: "Es existiert irgendeine große und kühne politische Idee einer generellen Säuberung a) im Zusammenhang mit einer Vorkriegszeit, b) im Zusammenhang mit dem Übergang zur Demokratie." 37

Im Text folgt eine sehr detaillierte Liste derjenigen Bevölkerungsgruppen, die Zielscheibe der Operation sein sollen (Zu den Zielgruppen des Befehls 00447, vgl. die folgende Nummer der Cahiers du Monde russe).

Abschnitt 2 regelt zunächst das Strafmaß, das die Trojki zu verhängen haben: "Die äußerst feindlich gesinnten Elemente" (erste Kategorie) sollen erschossen, die "weniger aktiven, aber dennoch feindlichen" (zweite Kategorie) werden für 8 bis 10 Jahre in Lager bzw. Gefängnisse eingewiesen.” Gegenüber der im Politbürobeschluß vom 2. Juli vorgeschlagenen "Verbannung" war dies eine drastische Verschärfung des Strafmaßes. Daran schließt sich die Verteilung der Repressionsquoten auf Gebiete, Regionen und Republiken an, aufgeschlüsselt in 1. und 2. Kategorie (insgesamt 64 territoriale Einheiten: 40 Gebiete ${ }^{38}$, Regionen und Autonome Sowjetrepubliken der RSFSR, je acht Gebiete in der Ukraine und in

34. Kniga pamjati žertv političeskich repressij. [Ul'janovskaja oblast']. Sost. Ju. M. Zolotov, Ul'janovsk, 1996, S. 766-780.

35. GULAG (Glavnoe upravlenie lagerei). 1917-1960. Sost. A. I. Kokurin, N. V. Petrov, Moskau, 2000, S. 96-104.

36. Vgl. dazu den häufig zitierten Brief des zu fünf Jahren ITL (Ispravitel'no-Trudovoj Lager') verurteiten Čekisten P. A. Egorov vom Dezember 1938 an Stalin, zitiert bei: V. N. Ujmanov, Repressii. Kak eto bylo... (Zapadnaja Sibir' v konce 20-ch - načale 50-ch godov), Tomsk, 1995, S. 95-96

37. W. Hedeler, R. Stoljarowa, "R. N. Bucharin an Stalin”, Sozialismus, 3, 1993, S. 59.

38. Bei der Liste der Territorien ist den Autoren des Befehls ein Fehler unterlaufen: Nr. 30 "Vostočno-Sibirskij kraj" muß sein "Vostočno-Sibirskaja oblast"' (Umwandlung am 5. Dezember 1936). 
Kazachstan ${ }^{39}$ und acht Sozialistische Sowjetrepubliken, vgl. Tabelle). Diese Regelung, die von der Zentrale festgelegten Tötungs- und Gulagquoten, unterscheidet Prikaz 00447 von der anderen zentralen Repressionskampagne des Großen Terrors; der Operation gegen die "konterrevolutionären nationalen Kontingente". Bei der Verfolgung der nationalen Minoritäten gab es keinen "rasstrel po raznarjadke" (Erschießung nach Kontingenten), die regionalen Machthaber, NKVD-Chef und Oberster Staatsanwalt $($ Dvojka $=$ Zweiergremium $)$ sanktionierten die von der Sicherheitspolizei zusammengestellten Verhaftungslisten und sandten diese per Kurrier nach Moskau, wo die "vysšaja (oberste) dvojka" (Volkskommissar des Innern Ežov und Staatsanwalt der UdSSR Vyšinskij) das endgültige Verdikt aussprachen.

Die Liste der administrativen territorialen Einheiten und der ihnen zugewiesenen Opferziffern dürfte entgegen immer wieder geäußerten Zweifeln keine wesentlichen Lücken aufweisen. Es fehlt die ASSR Jakutien, in der zwar per Politbürobeschluß vom 11. Juli 1937 eine Trojka eingesetzt worden war, ${ }^{40}$ die jedoch die Operation 00447 nicht durchführte. Der NKVD-Chef I. A. Dorofeev legitimierte das gegenüber der Moskauer Zentrale mit dem Hinweis, es gebe keine Kulaken in Jakutien, zudem sei die Republik "für einen ausländischen Nachrichtendienst nicht von Interesse, weil es hier keine Industrie, Armee oder andere kriegswichtige Objekte gibt." ${ }^{41}$ Dorofeev überlebte den Großen Terror als Volkskommissar des Innern und wurde erst im Februar 1939 verhaftet. Im Politbürobeschluß vom 11. Juli 1937 war auch festgelegt worden, kein spezielles Dreiertribunal für die Karakalpakische ASSR (Uzbekistan) ins Leben zu rufen. Trojki wurden also nur in den Autonomen Sozialistischen Sowjetrepubliken der Russischen Sozialistischen Föderativen Sowjetrepublik, ${ }^{42}$ nicht der anderen Republiken eingesetzt. Die im Prikaz 00447 zugewiesenen Kontingente weisen neben Auf- und Abrundungen einige gravierende Abweichungen von den im Politbüro im Juli festgelegten Quoten auf. So sind im Befehl Chruščevs monströse Planziffern für das Gebiet Moskau um fast $20 \%$ nach unten korrigiert, ebenso sind mehrfach Vernichtungsziffern erheblich herabgesetzt (z. B. für Mari, Kujbyšev, die Fernöstliche Region, Zapsibkraj, Čeljabinsk); die Liste enthält jedoch auch gravierende Korrekturen in die andere Richtung (Karelien, Omsk, Udmurtien, Saratov), so daß es schwer fällt, eine eindeutige Tendenz zu erkennen. Bei den im September 1937 durchgeführten Gebietsreformen - mehrere Großregionen und -gebiete wurden aufgeteilt - dürften den meisten neuen Territorien auch neue Kontingente (Tabelle Nr. 27, 30, 46)

39. Das Politbüro hatte zwar am 10. Juli 1937 eine Trojka für die gesamte Republik Kazachstan etabliert (RGASPI, f. 17, op. 162, d. 21,1.96.), beschloß dann aber noch am selben Tag, in jeder oblast'der Republik Dreiergremien einzusetzten.

40. RGASPI, f. 17, op. 162, d. 21,1.99.

41. Zitiert nach N. Petrov, “Tod nach Plansoll...”, op. cit., S. 8, der keine Quelle für dieses Zitat anführt.

42. Am 3. August 1937 wurde vom Politbüro zusätzlich in der Westsibirischen Region in der Ojrotskaja avtonomnaja oblast' eine Trojka eingerichtet, vgl. P51/684 in: Rossijskij Gosudarstvennyj Archiv Novejšej Istorii (RGANI), f. 89, op. 73, d. 67,1. 1. 
zugewiesen worden sein, da zu diesem Zeitpunkt die Erstquote bereits "aufgebraucht" war.

Der Prikaz 00447 sah die Erschießung von 75.950 Menschen, darunter 10.000 Gulaghäftlinge, und die Einweisung von 193.000 Personen in Lager und Gefängnisse vor, das gesamte Repressionskontingent umfaßte 268.950 "antisowjetische Elemente". Diese Zahlen galten als Richtwerte: Sie konnten, allerdings nur auf Antrag beim Volkskommissar des Inneren, erhöht, durften aber ohne Zustimmung Moskaus gesenkt werden. Die Umschichtung von Personen zwischen den beiden Kategorien war erlaubt. Die Operation sollte am 5. August beginnen (in den zentralasiatischen Republiken am 10. und in Ostsibirien, Krasnojarsk und der Fernöstlichen Region am 15.) und innerhalb von vier Monaten abgeschlossen werden. ${ }^{43}$ In der ersten Phase sollten sich die Repressionsmaßnahmen nur gegen die "äußerst feindlich Gesinnten" (erste Kategorie) richten, ${ }^{44}$ wodurch wohl eine Überfüllung der Haftorte vermieden werden sollte. Möglicherweise spielte aber auch eine Rolle, daß erst Mitte August die vorgesehene Einweisung in Lager der nach der zweiten Kategorie Verurteilten konkrete Formen annahm (vgl. unten). Den Übergang zur zweiten Phase sollte eine Direktive Ežovs anordnen, er konnte aber auch früher nach Zustimmung der Moskauer NKVD-Zentrale erfolgen. Jedes Territorium war in operative Sektoren einzuteilen, innerhalb derer operative Gruppen unter Leitung eines erfahrenen Čekisten die Verhaftungslisten zusammenstellten, die Arretierungen nach Bestätigung der Listen durch den NKVD-Chef vornahmen und das Untersuchungsverfahren durchführten. Dies sollte "auf beschleunigte und vereinfachte Weise" geschehen, d. h. ohne Rechtsbeistand, Zeugengegenüberstellung, Sachverständigenbefragung und Beschaffung und Überprüfung von Beweismaterial. Vyšinskij, laut Verfassung Hüter der sozialistischen Gesetzlichkeit und von 1934 bis Mitte 1937 bemüht, die außergerichtlichen Ansprüche der Staatssicherheit abzuwehren, instruierte die ihm unterstellten Staatsanwälte, "daß die Beachtung prozessualer Normen und die vorherige Genehmigung von Verhaftungen [durch die Staatsanwaltschaft], nicht erforderlich" seien. Daneben verlangte er von seinen Untergebenen "aktive Mitarbeit an der erfolgreichen Durchführung der Aktion" ${ }^{4}$ Im März 1937 hatte er, gleichsam Carl Schmitt paraphrasierend, erklärt, "daß es im

43. Da später der 10. Dezember 1937 als Abschlußtermin festgesetzt wurde und zwei Tage später die Wahlen zum Obersten Sowjet stattfanden, wurde der ganzen Operation auch eine wichtige Funktion in der Absicherung dieser Wahlen zugeschrieben. Auf dem Februar-März Plenum 1937 waren in der Tat Befürchtungen geäußert worden, daß "die Feinde" einige Wahlbezirke erobern könnten, u.a. von Stalin selbst, vgl. "Materialy fevral'sko-martovskogo plenuma CK VKP(b) 1937 goda”, Voprosy istorii, 7, 1993, S. 5. Dieses Motiv dürfte aber von nur sekundärer Bedeutung gewesen sein.

44. Soweit uns bis jetzt bekannt, haben sich nur die NKVD-Dienststellen in Kazan und Jaroslavl' an diese Bestimmung gehalten.

45. Auszüge aus diesem Telegramm sind zitiert in: B. B. Brjuchanov, E. N. Šoškov, Opravdaniju ne podležit. Ežov i ežovščina 1936-1938 gg., Sankt-Petersburg, 1998, S. 76. Verhaftungen sollten nur mit Zustimmung des Staatsanwalts erfolgen, hatten der Rat der Volkskommissare und das Zentrakomitee am 17. Juni 1935 verfügt. Vgl. auch Artikel 127 der Verfassung von 1936: "Niemand kann anders als auf Gerichtsbeschluß oder mit Genehmigung des Staatsanwaltes verhaftet werden." 
Leben der Gesellschaft und speziell in unserer Momente und Perioden gibt, wo sich die Gesetze als veraltet erweisen und man sie zur Seite schieben muß."46 Stalin selbst hat im Januar 1939 in einem Brief an die Parteileiter mitgeteilt, daß das Zentralkomitee 1937 die Folter beim Verhör gestattet habe. ${ }^{47}$ Über die Erzwingung von Geständnissen auf diesem Weg, über Manipulation und Fälschung im Untersuchungsverfahren liegt heute viel Material vor, vor allem zahlreiche Aussagen von an der Aktion beteiligten NKVD-Mitarbeitern. ${ }^{48} 1938$ wendeten die Čekisten mit der "stojka" oder "vystojka", die den Massenrepressionen adäquate Verhörmethode an, die weite Verbreitung fand: Man stellte Dutzende von Häftlingen in einem speziellen Raum nebeneinander vor die Wand, verbot ihnen zu schlafen oder sich hinzulegen und prügelte sie periodisch, bis sie gestanden. Nichts vermag die Grausamkeit der Methoden besser zu charakterisieren, als der Umstand, daß allein in Turkmenistan während der Verhöre über 20 Häftlinge getötet wurden. ${ }^{49}$ Als folgenschwer erwies sich die Instruktion des Befehls, "alle verbrecherischen Beziehungen der Verhafteten aufzudecken"; sie wurde zum Anlaß genommen, gigantische konspirative Netzwerke $\mathrm{zu}$ entlarven, an denen angeblich Tausende Verschwörer beteiligt waren.

Punkt V. des Befehls regelt Zusammensetzung und Kompetenz der Trojki, der Terrorinstanz par excellence in der Geschichte der sowjetischen Massenrepressionen, vom Bürgerkrieg bis zu den Morden von Katyn. Vielmehr als die immer wieder apostrophierten Schauprozesse können sie als ein spezifisches Merkmal der Repression des Stalinismus gelten. Die Geschichte der Trojki der dreißiger Jahre liegt noch weitgehend im Dunkeln, ihre Existenz wurde erst durch die Publikation von Archivalien der neunziger Jahre wieder in Erinnerung gerufen. Von den durch Befehl 44/21 der OGPU vom 2. Februar $1930^{50}$ eingerichteten Trojki bei den Bevollmächtigten Vertretungen der OGPU waren im Rahmen der Entkulakisierung zwischen 1930-1933 392.524 Personen wegen politischer Vergehen, meist Artikel 58 des Strafgesetzbuches der RFSSR, verurteilt worden.51 Zwischen den Trojki der Entkulakisierungsperiode und des Großen Terrors bestehen personelle (man denke an Namen wie Redens, Zakovskij, Evdokimov, Karuckij, Bak, Ejche usw.) und funktionale Kontinuitäten. Auch aus der Perspektive der Opfer ergeben sich Verknüpfungen: Viele Kulaken, die 1930-1934 von den Dreiergremien in konclagerja eingewiesen wurden, verloren 1937-1938 durch den Spruch der Trojki ihr Leben.

46. Zitiert nach N.R. Mironov, "Vosstavnovlenie i razvitie leninskich principov socialističeskoj zakonnosti (1953-1963 gg.)”, Voprosy istorii KPSS, 2, 1964, S. 19.

47. Memorial-Aspekt. Special'nyj vypusk informacionnogo bjulletenja Moskovskogo Memoriala, 1,1993, S. 1 .

48. Bol' ljudskaja, op. cit., Tom 5, S. 176-177, 224-225; V. N. Ujmanov, Repressii..., op. cit.; G. Stankovskaja, "Kak delali "vragov naroda", art. cit., S. 95-105.

49. O. Hlevnjuk, “Les mécanismes de la 'Grande Terreur' des années 1937-1938 au Turkménistan", Cahiers du Monde russe, 39, 1-2, 1998, S. 202-205.

50. Publiziert in: Neizvestnaja Rossija XX VEK, Bd 1, 1994, S. 237-245.

51. Vgl. V. P. Popov, "Gosudarstvennyj terror v sovetskoj Rossii. 1923-1953 gg. (istočniki i ich interpretacija)", Otečestvennye archivy, 2, 1992, S. 28. 
Auch wenn das Politbüro am 7. Mai 1933 den Trojki der OGPU das Recht, die Todesstrafe zu verhängen, entzog, hat es danach dieses Instruments des Ausnahmezustands immer wieder eingesetzt, wenn es galt, schnell und geräuschlos vermeintlich gefährliche "antisovetčiki" zu liquidieren. ${ }^{52}$ Zum letzten Mal übrigens am Vorabend der Massenoperationen: Am 28. Juni 1937 kam es zu einer Neuauflage der Trojka der Entkulakisierungsperiode: Das Politbüro beschloß, in der Westsibirischen Region eine Trojka einzusetzen, welcher der Leiter des UNKVD, der Erste Parteisekretär und der Staatsanwalt der Region Westsibirien angehören sollten; ihre Aufgabe war, Mitglieder einer konterrevolutionären Organisation, die unter verbannten Exkulaken einen Aufstand vorbereitet hätten, im beschleunigten Verfahren zum Tode zu verurteilen. ${ }^{53}$ Diese Trojka kann zu Recht als "direkter Vorbote" der Dreiergremien von Prikaz 00447 bezeichnet werden, ${ }^{54}$ ging sie doch nahtlos in diese über..$^{55}$

Der Umstand, daß es in den Quellen der Jahre 1937-1938 keine einheitliche Bezeichnung für das von Befehl 00447 geschaffene Schnelltribunal gibt, hat zu einiger Konfusion in der Literatur geführt. ${ }^{56}$ Selbst der Omsker Historiker V. M. Samosudov, der in seiner Studie über den Großen Terror im Gebiet Omsk detaillierte Regesten aller Trojkaprotokolle vom 5. August 1937 bis 23. Oktober 1938 vorlegt, sieht in diesem Zeitraum nur das durch Prikaz 00447 installierte Dreiergremium, das er "osobaja trojka" (Sondertrojka) nennt, in Funktion. Daß ab Protokoll Nr. 64 vom September 1938 Diskontinuitäten im Strafmaß (fünf Jahre ITL), in den Anklagepunkten (überwiegend 58.6, Spionage) sowie der ethnischen Herkunft der Beschuldigten (nahezu ausschließlich Angehörige der nationalen Minoritäten) auftreten, bleibt bei ihm ohne Kommentar und Konsequenz. Urteilt man nach den vielen Faksimilereproduktionen von Akten der im Rahmen von Befehl 00447 eingesetzten Dreiergremien, dann war die Selbstbezeichnung "trojka pri UNKVD SSSR po [Kalininskoj/Moskovskoj/Omskoj oblasti" usw.] die gebräuchlichste. Es sind jedoch zumindest zwei Abweichungen bekannt: In Leningrad nannte sich das Dreiergremium "Osobaja trojka UNKVD LO" 57 und in Jaroslavl'

52. Vgl. Stalinskoe Politbjuro v 30-e gody. Sbornik dokumentov. Sost. O. V. Chlevnjuk, A. V. Kvašonkin u.a., Moskau, 1995, S. 63-65.

53. Der Text des Politbürobeschlusses ist veröffentlicht bei M. Vylcan, V. Danilov, "Primenenie VMN ‘nami garantiruetsja”’, Nauka i žizn', 9, 1997, S. 68-72.

54. O. W. Chlewnjuk, Das Politbüro. Mechanismen der politischen Macht in der Sowjetunion der dreißiger Jahre, Hamburg, 1998, S. 272.

55. Vgl. Kniga pamjati žertv političeskich repressij Kemerovskoj oblasti, Bd 2. Sost. L. I. Gvozdkova, Kemerovo, 1996. Den Angaben läßt sich entnehmen, daß diese Trojka der Westsibirischen Region am 9., 25., 29. Juli und am 1., 3., 4. August 1937 tagte und allein über 30 Personen der Stadt Kemerovo und Umgebung zum Tode verurteilte.

56. Vgl. z. B. O. F. Suvenirov, Tragedija RKKA 1937-1938, Moskau, 1998, S. 231; M. Ilic, "The Great Terror in Leningrad. A quantitative analysis", Europe-Asia Studies, 52, 8, 2000, S. 1533.

57. Vgl. Leningradskij martirolog 1937-1938. Sost. A. Ia. Razumov u.a., Bd 1-4, Sankt Petersburg, 1995-1999. In den Bänden 2-4 sind zahlreiche Dokumente reproduziert, die "Osobaja trojka" im Kopf haben. In Bd 4 gibt es einen etwas kryptischen Hinweis der Herausgeber, daß von ihnen erstmals gesichtete Trojkaprotokolle aus der zweiten Augusthälfte 1937 über die Aburteilung von "Kriminellen und sozialgefährlichen Elementen" als "Sitzungen der Trojka (im Unterschied zu der Osobaja trojka) UNKVD L[eningradskoj O[blasti] überschrieben sind.” (S. 576). 
prangt über den Trojkaprotokollen der Kopf: trojka "pri Upravlenii NKVD Jaroslavskoj oblasti po vnesudebnomu rassmotrenija del" (Trojka des UNKVD des Gebiets Jaroslavl' zur außergerichtlichen Untersuchung von Fällen).58 In Dokumenten der Regierung, der Parteizentrale oder in der Korrespondenz von NKVD-Dienststellen finden sich neben "osobaja trojka" auch die euphemistische Bezeichnung "sudebnaja trojka" (Gerichtstrojka) oder "spectrojka"59 Trotz dieses Sprachgebrauchs in den Quellen sollte der Terminus “osobaja trojka” dem im September 1938 geschaffenen Dreiergremium reserviert bleiben, das nicht mehr im Rahmen von 00447, sondern der Verfolgung der "nationalen Minderheiten" operierte (vgl. unten); neben der durch Befehl 00447 und der im September 1938 eingesetzten Trojka gab es im Großen Terror noch eine dritte außergerichtliche Instanz, die sich trojka nannte, die sog. Miliz- oder Paßtrojka ${ }^{60}$ die Freiheitsstrafen bis zu fünf Jahren verhängen konnte.

Das Politbüro hat seine eigenen Entscheidungen über die Besetzung der Trojki vom 5.-11. Juli 1937 bereits in der zweiten Hälfte des Monats mehrfach korrigiert. Eklatantestes Beispiel hierfür sind die am 23. und 28. Juli vorgenommenen kompletten Umbesetzungen der Dreierkommissionen der Gebiete Saratov, ${ }^{61}$ Omsk und Ivanovo. ${ }^{62}$ Als Angehörige der regionalen Parteiführung, NKVD-Leitung und Staatsanwaltschaft gehörten die Herren über Leben und Tod selbst zu den Risikogruppen, die seit Juni 1937 zunehmend ins Visier der Verfolger gerieten. Allen voran die regionalen Parteisekretäre, ${ }^{63}$ aber

58. Archiv FSB Jaroslavskoj oblasti (ohne Archivsignatur).

59. M. Vylcan, V. Danilov, “Primenenie VMN...”, art. cit., S. $69-70$ (osobaja und spectrojka); ebenso M. Šrejder, NKVD iznutri. Zapiski čekista, Moskau, 1995, S. 70, 74, 76, 86, 103; Postanovlenie SNK SSSR i CK VKP(b) vom 17. November 1938 in Istoričeskij archiv, 1, 1992, S. 127 hat "sudebnaja trojka".

60. Dieser am 27. Mai 1935 in den Republiken, Regionen und Gebieten geschaffenen Instanz gehörten der entsprechende Leiter des NKVD, der Polizei und der Leiter der Abteilung des NKVD, in dessen Kompetenzbereich die behandelte Strafsache fiel, sowie der Staatsanwalt an. Die Miliztrojka behandelte keine politischen Strafsachen, sondern Verstöße gegen das Paßsystem, sie verurteilte berufsmäßige Bettler, rückfällige Kleinkriminelle, sowie Arbeits- und Obdachlose bis zu fünf Jahren ITL, vgl. G. T. Rittersporn, "Extra-judicial repression and the Courts: Their relationship in the 1930s", in: P. H. Solomon (Hrsg.), Reforming justice in Russia, 1864-1996. Power, culture, and the limits of legal order, New York, 1997, S. 207-227.

61. Zur Absetzung der Partei- und NKVD-Führung Saratovs in der zweiten Julihälfte 1937 vgl. den Brief (19. Juli) von A. A. Andreev und G. M. Malenkov, den Exekutoren der Säuberung, an Stalin, in: Sovetskoe rukovodstvo. Perepiska 1928-1941, Moskau, 1999, S. 364-365.

62. Vgl. Postanovlenie Politbjuro CK ob antisovetskich elementach, P51/187 vom 9. Juli 1937, P 51/199 und 206 vom 10. Juli 1937, P 51/351 vom 23. Juli 1937, P 51/409 vom 28. Juli 1937. in: RGASPI,f. 17, op. 162, d. 21, 11. 95-99, 108, 119. Die endgültige Liste der Trojkamitglieder, wie sie in den Prikaz 00447 aufgenommen wurde, ist veröffentlicht in: N. Gevorkjan, "Vstrečnye plany po uničtoženiju sobstvennogo naroda", Moskovskie novosti, 25, 21. Juni 1992, S. 18-19.

63. Starkovs Befund "On average, party and state leaders in the provinces changed five to six times between 1937 and 1938" - B. A. Starkov, "Narkom Ezhov", in: J. A. Getty, R. T. Manning (Hrsg.), Stalinist Terror. New perspectives, Cambridge, MA., 1993, S. 34 - dürfte etwas übertrieben sein. 
auch NKVD-Leiter ${ }^{64}$ und leitende Staatsanwälte. ${ }^{65}$ Unter den Trojkamitgliedern gab es bis zum Ende der Operation eine starke Fluktuation, die vom Moskauer Machtzentrum gesteuert wurde. Daß in den Politbüroakten nicht alle Ernennungen festgehalten sind, düfte auf die Einschränkung der Kompetenzen zugunsten der beiden Fünferkommissionen im höchsten Parteigremium zurückzuführen sein.

Prikaz 0047 enthält die Namensliste der Mitglieder der 64 Dreierkommissionen, wobei angegeben ist, wer der Vorsitzende (der lokale NKVD-Chef) und die beiden Mitglieder sind (Parteisekretär und in der Regel der leitende Staatsanwalt). ${ }^{66}$ Daß der NKVD, genauer die Hauptverwaltung Staatssicherheit, den Trojkavorsitzenden stellte, nachdem ihrem Apparat bereits Erfassung, Verhaftung, Ermittlung und Untersuchung übertragen worden waren, sicherte die dominante Position der "Organe" bei der Durchführung der Operation. Eine flüchtige Analyse der Liste der Trojkamitglieder bestärkt diese These noch. Nahezu alle prominenten NKVD-Leiter stehen auf der Liste, während die Parteileitungen häufig durch zweite Sekretäre repräsentiert sind, z. B. in Leningrad, Moskau, in der Fernöstlichen Region, in Kujbyšev, auf der Krim, in Voronež, Jaroslavl' etc.

Wie haben wir uns eine Sitzung dieses Gremiums vorzustellen?: Neben den drei "Schnellrichtern" waren der protokollierende Sekretär und der Vertreter der Behörde, die den Fall untersucht hatte (Geheimpolizei oder Miliz), anwesend. Nach einem kurzen Bericht des dokladčik und anhand der schriftlich vorliegenden Fallbeschreibungen, in denen die Zuordnung zu Kategorie 1 oder 2 vorgeschlagen war, fällte die Trojka ihr Urteil. In den Protokollen ist bisweilen (so in Jaroslavl') nicht einmal der ihrem Spruch zugrundeliegende Paragraph des Strafgesetzbuches angegeben (meist 58. 1-14). ${ }^{67}$ Diese Fließband-Justiz verurteilte pro Sitzung Hunderte "antisovetčiki".

Die Trojki fällten ihre Urteile meist nachts, hinter verschlossenen Türen, ohne die Angeklagten jemals gesehen oder gehört zu haben, ohne ihnen die geringste Möglichkeit zur Verteidigung einzuräumen, allein aufgrund der von den Untersuchungsführern präparierten Unterlagen und ihrem Vortrag. ${ }^{68}$ Revision gegen ihren Spruch, der im Gegensatz zu den Urteilen der Dvojki keiner Autorisierung durch eine andere Instanz

64. Vgl. N. V. Petrov, K. V. Skorkin, Kto rukovodil NKVD 1934-1941. Spravočnik, Moskau, 1999, S. 492-500. Die Säuberung der führenden NKVD-Kader hatte im Juli/August 1937 einen kurzen Höhepunkt (mit 8 bzw. 17 Verhaftungen) und erreichte von September 1938 bis Januar $1939(12,15,20,23,19)$ ihre Klimax.

65. Vgl. hierzu P. H. Solomon, Jr., Soviet criminal justice under Stalin, Cambridge, 1996, S. 244-247. 1937-1938 “...90\% of regional procurators were purged.” In manchen Gebieten war das Amt des Obersten Staatsanwalts im Frühjahr 1938 gar nicht besetzt, ebenda, S. 245.

66. In einigen wenigen Territorien gehörte nicht der Staatsanwalt, sondern der Vorsitzende des Gebietsexekutivkomitees der Trojka an, z. B. in Omsk (vgl. V. M. Samosudov, Bol'šoj terror v Omskom Priirtyš'e 1937-1938, Omsk, 1998, S. 47), ebenso in Tatarstan, wo der Staatsanwalt der Republik E. M. Lejbovič an den Sitzungen als "Gast" teilnahm, vgl. A. F. Stepanov, Rasstrel po limitu, op. cit., S. 56.

67. Vgl. hierzu die Statistiken in: Leningradskij martirolog 1937-1938, op. cit., Bd 3: Nojabr' 1937 goda, S. 589; Bd 4: Dekabr' 1937 goda, S. 689.

68. Vgl. dazu R. Gol'dberg, "Slovo i delo...”, art. cit., S. 85-87. 
bedurfte, sah der Text von Prikaz 00447 nicht vor, so daß die Urteile von den Leitern der operativen Gruppen schnell vollstreckt werden konnten. Die von der Trojka zum Tode Verurteilten starben, ohne daß ihnen das Urteil mitgeteilt wurde, die von Frinovskij gezeichnete NKVD-Direktive Nr. 424 vom 8. August 1937 untersagte das. ${ }^{6}$

Die Weisung im Prikaz 00447, "völliges Stillschweigen über den Zeitpunkt und den Ort der Urteilsvollstreckung zu bewahren" wurde lange befolgt. Über das Schicksal der "von außergerichtlichen Organen" zum Tode Verurteilten breitete der NKVD einen dichten Schleier von Lügen; über ein halbes Jahrhundert hielt er an dieser Täuschungsstrategie fest. Der 1939 erlassene Prikaz 00515 befahl, auf die Nachfrage von Angehörigen die berühmt-berüchtigte Antwort "Desjat' let ITL bez prava perepiski” (10 Jahre ITL ohne Recht auf Briefwechsel) zu geben..$^{70} 1945$ wurde ihnen schließlich mitgeteilt, der zu 10 Jahren ITL verurteilte Angehörige sei in der Haft gestorben. ${ }^{71}$ Erst im Rahmen der Rehabilitierung nach 1989 erfuhren Generationen von Sowjetbürgern die wirkliche Todesursache und das wahre Sterbedatum ihrer Kinder, Eltern und Freunde. Hinrichtungsorte und Massengräber sind ebenfalls erst in den neunziger Jahren entdeckt worden..$^{72}$

In Abschnitt VII. des Textes ist die Berichterstattung gegenüber dem Zentrum geregelt: Über den Gang und die Ergebnisse der Operation soll die NKVD-Zentrale alle fünf Tage informiert werden.

\section{Bürokratische Planung}

Am 31. Juli, als vom Politbüro der Befehl 00447, wahrscheinlich im Umlaufverfahren, gebilligt wurde, fielen auch wichtige Entscheidungen über die Durchführung der Operation: Auf 75 Millionen Rubel bezifferte das Politbüro deren Kosten, allein für den Transport der Häftlinge mit der Eisenbahn wurden 25 Millionen und für den Bau neuer Lager 10 Millionen Rubel angesetzt; der Kreis der bürokratischen Mittäter an der Aktion weitete sich aus: Beteiligt wurden der Rat der Volkskommissare, die Volkskommisariate für Verkehrswesen, Verteidigung (Leitungspersonal für die Lagerwache), Holzwirtschaft

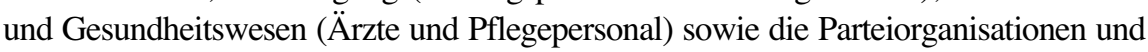

69. A. F. Stepanov, Rasstrel po limitu, op. cit., S. 30.

70. Der Schriftsteller Michail Prišvin notierte am 10. Oktober 1938 voll düsterer Vorahnungen in sein Tagebuch: "Die Grausamkeit ('ohne Recht auf Briefwechsel') der Macht ist grenzenlos, unerträglich - dies ist ein schwarzer Fleck in unserer Union; alles für das Volk, der Tod für das Individuum.” Vgl. M. Prišvin, "Dnevnik 1938 goda (hrsg. von L. A. Rjazanova)", Oktjabr', 1,1997, S. 133.

71. 1955 wurde ihnen ein fiktives Sterbedatum und eine frei erfundene "natürliche" Todesursache mitgeteilt; über den Sterbeort wurden keine Angaben gemacht, vgl. die faksimilierten Sterbeurkunden in Leningradskij martirolog 1937-1938, op. cit., Bd 2, Illustrationen 52-54. Zur bis 1989 verschleiernden Behandlung der Sterbedaten vgl. die Anweisung des Vorsitzenden des KGB V. Semičastnyj vom 26. Dezember 1962 und den Kommentar dazu von A. B. Roginskij in: Memorial-Aspekt. Special'nyj vypusk informacionnogo bjulletenja Moskovskogo Memoriala, 1, 1993, S. 2 .

72. Vgl. Butovskij poligon. 1937-1938 gg. Kniga pamjati žertv političeskich repressij, Bd 1, Moskau, 1997, S. 6, 17-30; Leningradskij martirolog 1937-1938, op. cit., Bd 1, S. 48-51. 
der Komsomol der Gebiete, in denen die Lager errichtet wurden. (Personal für Lagerverwaltung und -wache). Das Politbüro legte fest, daß ein Teil der nach der zweiten Kategorie verurteilten "antisowjetischen Elemente" im Rahmen der laufenden Großbauprojekte des Gulag, die Mehrzahl aber in der chronisch rückständigen Holzwirtschaft eingesetzt werden sollte. Zu diesem Zweck wurden im August 1937 sieben $^{73}$ und im Februar 1938 sechs neue Holzfällerlager eingerichtet, so daß am 15. Februar 1939 276.485 Sträflinge in diesen im Kontext der "Massenoperationen" eingerichteten 13 Lagern registriert waren. ${ }^{74}$ Das waren mehr als $60 \%$ der nach Befehl 00447 zu Freiheitsstrafen verurteilten "Kulaken, Kriminellen und anderen antisowjetischen Elemente."

\section{Durchführung der Operation}

\section{Phase 1}

Diese Untersuchung hat gerade erst begonnen, so daß zur Zeit eine Reihe ganz elementarer Fragen noch nicht geklärt ist: Z. B. die Dauer der Operation in den verschiedenen Republiken, Regionen und Gebieten, die vorrangigen lokalen Opferkategorien, die endgültigen Opferzahlen. Da die im Prikaz 00447 vorgegebenen Quoten in der Provinz offenbar wie Planziffern einer beliebigen Kampagne aufgenommen wurden, wäre es interessant zu wissen, ob es regionale Machthaber gab, die es wagten, unter den zugewiesenen Repressionsquoten zu bleiben, was der Text des Befehls zuließ. Auch über Mentalität und Motivation dieser Personengruppe wissen wir bisher nur wenig: Handelten sie aus Karrieregründen, ideologischer Überzeugung, Parteitreue? Wie beeinflußten lokale Umstände ihre Entscheidungen? Wie kooperierten Parteiführung und NKVD vor Ort? Weiterführen können hier vor allem Recherchen auf regionaler Ebene. Diese finden bereits statt, allein bereitet die Unübersichtlichkeit der Literaturproduktion in den Staaten der ehemaligen Sowjetunion ausländischen Interessierten - aber auch russischen Forschern - größte Schwierigkeiten, Schritt zu halten. Das gilt für Bücher und Zeitschriften, die von kleinen Verlagen, von Forschungsinstitution der Peripherie und von privaten Organisationen herausgebracht werden; ebenso für schmale Schriften, die Autoren in einer Art postsowjetischem samizdat drucken. In noch höherem Maße trifft es auf die Artikel zu, die in Zeitungen der Hauptstadt, ${ }^{75}$ noch mehr aber in der Presse "loin de Moscou"76 publiziert wurden.

In welch extremen Maße die Operation 00447 eine Zäsur in der Geschichte des Katastrophenjahres 1937 markiert, belegt die folgende Statistik der Verhaftungen und

73. Vgl. P51/442, in: RGASPI, f. 17, op. 162, d. 21, 11. 116-117.

74. GULAG (Glavnoe upravlenie lagerei). 1917-1960, op. cit., S. 422.

75. Selbst den Archiven nahe Autoren sind auf das in Zeitungen der Hauptstadt publizierte Material angewiesen.

76. T. Lahusen, "Loin de Moscou. Nouveaux écrits sur l'Extrême-Orient russe de l'ère stalinienne", Revue des Études slaves, 71, 1, 1999, S. 7-10. 
Verurteilungen in Tomsk ${ }^{77}$ dessen NKVD-Chef I. V. Ovčinnikov einer der furchtbaren Čekisten des Großen Terrors war. Die sibirische Stadt, die 1937 134.500 Einwohner zählte, gehörte bis Ende September 1937 zur Westsibirischen Region, nach deren Teilung zum Gebiet Novosibirsk. Die Tabelle registriert nur Verhaftungen und Verurteilungen, die aufgrund von Straftaten nach Artikel 58 (konterrevolutionäre Verbrechen) erfolgten:

\begin{tabular}{|l|r|r|r|r|r|r|}
\hline \multirow{2}{*}{ Tomsk } & \multicolumn{2}{|c|}{ Verhaftungen } & \multicolumn{2}{c|}{ Verurteilungen } & \multicolumn{2}{c|}{ davon zum Tode } \\
\cline { 2 - 7 } & 1937 & 1938 & 1937 & 1938 & 1937 & 1938 \\
\hline Januar & 28 & 508 & 18 & 642 & 1 & 592 \\
\hline Februar & 28 & 1672 & 27 & 470 & 4 & 456 \\
\hline März & 29 & 412 & 28 & 833 & 5 & 796 \\
\hline April & 110 & 109 & 66 & 955 & 33 & 928 \\
\hline Mai & 64 & 80 & 6 & 29 & - & 10 \\
\hline Juni & 276 & 370 & 16 & 84 & 6 & 62 \\
\hline Juli & 1557 & 99 & 158 & 79 & 137 & 34 \\
\hline August & 1227 & 16 & 1154 & 35 & 955 & 24 \\
\hline September & 1089 & 51 & 1583 & 12 & 1191 & 7 \\
\hline Oktober & 1926 & 18 & 1772 & 622 & 1287 & 500 \\
\hline November & 1395 & 19 & 1494 & 87 & 768 & 59 \\
\hline Dezember & 1754 & 4 & 2464 & 49 & 2280 & 6 \\
\hline
\end{tabular}

Quelle: V. N. Ujmanov, Repressii. Kak eto bylo... (Zapadnaja Sibir' v konce 20-ch - načale 50-ch godov), Tomsk, 1995, S. 99/127.

Die Tabelle zeigt die lawinenartige Zunahme der Verhaftungen und Verurteilungen, darunter insbesondere der Todesurteile, ab Juli/ August 1937. Höchst wahrscheinlich handelt es sich hier um eine Entwicklung, die auf die gesamte Sowjetunion zutrifft.78 Da dieses Datum der Beginn der Massenoperation nach Prikaz 00447 ist, darf angenommen werden, daß hier nicht nur eine chronologische Koinzidenz, sondern ein kausaler Zusammenhang vorliegt.

$\mathrm{Da}$ die Verhaftungsziffer in Tomsk in der Westsibirischen Region bereits im Juli 1937 signifikant stieg, könnte die mehrfach geäußerte Hypothese bestätigen, daß in manchen Regionen und Gebieten bereits vor der Zustellung des Befehls die Repressionsmaschinerie in Gang gesetzt worden war. Zwischen dem 31. Juli und dem 5.

77. Die Daten beziehen sich auf das Territorium des erst 1944 gebildeten Gebiets Tomsk. Statistiken, welche die Repressionen des Großen Terrors von Januar 1937 bis Dezember 1938 nach Monaten aufschlüsseln, gibt es inzwischen für mehrere Territorien, vgl. z. B. für Prikam'e bei G. Stankovskaja, "Kak delali "vragov naroda", art. cit., S. 107; für Nižnij Tagil V. M. Kirillov, Istorija repressij v Nižnetagil'skom regione Urala. 1920-e - načalo 50-ch gg. Bd 2: Tagillag 1940-e - nač. 50-ch gg., Nižnij Tagil, 1996, S. 210; für Leningrad, M. Ilic, "The Great Terror in Leningrad", art. cit., S. 1525-1526.

78. In die gleiche Richtung weist ein Rapport des Leiters des NKVD des Kreises Pskov vom Mai 1938: In der ersten Jahreshälfte 1937 seien 45, in der zweiten 3.655 Personen aus politischen Gründen verhaftet worden, vgl. Ne predat' zabveniju. Kniga pamjati žertv političeskich repressij, Bd 1, Pskov, 1996, S. 33. 
August, dem Beginn der Aktion in den meisten Territorien, wurde fieberhaft an deren Vorbereitung gearbeitet: Verhaftungslisten wurden angelegt, zusätzliche Räume für die Unterbringung der Verhafteten und zur Durchführung der Untersuchung gesucht, abgelegene Plätze, meist in Wäldern, als Erschießungsstätten präpariert, Exekutionskommandos zusammengestellt und Gruben zur "Entsorgung" der Leichen ausgehoben.79

Die ersten Sitzungen von Trojki sind für den 5. August 1937 bezeugt. ${ }^{80}$ Auffällig ist der hohe Anteil von ugolovniki (Kriminelle) unter den von den Trojki zu Beginn der Aktion Verurteilten. Das gilt für Karelien, Tatarstan, 81 aber ganz besonders für Jaroslavl', wo das Dreiergremium in den ersten acht Sitzungen (5. August - 13. September 1937) 635 Personen verurteilte (davon 634 zu VMN - Vyš̌aja mera nakazanija): Von diesen sind 246 als ugolovniki (Kriminelle), 167 als ehemalige Kulaken und 222 als "andere konterrevolutionäre Elemente" (Geistliche, Kirchenmitglieder, SRi usw.) angegeben. ${ }^{82}$ Neben programmatischen Zielsetzungen könnten auch sehr praktische Überlegungen das Motiv für dieses Verfahren gewesen sein: Nach Prikaz 00447 Punkt I.7 konnten vor dem 30. Juli 1937 verhaftete Kriminelle (ebenso nach I.5 verhaftete Konterrevolutionäre), deren Fall bereits untersucht, aber noch nicht von Gerichten entschieden worden war, vor die Trojka gestellt werden. Im OUR URKM lagen offenbar viele solcher Fälle vor, die schnell der Trojka übergeben werden konnten. Eines erreichte man sicher durch dieses Procedere: Die schnellere Entlastung der bereits überfüllten ${ }^{83}$ Gefängnisse und Haftorte ${ }^{84} \mathrm{Zu}$ dieser Beschleunigung trug auch bei, daß die zum Tod Verurteilten in der Regel unmittelbar nach dem Trojkaspruch erschossen wurden, Gnadengesuche waren ja ausgeschlossen. In Jaroslavl' geschah das nach ein bis zwei Tagen, in Karelien nach drei

79. Vgl. hierzu die Anweisungen (Faksimileabdruck) des Chefs des UNKVD des Gebiets Kujbyšev I. P. Popašenko an den Leiter der Stadtabteilung von Ul'janovsk vom 4. August 1937 in: Kniga pamjati žertv političeskich repressij, op. cit., S. 797-798; am 1. August hatte Popašenko dem Kapitän des UGB die für seine Arbeit relevanten Punkte des Befehls 00447 resümiert und ihm die Repressionsziffern (100/199) für die Stadt Ul'janovsk mitgeteilt, ebenda, S. 799-800. Popašenko spricht davon, daß die erste Phase der Aktion (Verhaftung und Verurteilung der ersten Kategorie) bis zum 20. August beendet sein solle! Ferner: "Die Existenz der Trojka beim UNKVD und die Überweisung von Strafsachen zur Behandlung durch sie müssen strengste Geheimhaltung unterliegen sowohl gegenüber den Repressierten wie gegenüber den nicht-operativen Mitarbeitern der Organe des NKVD.” (S. 800).

80. In Jaroslavl' und Omsk; in Karelien und in der Westsibirischen Region fand die erste Sitzung am 7., in Leningrad am 9., in Moskau (laut Butovskij poligon) am 14., in Tatarstan erst am 23. August statt. Zu Jaroslavl' vgl. Archiv FSB Jaroslavskoj oblasti.

81. I. Čuchin, Karelija-37: Ideologija i praktika terrora, Petrozavodsk, 1999, S. 76; A. F. Stepanov, Rasstrel po limitu, op. cit., S. 64; vgl. auch die Angaben für Leningrad in der Tabelle.

82. Zu Jaroslavl' vgl. Kopija doklada [A. M. Eršova] narkomu [N. I. Ežovu] o vypolnenii prikazov 00485, 00447, 00429, 00593, 00486, 941-386 (1937 g.), in: Archiv FSB Jaroslavskoj oblasti, f. 22, op. 4, d. 3,11. 1-18.

83. So M. Šrejder, NKVD iznutri, op. cit., S. 69.

84. Ein Blick in den ersten Band des Leningrader Gedenkbuches macht deutlich, daß auch hier auf den ersten Sitzungen vom August 1937 eine hohe Zahl Häftlinge verurteilt wurde, die seit Monaten in Haft saßen, einige seit November 1936, vgl. Leningradskij martirolog 1937-1938, op. cit., Bd 1, S. 576. 
bis 4 Tagen ${ }^{85}$ in Leningrad nach ca. einer Woche, ${ }^{86}$ ebenso in Moskau. Die Zeitspanne zwischen Verhaftung, Verurteilung und Hinrichtung betrug etwa zwei bis sechs Wochen, konnte aber auch extrem verkürzt werden, wenn die Moskauer Zentrale zur Eile drängte. So im November und vor allem Dezember 1937, als Ežov entsprechende Anweisungen verschickte. Im Gedenkbuch von Moskau ist dokumentiert, daß der Leidensweg zwischen Arretierung, Trojkaurteil und Erschießung oft nur eine Woche dauerte, bisweilen selbst noch weniger, ${ }^{87}$ so im Falle von Aleksej Karpovič Bykov, Häftling des Dmitlag, der am 15. November verhaftet, noch am selben Tag von der Trojka verurteilt und noch am 16. November erschossen wurde. 88

Die Trojki haben bereits im August 1937 ihrer Aufgabe, im Eilverfahren Urteile zu fällen, in hohem Maße erfüllt: Um die Monatsmitte waren bereits 100.990 Menschen verhaftet, gegen Monatsende war die Zahl auf 150.000 gestiegen, und waren bereits über 30.000 erschossen. ${ }^{89}$ Die Trojka in Moskau war so mit “Arbeit" überhäuft, möglicherweise auch weil ab Anfang September 1937 die Häftlinge des Dmitlag in ihren Kompetenzbereich fielen, daß das Politbüro am 3. September 1937 beschloß, in der Hauptstadt ein zweites Dreiergremium “zur Beschleunigung der Abhandlung der Straftsachen” einzusetzen. ${ }^{90}$ Für die "judikatorische" Qualität der Trojka-Praxis dürften einige quantitative Daten aufschlußreich sein: Laut Protokoll 81, 82 und 83 hat die Leningrader Trojka an einem Tag (9. Oktober 1937) 658 Häftlinge des Sondergefängnisses auf den Solovekkij-Inseln zum Tode verurteilt. ${ }^{11}$ Hinsichtlich der Dreierkommission der Tatarischen ASSR hat Stepanov ermittelt: "Über 200 Personen am Tag abzuurteilen, war für die Tattrojka eine alltägliche Angelegenheit." Für die Sitzungen vom 28. Oktober 1937 und 6. Januar 1938 sind 256 bzw. 202 Todesurteile bezeugt..$^{92}$ Von der karelischen Trojka wurden am 20. November 1937705 Personen verurteilt, davon 629 zum Tode. ${ }^{93}$ Lokale

85. Vgl. für Karelien das Verzeichnis der Trojkasitzungen mit den Urteilen sowie die Listen der Erschießungen mit Datum, Ort und Namen der Täter bei I. Čuchin, Karelija-37, op. cit., S. $146-147,153-156$.

86. Vgl. dazu Leningradskij martirolog 1937-1938, op. cit., Bd 1-4. Hier sind Datum der Verhaftung, Verurteilung und Hinrichtung der von August bis Dezember 1937 im Gebiet Leningrad Erschossenen angegeben. Vgl. auch M. Ilic, "The Great Terror in Leningrad", art. cit., S. 1527: "Nearly $88 \%$ of all victims were executed within one week of their trial."

87. Vgl. Butovskij poligon. 1937-1938 gg., op. cit., Bd 2. Sost. L. A. Golovkova u.a., Moskau, 1998, S. 169, 173, 174, 175, 182, 192, 199, 229, usw. Für Leningrad vgl. Leningradskij martirolog 1937-1938, op. cit., Bd 4, S. 27, 52, 69, 76, 444 usw.

88. Butovskij poligon. 1937-1938 gg., op. cit., Bd 2, S. 298.

89. Vgl. "Rešenija Osobych troek privodit' v ispolnenie nemedlenno", Istočnik, 5, 1999, S. 85 und N. Ochotin, A. Roginskij, "Iz istorii 'nemeckoj operacii' NKVD 1937-1938 gg." in: I. L. Ščerbakova (Hrsg.), Nakazannyj narod. Repressii protiv rossijskich nemcev, Moskau, 1999, S. 35-75, hier S. 38.

90. P51/872, in: RGANI, f. 68, op. 73, d. 76,1. 1 .

91. Leningradskij martirolog 1937-1938, op. cit., Bd 2, Illustration 82, Bd 3, S. 590-591.

92. A. Stepanov,"Rasstrel po limitu”, Volja, 6-7, 1997, S. 106.

93. I. Čuchin, Karelija-37, op. cit., S. 146. 
Untersuchungen in Krasnodar haben ergeben, daß die Trojka der Region am 20. November 1937 1.252 Personen verurteilte. ${ }^{94}$ Überboten wurde dieser "justizielle" Terror noch von der Omsker Trojka, die am 10. Oktober 19371.301 und am 15. März 19381.014 Menschen verurteilte, davon 937 bzw. 354 zum höchsten Strafmaß. ${ }^{95}$ Unter diesen Umständen war eine Überprüfung des Einzelfalles auf den Trojkasitzungen absolut ausgeschlossen; die Mitglieder waren völlig von den Ermittlungsergebnissen der Untersuchungsleiter des NKVD abhängig, sie konnten einen flüchtigen Blick auf die langen Namenslisten und die kurzen Fallbeschreibungen werfen und diese durch ihre Unterschrift gutheißen; zu mehr reichten weder Absicht noch Zeit. Bisher spricht nichts dagegen, daß die Pseudorichter der Trojki bereitwillige Vollstrecker der Intentionen der Autoren von Prikaz 00447 waren. Der bereits zitierte anonyme NKVD-Funktionär, der in Tjumen' an der Operation beteiligt war, berichtet: 'In die Entscheidung 'der Trojka' wurde aufgenommen, worauf wir in unseren Berichten hingewiesen hatten. Eine Untersuchung des Tatbestands wurde auf den Trojkasitzungen nicht vorgenommen. An einzelnen Tagen berichtete ich 'der Trojka' innerhalb einer Stunde über die Fälle von 50-60 Personen." 96 Erleichtert wurde diese Fließbandjustiz der Trojki durch den von der offiziellen Propaganda geschürten Verdacht, ${ }^{97}$ daß überall im Lande konspirative Organisationen am Werk waren; deren Entlarvung, vor allem die Aufdeckung “der Führungsstäbe dieser Organisationen", befahl die NKVD-Führung den lokalen Untersuchungsführern. Einer von ihnen berichtet darüber: "Die verhafteten konterrevolutionären Einzelpersonen, die disparaten Gruppen und Organisationen begannen sich während der Bearbeitung durch uns zu festen Organisationen mit riesigen Filialen zusammenzufügen." 98 So entstanden in den Folterkammern des NKVD fiktive konspirative Gruppen von 30 bis 40 Personen, aber auch regionale und nationale Untergrundorganisationen gewaltigen Ausmaßes, als deren Mitglieder die verhafteten "antisowjetischen Elemente" im Verlauf der Untersuchung identifiziert wurden. Damit war der vom Prikaz 00447 geforderte Nachweis der "antisowjetischen Tätigkeit" erbracht.

Für die Westsibirische Region hat Papkov aufgrund eines Berichts des UNKVD ermittelt, daß 193734.872 Personen "repressiert" wurden, die sich auf 11 solcher Megaorganisationen verteilten: Als Kontingente für den Befehl 00447 dürften die folgenden fiktiven Organisationen in Frage gekommen sein: "Die weißgardistisch-mon-

94. S. Kropačev, Chronika kommunističeskogo terrora. Tragičeskie fragmenty novejšej istorii Otečestva. Sobytija. Masštaby. Kommentary, Bd 1, 1917-1940, Krasnodar, 1995, S. 47.

95. V. M. Samosudov, op. cit., S. 161,241.

96. R. Gol'dberg, "Slovo i delo...", art. cit., S. 86.

97. Vgl. z. B. L. Zakovskij, Špionov, diversantov i vreditelej uničtožim do konca! Moskau, 1937 (Auflage 500.000); Id., O nekotorych metodach i priemach razvedyvatel'nych organov $i$ ich trockistsko-bucharinskoj agentury, Moskau, 1937 (Auflage 800.000). Der Autor war der Leiter des Leningrader NKVD.

98. Zitiert nach V. N. Ujmanov, Repressii..., op. cit., S. 96. 
archistische Organisation ROVS" (20.731 angebliche Mitglieder) ${ }^{99}$ die sibirische Filiale der "Werktätigen Bauernpartei" (3.617), "die kirchlich-monarchistische Organisation von Aufständischen" (1.562), "die Spionage-Diversions Organisation unter den Sektenangehörigen des Westsibirischen Kreises" (793), "die terroristische Spionage-und Diversionsorganisation der Sozialrevolutionäre" (617). ${ }^{100}$ Der NKVD-Leiter des Gebiets Poltava O. Volkov meldete im April 1938 dem Volkskommissar für Inneres der Ukraine die Entlarvung einer Untergrundorganisation ehemaliger Petljura-Anhänger, die nicht weniger als fünf Regimenter, ein Bataillon, 14 Kompanien und 15 Abteilungen umfaßte. ${ }^{101}$ Alle Dimensionen sprengt die von dem ehemaligen Čekisten S. N. Mironov - er war bis August 1937 Leiter des UNKVD der Westsibirischen Region - aufgedeckte Konspiration. Als Botschafter in der Mongolischen Volksrepublik organisiert er offenbar den Großen Terror in diesem sowjetischen Satellitenstaat. Am 18. Oktober 1937 meldet er "die Entdeckung einer großen konterrevolutionären Organisation" nach Moskau; am 3. April 1938 informiert er die Moskauer NKVD-Zentrale, daß im Falle des vereinigten Zentrums der Verschwörung 10.728 Personen verhaftet worden seien, darunter 7.814 Lamas, und daß die Verhaftung weiterer 7.000 Personen, darunter 6.000 Lamas, bevorstehe. ${ }^{102}$ Die Verfahren gegen die Lamas sollten von Trojki (!!!) durchgeführt werden. Das hatte das Politbüro auf Antrag Frinovskijs im September 1937 beschlossen. ${ }^{103}$

Dieser Befund einer von den Trojki ausgeübten Fließband-Justiz dürfte auch auf die Dreiertribunale der Gebiete und Regionen zutreffen, für die bisher die entsprechenden Daten noch nicht vorliegen.

Befehl 00447 hatte den territorialen Einheiten die Möglichkeit eingeräumt, bei der NKVD-Zentrale in Moskau eine Erhöhung der Repressionsquoten zu beantragen. Zumindest von zwei Gebieten wissen wir bis jetzt, daß sie noch vor dem offiziellen Beginn der Kampagne, dem 5. August 1937, entsprechende Gesuche nach Moskau richteten: Vor allem am Beispiel Omsk, einem der klassischen Deportationszentren für Kulaken und andere "antisovetčiki", läßt sich eine Art "Gesetzmäßigkeit" demonstrieren, die man umschreiben kann als "Intensivierung des Terrors durch Abberufung zögerlicher Repressionsagenten”. Die am 9. Juli 1937 vom Politbüro bestätigte Trojka

99. Zur angeblichen Tätigkeit und Entlarvung des ROVS (Russkij Ob̌̌̌̌evoinskij Sojuz) im Ural und in Westsibirien vgl. die Berichte der Trojka-Vorsitzenden/NKVD-Leiter der Gebiete Sverdlovsk (D. M. Dmitriev) vom 25. Oktober 1937 und Novosibirsk (Gorbač) vom 10. Dezember 1937 an Ežov, in: Istočnik, 1, 1994, S. 94-105. Wahrscheinlich beschuldigte man auch Soldaten und Offiziere der russischen Armee des Ersten Weltkrieges, die in deutsche Kriegsgefangenschaft geraten waren, der Zugehörigkeit zum ROVS. Ihre Erschießung empörte den Čekisten-Memoirenschreiber Šrejder vor allem, weil unter ihnen viele Rotarmisten aus dem Bürgerkrieg gewesen seien, vgl. M. Šrejder, NKVD iznutri, op. cit., S. 92-93.

100. S. A. Papkov, Stalinskij terror, op. cit., S. 219-220

101. J. Šapoval, "NKVD-Terror in der Ukraine", S. 12 (Referat auf der Hamburger Arbeitstagung "Stalinistischer Terror, Massenrepressalien, Gulag" vom 21.-22. Februar 1998).

102. Archivy kremlja i staroj ploščadi. Dokumenty po "delu KPSS". Annotirovannyj spravočnik dokumentov, predstavlennych v konstitucionnyj sud Rossijskoj Federacii po "delu KPSS", Novosibirsk, 1995, S. 20.

103. J. Arch Getty, O. V. Naumov, The road to terror, op. cit., S. 481. 
für das Gebiet Omsk war noch vor Beginn der Operation am 28. Juli durch eine ganz neu besetzte Dreierkommission ersetzt worden; es gibt Anzeichen dafür, daß Stalin selbst diese Umbesetzung veranlaßte, weil die Omsker Partei-und NKVD-Leitung zu wenig Engagement im Kampf gegen die Feinde zeigte und zu niedrige Repressionsziffern angefordert hatte. ${ }^{104}$ Der neue Trojkavorsitzende Grigorij Fedorovič Gorbač galt als einer der skrupellosesten Čekisten des Großen Terrors. Er stellte seine "bolschewistische Wachsamkeit" sofort unter Beweis, indem er in Omsk Massenverhaftungen anordnete und in der NKVD-Zentrale in Moskau am 1. August 1937 um höhere Repressionszahlen nachsuchte, "da wir inzwischen auf Grund unserer StachanovArbeit 3.008 Personen für die erste Kategorie verhaftet haben." 105 Zwei Wochen später, als die Zahl seiner Verhaftungen bereits auf über 5.000 gestiegen war, richtete Gorbač ein Schreiben an die NKVD-Zentrale, in dem er darum nachsuchte, die Obergrenze für die erste Kategorie in seinem Gebiet auf 8.000 zu erhöhen. Auf dem linken Briefrand des Originals ist handschriftlich vermerkt: "Genosse Ežov, ich bin für die Erhöhung des Limits auf 8 Tausend. I. Stalin.”106 Auch aus Smolensk, wo seit 15. April 1937 V. A. Karuckij neuer NKVD-Leiter war und Mitte Juni 1937 das ZK-Mitglied I.P. Rumjancev als langjähriger Erster Parteisekretär von dem aus Moskau importierten D. S. Korotčenkov abgelöst worden war, wurde Ežov bedrängt, die im Prikaz 00447 festgelegten Kontingente auf 3.000 und 6.000 zu erhöhen (vgl. Tabelle). Der auf Rehabilitierung bedachte Karuckij - Jagoda hatte ihn 1936 wegen exzessiven Alkoholismus als NKVD-Chef der Westsibirischen Region abgesetzt - hatte bereits Ende Juli 1937 2.000 zur Erschießung vorgesehene Exkulaken verhaftet und berichtete Ežov am 1. August von weiteren 11.000 "konterrevolutionären" und "kriminellen Elementen", denen "die Organe" auf die Spur gekommen seien. Um die zugewiesenen Quoten nicht zu überschreiten, übergebe der NKVD Kriminelle, die für die zweite Kategorie bestimmt seien, der Miliztrojka. Karuckij führt zwei "lokale" Gründe für die enorme Anzahl Feinde in dem Gebiet an: Der abgesetzte Parteichef habe die Entkulakisierung nur halbherzig durchgeführt und 1931 von 22.000 Kulaken nur 5.000 deportieren lassen. Dazu sei in den letzten Jahren eine hohe Zahl verurteilter Krimineller, denen Moskau, Leningrad und Kiev die Aufenthaltsgenehmigung verweigere, ins Westliche Gebiet ausgewiesen worden. Der neue Parteichef Korotčenkov unterstützte in seinem Brief an Ežov vom 3. August Forderung und Argumentation seines NKVD-Chefs beide hatten sich offenbar abgesprochen - , betonte jedoch noch, daß die große Schar der Konterrevolutionäre, Kulaken und Kriminellen "im Falle eines Krieges angesichts der Nähe der Front zum Problem werden könnte.”107 Wie Gorbač und Karuckij gingen

104. Vgl. V. M. Samosudov, op. cit., S. 42-43, 52-53, 101-107.

105. A. A. Petrušin, “My ne znaem poščady...” Izvestnye, maloizvestnye i neizvestnye sobytija iz istorii Tjumenskogo kraja po materialam VČK-GPU-NKVD-KGB, Tjumen', 1999, S. 137.

106. Ju. Feofanov, "Rasstrel po 1-j kategorii”, Izvestija, 3. April 1996, S. 1, 5.

107. R. Manning, "Massovaja operacija protiv 'kulakov i prestupnych elementov': apogej Velikoj Čistki na Smolenščine”, in: Stalinizm v rossijskoj provincii. Smolenskie archivnye dokumenty v pročtenii zarubežnych i rossijskich istorikov. Sost. E. V. Kodin, Smolensk, 1999, S. 230-254, hier 239-241. 
viele NKVD-Leiter vor: Sie organisierten Massenverhaftungen, bis die Gefängnisse zu klein wurden, anschließend wandten sie sich hilfesuchend an Moskau, um eine Erhöhung der Tötungs- und Lagerquote zu erreichen. So meldet Berija, der Erste Sekretär der gruzinischen Parteiorganisation, am 30. Oktober 1937 der Moskauer Parteizentrale, daß von über 12.000 in Gruzinien verhafteten Personen 7.374 verurteilt worden seien, davon 5.236 durch die Trojka. Was solle mit den restlichen 5.000 geschehen, die "unter anormalen [schwer kontrollierbaren] Haftbedingungen" gehalten würden? Berija favorisiert die Einschaltung der Trojka. ${ }^{108}$ Die beigefügte, keineswegs vollständige Tabelle enthält Belege dafür, daß bis Mitte Dezember 1937 neben dem Westlichen Gebiet, Georgien und Omsk noch 16 andere Gebiete, Regionen, Republiken um Erhöhung der zugewiesenen Repressionsquote nachsuchten, einige selbst mehrere Male. Stalin, das Politbüro und die NKVD-Zentrale unter Ežov scheinen diese Initiativen 1937 nie abgewiesen, sondern eher durch Abrundungen nach oben ermutigt zu haben. So wurde auf Initiative Stalins und Molotovs die Vernichtungsquote für die Region Krasnojarsk, ${ }^{109}$ wahrscheinlich bereits im August 1937, um 6.600 erhöht. (vgl. Tabelle Nr. 28), was gegenüber den Ziffern von Prikaz 00447 eine Steigerung um den Faktor 8.8 darstellt. Bis Ende des Jahres hatte so mehr als ein Drittel der Territorien das ihnen im Befehl 00447 zugeteilte Kontingent beträchtlich erhöht, einige gar weit mehr als verdoppelt. (Vgl. Tabelle Nr. 2, 7, 10, 11, 12 , 15, 17, 19, 20, 21 , 27, 28, 33 , 35, 38, 39, 41, 42, 48, Kazachische SSR und Ukraine mit Gebieten). Nach einer auf der Grundlage der Politbüroprotokolle vorgenommenen Kalkulation von Oleg Chlevnjuk war dadurch die Repressionsziffer gegenüber den am 30. Juli 1937 festgelegten Planziffern um ca. 40.000 erhöht worden. Die tatsächliche Zahl der (zusätzlichen) Erschießungen und Einweisungen in Lager liegt jedoch noch weit höher. Denn ein Teil der Anfragen aus der Provinz - Chlevnjuk belegt dies am Beispiel Turkmenistans - wurde nicht vom Politbüro beantwortet, sondern auf dem kurzen Dienstweg zwischen lokalem NKVD, der Moskauer Zentrale und Stalin als Repräsentanten des Politbüros erledigt (vgl. Tabelle, Endrechnung). Über die in diesem Verfahren bewilligten Eingaben enthalten die Politbüroprotokolle keine Angaben. Chlevnjuk scheint jedoch darüber hinaus zu vermuten, daß NKVD-Leiter vor Ort in der Endphase der Operation 1938 ihre "Initiativen" überhaupt verschwiegen, also auch gegenüber ihrem Moskauer Dienstherrn. ${ }^{110}$

Im Prikaz 00447 war festgelegt, daß die Operation vier Monate dauern, also etwa in der zweiten Dezemberwoche enden sollte. Am 3. November 1937 erreichte die Dienstellen des NKVD in den Republiken, Regionen und Gebieten ein Telegramm Ežovs, das kritisierte, daß die Repressionskampagne gegen die "antisowjetischen Elemente" und die nationalen Minderheiten - genannt werden Deutsche, Polen, Charbiner - "in einigen Gebieten äußerst langsam vorankomme.” Der NKVD-Chef befahl: Die Durchführung der Operation zu forcieren und bis zum 10. Dezember 1937 abzuschließen.

108. M. Vylcan, “Garantiruetsja vysšaja mera”, Trud, 2. August 1997, S. 5.

109. Das Politbüro hatte der Region Krasnojarsk und der Tatarischen ASSR am 9. Juli 1937 zugestanden, ihre Repressionsdaten erst im August vorzulegen, vgl. P51/187, in: RGASPI, f. 17, op. 162, d. 21, 1.95. Wir nehmen an, daß die von Stalin geschriebene undatierte Notiz die Reaktion auf den nachgereichten Repressionsplan aus Krasnojarsk ist.

110. O. Hlevnjuk, “Les mécanismes de la ‘Grande Terreur'...”, art. cit., S. 197-208. 
"Bis zu diesem Datum sollten alle Verhaftungen durchgeführt, die Untersuchungen abgeschlossen und alle Fälle behandelt sein."111 Noch am 10. Dezember 1937 glaubte der Leiter des UNKVD des Gebiets Omsk, K. N. Valuchin, die Operation werde am selben Tag beendet: Seinen Rapport an Ežov leitet er mit der Feststellung ein, daß “die aufgrund Ihres Befehls durchgeführte Operation heute beendet wurde."'112 Offensichtlich wurde dieser Plan aber in letzter Minute umgestoßen, und die Operation bis Anfang Januar 1938 verlängert. ${ }^{13}$ Anhand des Kemerover Gedenkbuches läßt sich nachweisen, daß die Trojka des Gebiets Novosibirsk in der zweiten Dezemberhälfte nicht weniger als 11 mal zusammentrat, zum letzten mal am 29. Dezember, und daß die Frist zwischen Verhaftung und Verurteilung in der zweiten Dezemberhälfte extrem kurz war, häufig nur wenige Tage. In der Tatarischen ASSR verurteilte die Trojka im Dezember 1937 2.561 Personen, weitaus mehr als in jedem anderen Monat. ${ }^{114}$ Das gilt auch für Moskau, wo selbst an dem mit viel Pomb gefeierten 20. Jahrestag von VČK/OGPU/ NKVD (20. Dezember 1937) die Trojka zusammentrat, und für Karelien, wo das Dreiergremium allein vom 18. bis 31. Dezember, über 1.200 Todesurteile fällte. ${ }^{115} \mathrm{Zu}$ Anfang des Jahres 1938 waren so im Rahmen von Prikaz 00447 ca. 500.000 Menschen verhaftet worden. ${ }^{116}$

\section{Phase 2}

“Anfang 1938 gingen von Moskau Signale aus, die auf eine mögliche Beendigung der Säuberungen hinzudeuten schienen." 117 Von diesen Überlegungen scheint die Arbeit der Trojki nur am Rande tangiert worden zu sein. Die Dreierkommissionen wurden im Januar 1938 nicht im nationalen Maßstab aufgelöst, wohl aber stellten sie in einigen Territorien ihre Arbeit ein. So in der Tatarischen ASSR, wo die Trojka am 6. Januar

111. Auszüge des Telegramms in: N. Ochotin, A. Roginskij, "Iz istorii 'nemeckoj operacii' NKVD...", art. cit., S. 43 .

112. R. Gol'dberg, "Slovo i delo...”, art. cit., S. 87.

113. Der bereits genannte inhaftierte NKVD-Funktionär Egorov erwähnt in seinem Brief an Stalin, der stellvertretende Leiter des UNKVD von Novosibirsk, I. A. Mal'cev, sei am 10. Dezember 1937 nach Tomsk gekommen und habe mitgeteilt: "Partei und Regierung haben die Frist für die Arbeit der Trojka bis zum 1. Januar 1938 verlängert.”. Insgesamt sollten bis 1. Januar 2.000 Fälle der Dvojka und Trojka von Novosibirsk vorgelegt werden. V. N. Ujmanov, Repressii..., op. cit., S. 98.

114. A. F. Stepanov, Rasstrel po limitu, op. cit., S. 93.

115. L. Takala, "Nacional'nye operacii OGPU/NKVD v Karelii", in: $V$ sem'e edinoj. Nacional'naja politika partii bol'ševikov $i$ ee osuščestvlenie na Severo-Zapade Rossii v 1920-1950-e gody. (Pod redakciej T. Vichavajnena i I. Takala), Petrozavodsk, 1998, S. 189; I. Čuchin, Karelija-37, op. cit., S. 146. Cuchins Studie enthält in der Beilage eine Tabellle, welche die relevanten Daten über die Trojka der KASSR reproduziert (Datum der Sitzungen, Mitglieder, Urteile nach beiden Kategorien).

116. N. Petrov, A. Roginskij, “'Pol'skaja operacija' NKVD 1937-1938”, in: Repressii protiv poljakov i pol'skich graždan, Moskau, 1997, S. 30.

117. O. W. Chlewnjuk, Das Politbüro, op. cit., S. 277. 
zum letzten Mal tagte. ${ }^{118}$ Kurzfristig scheint Unsicherheit bestanden zu haben, ob die Operation fortgesetzt werde. Wahrscheinlich hat die Arbeit der Trojki - im Gegensatz zu den im Rahmen der Verfolgung der nationalen Minderheiten wirkenden Zweierkommissionen ( $d v o j k i)$ - in vielen Territorien im Januar weitgehend still gelegen, die Kampagne kam ins Stocken. In der oblast' Moskau scheinen die Herren über Leben und Tod des Schnellgerichts am 10., 20., 21. und 26. Januar 1938 vorrangig Lagerhäftlinge vor die Erschießungskommandos geschickt zu haben. Gleiches gilt für Karelien. Erst gegen Ende der Tagung des ZK-Plenums (11., 14., 18., 20. Januar), das sicher nicht, wie lange angenommen, eine Abschwächung der Massenrepressalien beschloß,119 setzen die Trojki in Moskau (am 20.) ${ }^{120}$, Novosibirsk (26.), Petrozavodsk (17. Januar) ihren mörderischen Auftrag fort, während in Omsk vom 3. Januar bis 4. März und in Jaroslavl' zwischen 13. Januar und 13. Februar keine Sitzungen stattfanden. ${ }^{121}$ Der karelische Historiker Ivan Čuchin hat eruiert, daß die NKVD-Leitung am 14. Januar 1938 allen Dienststellen im Chiffretelegramm 109 mitteilen ließ, daß die Arbeit der Trojki bis auf weiteres verlängert worden sei.122 Am 31. Januar 1938 brachte ein Beschluß des Politbüros ${ }^{123}$ Klarheit über die Fortsetzung der Operation gegen "ehemalige Kulaken, Kriminelle und das aktive antisowjetische Element." 12422 administrativen Einheiten (neun Unionsrepubliken, ${ }^{125}$ zwei autonomen Sowjetrepubliken und elf Regionen und Gebieten der RSFSR) wurden neue Kontingente zugewiesen: 48.000 für die erste und 9.200 für die zweite Kategorie. Das Politbüro gab den Čekisten anderthalb (im Fernen Osten zwei) Monate Zeit zur Durchführung der Aktion, die also am 1. April 1938 zu Ende gehen sollte. In allen in der Liste nicht genannten Territorien sollten die Dreiergremien spätestens am 15. Februar 1938 ihre Arbeit einstellen. Pauschal kann

118. Vgl. A. Stepanov, Rasstrel po limitu, op. cit., S. 105-106.

119. Das hatte man in der "alten" Sowjetologie, gestützt auf die Resolution des Plenums, angenommen. Diese postuliert in der Tat ein Ende der "massenhaften, wahllosen" Repressionen, beschränkt die Forderung jedoch eindeutig auf Parteimitglieder, fordert aber gleichzeitig eine Verschärfung des Kampfes gegen die "in den Parteiapparat eingedrungenen maskierten Feinde der Partei”, vgl. Chrestomatija po istorii KPSS, Bd 2, Moskau, 1989, S. 255-263.

120. Vgl. hierzu Butovskij poligon. 1937-1938 gg., op. cit., Bd 1 und 2.

121. L. Takala, “Nacional'nye operacii OGPU/NKVD v Karelii”, art. cit., S. 190-191.

122. I. Čuchin, Karelija-37, op. cit., S. 18.

123. Veröffentlicht als Faksimilenachdruck in: Ju. Feofanov, "Rasstrel po 1-j kategorii”, art. cit., S. 5.

124. Am selben Tag wurde vom Politbüro beschlossen, die Operation gegen die "nationalen Kontingente" - genannt sind 12 "Diasporanationalitäten" (Polen, Letten, Deutsche, Esten, Finnen, Griechen, Iranier, Chinesen, Rumänen, Bulgaren, Makedonier und die Charbiner bis zum 15. April fortzusetzen, vgl. N. Gevorkjan, "Vstrečnye plany...", art. cit., S. 19. Auch hier hatte man die ursprünglich gesetzten Fristen nicht eingehalten, die größte Aktion (gegen die Polen) sollte am 20. November 1937 abgeschlossen sein, wurde dann aber zusammen mit anderen bis zum 10. Dezember und 1. Januar verlängert, vgl. N. Petrov, A. Roginskij, “"Pol'skaja operacija' NKVD...", art. cit., S. 22-43.

125. Es fehlt die Kazachische SSR, deren Kennziffern in der ersten Phase der Operation nicht weniger als viermal erhöht worden waren (vgl. Tabelle). Im Nord-Kazachischen und Süd-Kazachischen Gebiet fanden noch am 5. und 8. Februar 1938 Trojkasitzungen statt, vgl. Političeskie repressii v Kazachstane v 1937-1938 gg. Sbornik dokumentov. Sost. I. N. Buchanova u.a., Alma-Ata, 1998, S. 263/309. 
gesagt werden, daß den 22 Territorien bereits nach Prikaz 00447 die höchsten Kontingente "antisowjetischer Elemente" zugewiesen worden waren. Die meisten von ihnen hatten auch Nachfragen um Erhöhung der Quoten nach Moskau gerichtet. Vergleicht man die Summe der Vernichtungsziffern vom 31. Januar 1938 mit den entsprechenden von Prikaz 00447, so liegen die neuen Quoten für die erste Kategorie (48.000) um 7.600 höher als die alten. Diese Tendenz zur Verschärfung der Strafmaßnahmen durch die Trojki (Ansteigen der Todesurteile, 48.000, gegenüber Lager- und Gefängnisstrafen, 9.200) hält sich das ganze Jahr hindurch. " 1938 hingegen brannte die Obrigkeit aufs Erschießen", notiert Solchenizyn. ${ }^{126}$ Auffällig ist ferner, daß das Politbüro zu noch gröBerer Eile drängt: In der Fernöstlichen Republik sollten in zwei Monaten nicht weniger als 8.000 Todesurteile verhängt werden - wohlgemerkt ohne die am 1. Februar 1938 dort angeordneten Massenhinrichtungen in den Lagern (vgl. Tabelle). Ob an der Festlegung der neuen Sollzahlen die betroffenen Regionen beteiligt waren, etwa analog dem Verfahren vom Juli 1937, ist nicht bekannt. Es liegt aber nahe, daß die NKVD-Leitung die Dienststellen der Peripherie vor Vorlage der Liste im Politbüro hörte. Wahrscheinlich geschah das auf einer Konferenz regionaler NKVD-Leiter, die Ende Januar 1938 in Moskau stattfand. Man darf annehmen, daß die NKVD-Leitung über die Einstellung der NKVD-Leiter aus der Provinz zur Fortsetzung der "Kulakenaktion" bereits informiert war, u.a. auf Grund der im Januar nach Moskau geschickten Rechenschaftsberichte über ihre Amtsführung im Jahre 1937.127 Möglicherweise wurden auf dieser Versammlung die neuen Sollziffern für die Regionen festgelegt, die dann "als Antrag des NKVD" dem Politbüro bei seiner Entscheidung am 31. Januar vorlagen. Glaubt man den Aussagen des an der Konferenz beteiligten NKVD-Chefs von Altaj, S. P. Popov, - "Ich erinnere mich an keinen NKVD-Leiter einer Region oder eines Gebiets, der gesagt hätte, daß man die Massenoperation als beendet ansehen könne" 128 - dann standen Ežov und Frinovskij vor dem Problem, den Repressionseifer der Leiter "des bewaffneten Vortrupps unserer Partei" zu zügeln. Das geschah ganz sicher im Falle des Volkskommissars des Inneren der Tatarischen ASSR: Vasilij Ivanovič Michajlov (1901-1940) hatte seinem langen, mit vielen interessanten Statistiken untermauerten Bericht über den erfolgreichen Feldzug gegen Kulaken, Kriminelle und andere antisovetčiki einige kritische Schlußfolgerungen (vyvody) beigefügt, die plausibel machen sollten, warum der Kampf noch immer nicht gewonnen war. Der seit August 1937 amtierende NKVD-Chef greift zur Standarderklärung: Hauptschuldiger sei die alte Partei- und Sowjetführung in Kazan, die nicht gegen, sondern im Bündnis mit den Feinden gekämpft und den Aufbau mächtiger Netzwerke in allen politischökonomischen Sektoren unterstützt habe. "Die durchgeführten Massenoperationen erwiesen sich unter diesen Bedingungen als unzureichend." Die auf Grund dieser

126. A. Solschenizyn, Der Archipel GULAG, op. cit., Bd 3, Reinbek, 1982, S. 353.

127. Vgl. z. B. "Dokladnaja zapiska ob itogach massovych operacij, provedennych po linii UGB Tatarskoj ASSR", in: A. F. Stepanov, Rasstrel po limitu, op. cit., S. 86-117; bzw. Doklad Narkomu o vypolnenii prikazov 00485, 00447, 00429. 00593, 00486, 941-386 (1937 goda) [vom 14. Januar 1938]: Archiv FSB Jaroslavskoj oblasti, f. 22, op. 4, d. 3, 11. 1-18.

128. Zitiert nach V. Grišaev, Reabilitirovany posmertno. (K istorii stalinskich repressij na Altae), Barnaul, 1995, S. 39 
Konstellation zwingend notwendige "gründliche Säuberung Tatarstans von den aktiv antisowjetischen und konterrevolutionär nationalistischen Elementen" werde lange Zeit in Anspruch nehmen, versuche man es "auf dem normalen Weg" ( $v$ obyčnom porjadke). Michajlov empfiehlt die Straftaten des "aufständischen Fußvolks" (povstančeskoj nizovki) von der Trojka, nicht von Gerichten verhandeln zu lassen. Die Essenz seines langen Diskurses bringt der letzte Satz: "Ich bitte, die Frist für die Tätigkeit der Trojka bis zum 1. April zu verlängern und ein Limit von nicht weniger als 5.000 Menschen zu gewähren." 129 Aus welchen Gründen Michajlovs Eingabe von der NKVD-Leitung (vom Politbüro?) abgewiesen wurde, ist unbekannt. Ebenso wissen wir nicht, ob es im Januar 1938 mehrere solcher Ablehnungen für regionale NKVD-Chefs gegeben hat. Diese Absage dürfte der erste bisher bekannte Fall sein, wo die MoskauerZentrale als Bremser der Repressionsdynamik auftritt. Die von Stepanov vorgelegte Dokumentation macht jedoch deutlich, daß mit der Auflösung der Trojka der Terror in Tatarstan keineswegs abstarb.

Es muß festgehalten werden, daß das Politbüro sich an keine der am 31. Januar beschlossenen Richtlinien für den weiteren Verlauf der Operation gehalten hat. Schon im Februar 1938 bewilligte es über die im Januar-Beschluß festgelegten Quoten neue Opferkontingente und verlängerte die Fristen für die Dauer der Operation: So wurde den ukrainischen Gebieten am 17. Februar ein Repressionskontingent von 30.000 Menschen zugewiesen, wobei nicht nach Kategorien differenziert war. Dies geschah das als Antwort auf eine entsprechende Anfrage in Moskau ${ }^{130}$ : Anträge auf Fortsetzung der Mordoperationen gingen in Moskau bis Ende Okkober 1938 ein. ${ }^{131}$ Vom 1. Februar 1938 bis zum Ende der Operation am 15. November haben das Leitungsgremium der Partei bzw. die NKVD-Zentrale mehr als der Hälfte der im Politbürobeschluß vom 31. Januar genannten Gebiete, Regionen und Republiken zumindest noch einmal neue, z. T. drastisch erhöhte Repressionsziffern zugewiesen (vgl. Tabelle Nr. 3, 4, 7, 10, 12, 26, 27/Novosibirsk, 28 ${ }^{132}$, 30/Čita/Irkutsk, 39, 40, 41, 45). Damit verbunden war jeweils eine Verlängerung der Funktionsfrist der Trojki um anderthalb bis zwei Monate. Noch am 29. August 1938 hat das Politbüro beschlossen, "der Bitte des Gebietskomitees der VKP (b) Čitas über die Fortsetzung der Arbeit der Trojka zu entsprechen.”'133 Buchstäblich bis zum letzten Tag der Operation hat das höchste Parteigremium Umbesetzungen in den Trojki vorgenommen und selbst noch neue Dreierkommissionen eingesetzt. So

129. "Dokladnaja zapiska...", art. cit., S. 117

130. Vgl. Tabelle Ukrainische SSR, FN 123.

131. Der letzte kam möglicherweise am 28. Oktober 1938 aus der Burjato-Mongolischen ASSR, vgl. M. Vylcan, V. Danilov, "Primenenie VMN...”, art. cit., S. 70.

132. Den fettgedruckten Gebieten/Regionen zweimal.

133. Postanovlenie Politbjuro CK vom 29. August 1938, P68/168 in: RGANI, f. 68, op. 73, d. 151, 1. 1. In Moskau scheint die Dreierkommission bis Anfang Juli noch "regelmäßig" (10-12 mal per Monat) zusammengetreten zu sein (im April nur zweimal). Ermittelt anhand von Butovskij poligon. 1937-1938 gg., op. cit., Bd 1-4. 
für die Regionen Chabarovsk und Primor'e, die am 20. Oktober 1938 durch die Teilung der Fernöstlichen Region entstanden waren. ${ }^{134}$

In der Resolution vom 31. Januar 1938 war dekretiert, daß in allen Republiken, Regionen und Gebieten, denen keine neuen Kontingente zugeteilt waren, die Trojki ihre Tätigkeit spätestens am 15. Februar 1938 beenden sollten. Auch diese Order wurde nicht eingehalten; in wenigstens drei dieser Territorien fungierten die Schnelltribunale über diesen Termin hinaus (vgl. Tabelle, 25/Rostov, 32, 48). In der ASSR der Čečenen und Ingušen, wo die Operation 00447 am 15. Februar abgeschlossen worden war, versuchte der neu ernannte Parteisekretär F. P. Bykov, die Trojka zu reanimieren: Am 13. Juli 1938 bat er das Zentralkomitee in Moskau, zur Bekämpfung "konterrevolutionärterroristischer Gruppen der Einrichtung einer besonderen Trojka mit Sondervollmachten für 4-5 Monate, nach dem Beispiel der zuvor durchgeführten Operation, zuzustimmen." 135 In diesem Falle hielt sich das Politbüro an seinen Beschluß vom 31. Januar 1938. Die Ziffer der Erschießungen und Lagereinweisungen nach Befehl 00447 stieg zwischen dem 1. Februar und dem 29. August 1938 nochmals um 90000 (erste und zweite Kategorie). ${ }^{136}$ Bis zum 1. Februar 1938 waren von den Trojki ca. 600.000 Personen verurteilt worden. ${ }^{137}$

Die Zahl der noch fungierenden Trojki war ab März 1938 stark rückläufig. Leider liegt bisher keine Übersicht darüber vor, wann die Tribunale in den einzelnen Republiken, Regionen und Gebieten ihre Tätigkeit einstellten. Ab Frühjahr 1938 wurden die Repressalien gegen die "konterrevolutionären" ethnischen Minoritäten zur Hauptstoßrichtung in der Tätigkeit des NKVD, ${ }^{138}$ und im Sommer 1938 scheinen die wenigen noch bestehenden Dreiergremien ihre monatlichen Sitzungen erheblich reduziert zu haben; z. B. in Moskau auf 3 im Juli und August, in Novosibirsk auf 0/1/ im selben Zeitraum, in Karelien fanden von Mai bis November nur noch 4 Sitzungen statt, ${ }^{139}$ in Omsk nach dem 15. März noch 5. ${ }^{140}$ Weitaus höher war die Frequenz der Trojkasitzungen im Sommer 1938 in den Ostsibirischen Gebieten, in der oblast'Sverdlovsk und in der Fernöstlichen Region. In Irkutsk tagte das Gremium im Juli ca. 12 und im August ca. 6 mal, vgl. Tabelle, FN 70.

134. Vgl. Politbürobeschluß vom 15. November 1938, in: N. Gevorkjan, "Vstrečnye plany...", art. cit., S. 19.

135. Vgl. zapiska Bykova, in: RGANI, f. 89, op. 73, d. 147, 1. 7.

136. O. W. Chlewnjuk, Das Politbüro, op. cit., S. 278. Das Politbüro gab häufig eine Gesamtzahl für beide Kategorien vor, die heute nicht mehr differenziert werden kann.

137. N. Ochotin, A. Roginskij, “Iz istorii ‘nemeckoj operacii’ NKVD...”, art. cit., S. 74.

138. N. Petrov, A. Roginskij, “'Pol'skaja operacija' NKVD...”, art. cit., S. 30.

139. Ermittelt anhand der Angaben in Butovskij poligon. 1937-1938 gg., op. cit., Bd 1 und 4. Für Karelien vgl. I. Čuchin, Karelija-37, op. cit., S. 147.

140. Vgl. V. M. Samosudov, op. cit., S. 241. Wir nehmen auf Grund der S. 14 angegebenen Kriterien an, daß die Sitzung vom 13. September 1938 die letzte im Rahmen von Prikaz 00447 war. Die vom Autor resümierten Sitzungsprotokolle vom 28. September bis 23. Oktober betreffen die vom Politbüro am 15. September 1938 eingesetzte Osobaja trojka. 


\section{Sonderaktionen}

Im Rahmen von Prikaz 00447 fanden zumindest zwei "kleinere" Aktionen statt, die Tötungsaktionen in den "Gefängnissen zur besonderen Verwendung" (tjurmy osobogo naznačenija - TON) des GUGB ${ }^{141}$ und in den Arbeitsbesserungslagern (ITL). Besondere Instruktionen der NKVD-Leitung regelten die Durchführung. Beide Maßnahmen richteten sich gegen spezielle Opfergruppen und kannten nur ein Strafmaß (VMN), die NKVD-Leitung bestimmte zudem die Dauer der Aktion und die Zahl der Erschießungen pro Gefängnis und Lager. Beide Aktionen erweisen sich besonders hinsichtlich der beiden letzten Punkte als getreue Abbilder der großen Aktion. Zur Erschießung der Häftlinge in den Sondergefängnissen der 10. Abteilung (tjuremnyj otdel) des GUGB wurde von der NKVD-Leitung am 16. August 1937 die Direktive Nr. 59190 ausgegeben. ${ }^{142}$ Sie sah vor, die Operation am 25 . August zu beginnen und innerhalb von zwei Monate abzuschließen. Wegen antisowjetischer Aktivität im Gefängnis sollten von der Trojka belangt werden: Die “aktivsten konterrevolutionären Elemente, die wegen Spionage, Diversion, terroristischer, aufständischer und Banditenaktivitäten verurteilt waren, aber auch verurteilte Mitglieder antisowjetischer Parteien"; unter ihnen werden auch die im Prikaz 00447 nicht genannten Trotzkisten angeführt, die laut offizieller Feindpropaganda der sowjetischen Presse im Herbst 1937 immer noch der Feind Nr. 1 waren, meist in der Kombination mit den Bucharinisten ("Trockistsko-bucharinskoe ochvost'e", Izvestija, 22. November 1937, S. 1). Auch ugolovniki, die sich im Gefängnis "verbrecherisch" betätigten, sollten erschossen werden. Die Zusammenstellung der Erschießungslisten, auf Grund derer die Trojka entschied, oblag der Gefängnisleitung. Neue Verhöre, Zeugenbefragungen, Gegenüberstellungen oder Überprüfung von Beweismitteln gab es nicht. Über die "nach der Gefängnislinie" (NKVD-Jargon) Erschossenen wurde getrennt Buch geführt, sie wurden also nicht über das der Republik, Region oder dem Gebiet zugewiesene Kontingent "abgerechnet".

Am intensivsten erforscht ist das Massaker an den Häftlingen des 1937 eingerichteten Gefängnisses auf der Insel Solovki (STON), ${ }^{143}$ auf dem Boden des berüchtigten "Soloveckij ITL", der Mutter des sowjetischen Lagersystems. Ežovs Direktive vom 16. August 1937 hatte dem Gefängnis ein Vernichtungskontingent von 1.200 Häftlingen zugewiesen. Die Leningrader Trojka verurteilte am 9., 10., 14. Oktober 1.116 Häft-

141. In ihnen befanden sich "die gefährlichsten politischen Gegner der damals in der Sowjetunion Herrschenden", aber auch Schwerverbrecher mit langen Haftstrafen. Am 1. März 1939 gab es in der Sowjetunion noch 15 solcher Gefängnisse mit 6.733 Häftlingen, vgl. V. N. Zemskov, "Zaključennye v 1930-e gody: social'no-demografičeskie problemy", Otečestvennaja istorija, 4, 1997, S. 75 .

142. Faksimile-Abdruck der an L. M. Zakovskij, den Leiter des UNKVD des Leningrader Gebiets, adressierten Anweisung in: Leningradskij martirolog 1937-1938, op. cit., Bd 2, Illustration 78-79.

143. Vgl. dazu die Übersicht in: Leningradskij martirolog 1937-1938, op. cit., Bd 4, S. 665668. 
linge, ${ }^{144}$ am 10., 25. November $1937509{ }^{145}$ und am 14. Februar 1938 200, insgesamt 1.825 Häftlinge, jeweils in gesonderten Sitzungen zum Tode. ${ }^{146}$ In den Trojkaprotokollen sind die "Angeklagten" nach dela (Strafsachen) zu großen Gruppen von bis zu 200 Häftlingen zusammengefaßt. Während die Vorstrafen für jeden individuell angegeben sind (ca. fünf bis sieben Zeilen), wird die aktuelle "Straftat", derentwegen Anklage erhoben wird, nur noch kollektiv für die ganze Gruppe angeführt (zwei bis vier Zeilen): "Delo Nr. 100307-37 g. [...] gegen 182 Personen, die wegen konterrevolutionärer trotzkistischer, terroristischer Spionage-Tätigkeit zu unterschiedlichen Haftzeiten verurteilt sind. Diese Personen halten an ihren früheren konterrevolutionären Positionen fest, betreiben weiterhin unter den Häftlingen konterrevolutionäre trotzkistische Arbeit und äußern terroristische Absichten." 147

Der NKVD sah in diesen Häftlingen nicht besserungsfähige politische Regimegegner, die zudem durch kollektive Protestaktionen, mit dem Hungerstreik als schärfster Waffe, die Gefängnisordnung zu verändern suchten. In dem Protokoll der Sitzung der Jaroslavl'er Trojka vom 3. September 1937, auf der 28 Häftlinge mit politischer Vergangenheit des Spezialgefängnisses des GUGB in den Tod geschickt wurden, tritt das deutlich zu Tage: Als todeswürdige Vergehen werden genannt: "Kollektive Proteste, Verbreitung von Flugblättern, Verletzung der Gefängnisordnung, Fortsetzung des politischen Kampfes, Organisation von Hungerstreiks, Selbstmordversuch."148

Die Tötungsaktion in den Arbeitsbesserungslagern des GULAG ist bisher nur unzureichend erforscht. Sie war bereits im Befehl 00447 angekündigt, so daß man Ežovs kurze Direktive Nr. 409 vom 5. August 1937 als Ausführungsbestimmung zu Abschnitt

144. Vgl. ebenda, Bd 2, Illustrationen 81-124 (Trojkasitzung vom 9. Oktober 1937/Protokoll Nr. 81 mit 210 Todesurteilen), Bd 3, Illustrationen 87-291 (Sitzungen vom 9., 10., 14. Oktober 1937 /Protokolle 82-85 mit 907 Todesurteilen).

145. In Leningradskij martirolog 1937-1938, op. cit., Bd 4 sind die Namen dieser 509 zeki des Solovki-Gefängnisses nicht mehr gesondert, sondern zusammen mit den anderen im Dezember 1937 erschossenen Personen aufgeführt. Es gibt auch die durchaus sinnvolle getrennte Statistik, wie in Band 3, nicht mehr.

146. Unter den 1.116 Häftlingen des Solovki Gefängnisses, die im Oktober 1937 von der Trojka zum Tode verurteilt wurden, befand sich ein Großteil (vor allem im Dezember) 1936 verurteilter Trotzkisten, ukrainischer und kaukasischer "bürgerlicher Nationalisten" und wegen "konterrevolutionärer bourgeois-nationalistischer Tätigkeit" verhafteter Anhänger von M. Ch. Sultan-Galiev; dazu ehemalige Offiziere der zarischen und Weißen Armeen, kriminelle Wiederholungstäter, die wegen der Bildung bewaffneter Banden (Art. 59.3), Hooliganismus (Art. 74), Flucht aus Haft, Lager und Verbannung (82), Diebstahl (62) und Erpressung (174) verurteilt waren. Viele Insassen des Sondergefängnisses waren bereits 1932-1934 von den Trojki der Entkulakisierungsperiode zum Tode verurteilt worden, wurden dann aber zu längjährigen Haftstrafen begnadigt. Unter ihnen waren nur wenige Bauern $(1,8 \%)$, mehr Arbeiter $(18,2 \%)$, es dominierten Wissenschaftler, Lehrer, Studenten und Angestellte (70\%); mit 60\% war der Anteil der Parteimitglieder außergewöhnlich hoch, was auch darauf verweist, daß es sich hier um Angehörige der technischen und administrativen Intelligenz handelt, vgl. die Statistik in Leningradskij martirolog 1937-1938, op. cit., Bd 3, S. 590-591. Nach der in Bd 4 publizierten Statistik wurden von den 1.627 im Jahre 1937 hingerichteten Solovki-Häftlingen 1.448 wegen politischer Delikite (Paragraph 58), darunter 780 wegen "trotzkistischer Tätigkeit", und 179 wegen krimineller Vergehen verurteilt (S. 664). Unter den Erschossenen war auch der berühmte russische Religionsphilosoph P. A. Florenskij.

147. Leningradskij martirolog 1937-1938, op. cit., Bd 4, Illustration 87.

148. Archiv FSB Jaroslavskoj oblasti (ohne Archivsignatur). 
I (Von den Repressionsmaßnahmen betroffene Kontingente), Punkt 6 des Befehls 00447 lesen darf. Der Text ist bisher nur unvollständig publiziert. ${ }^{149}$ Die Vernichtungsaktion sollte am 10. August 1937 beginnen und zwei Monate dauern. Als Zielgruppe der Verfolgung sind genannt: "Ehemalige Kulaken, Mitglieder zarischer Straforgane (karateli), Banditen, Weiße, Anhänger von Sekten und Kirchenmitglieder sowie andere Konterrevolutionäre, die sich in den Lagern aktiv und subversiv antisowjetisch betätigen." Und natürlich gehören auch "die kriminellen Elemente, die in den Lagern ihre verbrecherische Tätigkeit ausüben”, dazu. Der Befehl 00447 hatte für die Lager des NKVD eine Tötungsquote von 10.000 festgelegt; in Ežovs Direktive, die an die Leitung der regionalen NKVD-Dienstellen und der Lager auf ihrem Territorium adressiert war, wird das Vernichtungsoll für die einzelnen Lager zugeteilt. ${ }^{150}$ Die Listen der Todeskandidaten, die in den Lagern von der dritten (operativ-čekistischen) Abteilung zusammengestellt wurden, ${ }^{151}$ wurden ebenfalls ohne neue Untersuchungen den Trojki zugestellt.

Die ersten Lagerhäftlinge wurden im August 1937 von den Schnelltribunalen verurteilt, so in Karelien; ${ }^{152}$ die Operation dürfte zwischen Februar und April 1938 ihren Höhepunkt erreicht haben (vgl. auch Tabelle: Lager des NKVD) und erst im November 1938 zu Ende gegangen sein. In mehreren Territorien war die Kampagne gegen die Gulaghäftlinge 1938 noch im Gang, als die Repressalien (nach 00447) außerhalb der durch Stacheldraht abgetrennten Welt bereits eingestellt worden waren. So im Gebiet Archangel'sk, wo die Trojka von Oktober 1937 bis April 19382.755 Häftlinge des Uchtpečlag zur Exekution befahl ${ }^{153}$ oder in Karelien, wo die Operation 00447 am 15. April 1938 auslief, danach aber noch vier Trojkasitzungen stattfanden - die letzte am 10. November 1938 - auf denen ausschließlich Häftlinge des Belbaltlag abgeurteilt wurden. ${ }^{154}$ In dem sich über Stadt und Gebiet Moskau erstreckenden Dmitlag - Mitte der dreißiger Jahre mit 192.000 Insassen das größte Lager im Archipel Gulag -, dessen Häftlinge den Moskau-Wolga Kanal bauten, begannen die Verhaftungen unmittelbar nach der Eröffnung der Wasserstraße (14. Juli 1937). Vom 2. September 1937 bis zum 5. Juni 1938 verurteilte die Trojka beim UNKVD der oblast' Moskau Lagerinsassen zum Tode; die meisten wahrscheinlich im März 1938, als auf 9 von 14 Trojkasitzungen

149. Vgl. I. Čuchin, Karelija-37, op. cit., S. 123 und S. 160 (Faksimileabdruck).

150. Im konkreten Fall 800 zeki für das Belomoro-Baltijskij ITL/Belbaltlag/BBL, I. Čuchin, Karelija-37, op. cit., S. 123, 160.

151. Für die Lagerleitungen war Ežovs Prikaz 409 ein willkommenes Instrument, um die Disziplin im Lager zu stabilisieren. Der Leiter der Dritten Abteilung der Lagerverwaltung des Uchtinsko-Pečorskij ITL (Komi ASSR) gab am 30. August 1937 die Anweisung, vorrangig "die Organisatoren von Hungerstreiks und Arbeitsverweigerer sowie Insassen, die konterrevolutionäre Agitation betrieben und Häftlinge und Ausreißer korrumpierten", für die Trojka zu selektieren, zitiert nach S. Kuz'min, "Lagerniki. GULAG bez retuši", Molodaja gvardija, 4, 1993, S. 170-212, hier S. 201.

152. Vgl. die Liste der Trojkasitzungen bei I. Čuchin, Karelija-37, op. cit., S. 146-147. Sitzungen, auf denen nur Todesurteile verhängt wurden, dürften "Verhandlungen" gegen Gulaghäftlinge sein.

153. Vgl. hierzu S. Kuz'min, "Lagerniki”, art. cit., S. 211.

154. I. Čuchin, Karelija-37, op. cit., S. 77/147. Der Autor schätzt, daß circa 3.000 Häftlinge des Belbaltlag im Rahmen der Operation 409 erschossen wurden, S. 125. 
Todesstrafen gegen zeki verhängt wurden. ${ }^{155}$ Die blutigste Aktion im Rahmen der Direktive 409 fand 1938 in der Fernöstlichen Region statt: Im Rahmen der Säuberung der Grenzgebiete von "antisowjetischen Elementen" billigte das Politbüro am 1. Februar 1938 unter dem Punkt "Maßnahmen zur Verminderung der Häftlingspopulation der fernöstlichen Lager", den folgenden Vorschlag des NKVD: In der Fernöstlichen Republik sollten bis zum 1. April 1938 zusätzlich ${ }^{156} 12.000$ Häftlinge, die wegen schwerer Delikte (Spionage, Terror, Landesverrat, kriminelle Vergehen) bestraft worden waren, durch die Trojka zum Tode verurteilt werden. (vgl. Tabelle, Lager des NKVD). Nach den Angaben von Stanislav Kuz'min, 1993 Professor an der Akademie des MVD, der NKVD-Archivalien ausgewertet hat, wurden im Rahmen der Aktion in den Lagern des NKVD 30.178 Menschen getötet. ${ }^{157}$

Ob es auch eine besondere Anweisung zur Säuberung der Arbeitsbesserungskolonien gegeben hat, ist bisher nicht bekannt, wohl aber, daß Insassen der ITK von Trojki zur Höchststrafe verurteilt wurden. ${ }^{158}$ Wahrscheinlich gab es auch keine spezielle Direktive zur Durchführung von Befehl 00447 in den “Arbeitssiedlungen” der deportierten Kulaken. Wir wissen aber, daß Tausende trudposelency der Operation zum Opfer fielen. ${ }^{159}$

In diesem Kontext soll noch kurz auf zwei lokale Aktionen eingegangen werden, die vielleicht nur deshalb als singulär erscheinen, weil wir bisher über die Umsetzung von Befehl 00447 noch wenig wissen:

In der Tatarischen Republik geschah am 1. November 1937 Außergewöhnliches: Die "Organe" übergaben dem Gericht 19 alte (über 60 Jahre) und kranke Menschen, die sie festgenommen hatten, als Anfang Oktober befohlen wurde, mit den Verhaftungen für die zweite Kategorie (Gulag-bzw. Gefängniseinweisungen) zu beginnen. Der Kazaner Historiker Stepanov, der den Vorfall berichtet, scheint der Ansicht zu sein, daß die Sicherheitspolizei den für die harte Arbeit in den Lagern nicht geeigneten Personen zu milderen Strafen verhelfen wollte. ${ }^{160}$ In Moskau stand die Staatssicherheit Anfang 1938 vor einem ähnlichen "Problem", sie entschied sich für die brutalste Lösung. Von der Trojka waren Ende 1937 einige Hundert Invaliden und "begrenzt Arbeitsfähige" zu unterschiedlichen Lagerstrafen verurteilt worden. Da es nicht gelang, alle Verurteilten in konclagerja einzuweisen - die Hauptverwaltung der Lager sperrte sich gegen die Aufnahme ${ }^{161}$ — befahl der berüchtigte NKVD-Funktio-

155. Ermittelt anhand der in Butovskij poligon. 1937-1938 gg., op. cit., Bd 2, S. 291-344, Bd 3, S. 269-340 und Bd 4, S. 275-330 abgedruckten Kurzbiographien verurteilter Lagerhäftlinge.

156. Also über die den Lagern der Region im Rahmen der Direktive 409 bereits zugeteilten (bisher nicht bekannten) Quote.

157. S. Kuz'min, “Lagerniki”, art. cit., S. 211.

158. Butovskij poligon. 1937-1938 gg., op. cit., Bd 2, S. 75, Bd 4, S. 47, 51, 54, 153.

159. Vgl. z. B. V. M. Kirillov, Žertvy repressii. Nižnij Tagil 1920-1980-e gody, Ekaterinburg, 1999, S. 94; G. Stankovskaja, "Kak delali “vragov naroda”, art. cit., S. 97/99.

160. A. F. Stepanov, Rasstrel po limitu, op. cit ., S. 14.

161. Ein Prikaz Jagodas vom 12. Dezember 1934 verbot die Einweisung von Kranken und Invaliden in Lager (ITL), es sei denn, sie waren nach Paragraph 58 und 59.3 (Banditentum) verurteilt, vgl. A. Kokurin, N. Petrov, "Gulag: Struktura i kadry", Svobodnaja mysl'-XXI. Teoretičeskij i političeskij žurnal, 9, 1999, S. 114, 117, 119. 
när L. M. Zakovskij, seit 20. Januar 1938 NKVD-Chef von Moskau und Stellvetreter Ežovs, sie erneut vor das Dreiergremium zu bringen. Er instruierte den Vorsitzenden der Trojka, M. I Semenov, daß alle zum "höchsten Strafmaß” (VMN) zu verurteilen seien, was im Februar 1938 auch geschah: 170 Invaliden (Arm- und Beinamputierte), Blinde, Tuberkulose- und Herzkranke wurden in den Tod geschickt, ${ }^{162}$ weil in den Moskauer Gefängnissen Platz für neue Häftlinge geschaffen werden sollte und die GULAG-Leitung sie als “Ausschuß” (brak) ${ }^{163}$ betrachtete, der in der Gulagökonomie nicht eingesetzt werden konnte.

Auf den ersten Blick haben auch die Repressionsmaßnahmen gegen die Taubstummengemeinde in Leningrad Ähnlichkeit mit gewissen NS-Operationen (Aktion T 4): Im August 1937 hatte die Polizei bei einer Hausdurchsuchung in der Wohnung eines Taubstummen einige Hitler-Bildchen gefunden. Diese waren deutschen Zigarettenpakkungen beigelegt, die dem ebenfalls taubstummen, im selben Hause wohnenden deutschen Politemigranten Albert Blüm gehörten. Der die Untersuchung leitende Polizeichef konstruierte aus diesen für einen Verschwörungsarchitekten verlockenden Ingredienzen die "Strafsache der antisowjetischen, faschistischen Terrororganisation des Gestapoagenten A. Blüm", die auch noch mit dem deutschen Konsul in Leningrand in Verbindung stand. 54 Taubstumme, unter ihnen die kulturelle Elite der großen Leningrader Taubstummengemeinde, wurden verhaftet. Nach der üblichen Manipulation bei der Abfassung der Verhörprotokolle wurden sie am 17. Dezember 1937 von der Trojka verurteilt: 34 zur Höchstrafe, 19 zu 10 Jahren Lager. ${ }^{64}$ Der naheliegende Vergleich mit der Verfolgung Geisteskranker und Behinderter im NS-Regime verbietet sich jedoch wahrscheinlich in diesem Fall, weil nach unserem aktuellen Kenntnisstand diese Behinderung in der Sowjetunion der dreißiger Jahre keine Ursache für Diskriminierung war. Gerade die Taubstummen, die gut in die Arbeitswelt integriert waren, wurden vom Regime gefördert. ${ }^{165}$ Ein Indiz für zunehmende Brutalisierung der Operation 00447 sind die beiden Aktionen in jedem Fall. Noch eine letzte Bemerkung in diesem Zusammenhang: Bei der Durchsicht der Gedenkbücher fällt auf, daß viele Menschen über 60 Jahre unter den Ermordeten sind, 70-80jährige sind keine Seltenheit,

162. Unsere Ausführungen zu diesem Fall beruhen auf dem Artikel von I. Osipova, "Pjat' del", in: Soprotivlenie v Gulage. Vospominanija. Pis'ma. Dokumenty. Sost. S. S. Vilenskij, Moskau 1992, S. 114-127. Der Beitrag enhält eine Reihe von Ungenauigkeiten und Widersprüchlichkeiten, so wird nicht zwischen Miliztrojka und Trojka nach 00447 unterschieden.

163. So K. A. Pavlov, Direktor von Dal'stroj, in einem Brief an den Stellverteter Ežovs am 19. September 1938, in: 30 Oktjabrja, 10, 2000, S. 12.

164. Vgl D. L. Ginzburg, "Pomnju tragičeskij 1937-j", in: Leningradskij martirolog 19371938, op. cit., Bd 4, S. 675-678 und A. Razumov, Ju. Gruzdev, "Delo Leningradskogo obščstva gluchonemych", ebenda, S. 678-681.

165. Vgl. dazu S. Burch, "Transcending revolutions: The tsars, the Soviets and deaf culture", Journal of Social History, 34, 2, 2000, S. 393-401. 
besonders unter den “byvšie ljudi”. ${ }^{166}$ Unter den 3.859 im November 1937 in Leningrad erschossenen Personen waren $418(11,1 \%)$ über 60 Jahre alt, im Dezember waren es $413(9,2 \%) .{ }^{167}$ Hing dieser hohe Anteil alter Menschen damit zusammen, daß die furchtbaren "Richter" der Dreier- und Zweiergremien wußten, daß eine Verurteilung der Alten zu Lagerhaft nicht erwünscht war, da sie "keiner nützlichen Arbeit" mehr nachgehen konnten? ${ }^{168}$

\section{Auslaufen der Operation}

Ein Indiz für das allmähliche Auslaufen der Operation 00447 ist der Politbürobeschluß169 vom 15. September 1938 der ein neues System der Verurteilung der "konterrevolutionären nationalen Kontingente" schuf. Das alte Verfahren, nach dem die regionale Dvojka, NKVD-Chef und Oberster Staatsanwalt, der "Komissija NKVD i Prokuratury SSSR” in Moskau, auch “vysšaja dvojka” (Oberste Dvojka) genannt, Listen (die sog. "Alben”) mit kurzer Fallbeschreibung und Vorschlägen für das Strafmaß (Todesstrafe oder 5-10 Jahre Haftstrafe) zur Bestätigung zusandten, hatte sich als ineffizient erwiesen: Ežov bzw. die zuständigen Abteilungen der Sicherheitspolizei und Vyšinskijs Staatanwaltschaft der UdSSR gerieten 1938 mit der Erledigung dieser Aufgabe in erheblichen Rückstand. Zwischen Absendung und Rückerhalt der "Alben" lagen oft mehrere Monate, was sich auch anhand der Kurzbiographien in den Gedenkbüchern belegen läßt. ${ }^{170}$ Anfang September 1938 hatten sich in Moskau mehr als 126.000 unbearbeitete Strafakten angesammelt. Diese Trägheit des Zentrums führte zu überfüllten Gefängnissen in der Provinz und provozierte Beschwerdebriefe der betroffenen Machhaber. ${ }^{171}$ Daher verfügte das Politbüro, daß in den Gebieten, Regionen und

166. Samosudov berichtet von einem 1840 geborenen Oberst der zarischen Armee, der am 17. September 1937 von der Trojka zum Tode verurteilt wurde; mit ihm der 74-jährige Weltkriegsinvalide A. P. Bykov (V. M. Samosudov, op. cit., S. 109). Seine Frau, die noch zwei Jahre später nichts über das Schicksal ihres Mannes weiß, schreibt 1939 an Berija, die Verhaftung müsse auf einem Mißverständnis beruhen, da ihr Mann wegen Krankheit und geistigen Verfalls ein totaler Pflegefall war. Unter den älteren Erschossenen in Leninrad (im September 1937) sind V. A. Prus (1874 in Warschau geb.) "Mitglied der VKP(b) seit 1899, 1937 im Zusammenhang mit der Verhaftung ausgeschlossen, in der Vergangheit Mitarbeiter des UNKVD LO". Daneben A. A. Bibiksarov (1859 geb.), "ohne feste Arbeit und ohne festen Wohnsitz". Die ältesten in Leningrad 1937 hingerichteten Frauen dürften die 1859 geborene Äbtissin A. J. Koževnikova und die im gleichen Jahr geborene Blumenverkäuferin ("ehemalige Baronesse") S. I. Mengden-Turovskaja sein; der älteste Mann der 1852 geborene Hirte F. V. Solov'ev. Vgl. Leningradskij martirolog 1937-1938, op. cit., Bd 1, S. 480/110, Bd 4, S. 211/303, Bd 3, S. 384.

167. Ebenda, Bd 3, S. 587, Bd 4, S. 686.

168. Leider wissen wir nicht, wie hoch der Anteil der Alten an den zu Lagerstrafen Verurteilten in Leningrad war, weil im martirolog nur Erschossene registriert sind.

169. Text bei Ju. Feofanov, "Rasstrel po 1-j kategorii", art. cit., S. 5.

170. Vgl. Butovskij poligon. 1937-1938 gg., op. cit., Bd 4, S. 56: A. A. Gajdenak, Sowjetbürger ungarischer Nationalität, wurde am 8. März 1938 verhaftet und am 10. Oktober 1938 von der Osobaja Trojka der oblast' Moskau zum Tode verurteilt.

171. N. Ochotin, A. Roginskij, "Iz istorii 'nemeckoj operacii' NKVD...”, art. cit., S. 61; N. Petrov, A. Roginskij, “Pol'skaja operacija' NKVD...”, art. cit., S. 30. 
Republiken "osobye trojki" (Sondertrojki) zu bilden seien, welche die von den Dvojki nicht erledigten Strafsachen gegen vor dem 1. August $1938^{172}$ verhaftete Angehörige der Diaspora-Nationalitäten entscheiden sollten. Auch die Sondertrojki erhielten die Vollmacht, Todesstrafen sowie Lager- und Gefängnishaft von 5 bis 10 Jahren zu verhängen, waren aber auch befugt, Untersuchungsverfahren neu zu eröffnen und Verhaftete bei Mangel an Beweisen freizusprechen. Der Text von Prikaz 00447 sah solches nicht vor. Näheres regelte der Prikaz 00606 des NKVD vom 17. September 1938. ${ }^{173}$ Die personelle Zusammensetzung der traditionellen Dreierkommission und der Sondertrojka war identisch; in einigen wenigen Regionen und Gebieten gab es somit im September/Oktober 1938 zwei identisch besetzte Dreiertribunale, die jedoch unterschiedliche Kompetenzen und Zuständigkeiten hatten.

\section{Ende der Massenrepressionen}

Anfang November 1938 hatten sich die Anzeichen für einen Kurswechsel in der sowjetischen Repressionspolitik so sehr verdichtet, daß in Moskau bereits Gerüchte über das Ausscheiden Ežovs aus dem Amt die Runde machten; vielen galt er als die treibende Kraft des Massenterrors. ${ }^{174}$ Am 15. November 1938 war es dann soweit: Das Politbüro billigte auf Anfrage der Staatsanwaltschaft der Sowjetunion den Entwurf einer Direktive, die vom Rat der Volkskommissare und dem Zentralkomitee der Partei verabschiedet werden sollte und deren Kernsatz lautete: "Wir erteilen die strengste Anweisung: $\mathrm{Ab}$ dem 16. November dieses Jahres sind bis auf weiteres alle Verhandlungen von Strafsachen durch die Trojki einzustellen." 175 Einen Tag später wurde der Beschluß des Rats der Volkskommissare und des Zentralkomites "Über Verhaftungen, staatsanwaltliche Aufsicht und Durchführung des Untersuchungsvefahrens"176 von Molotov und

172. Das Politbüro hatte am 26. Mai 1938 die Operation gegen die "konterrevolutionären nationalen Kontingente" zum viertenmal verlängert, diesmal bis zum 1. August 1938. Neben den im Politbürobeschluß vom 31. Januar 1938 aufgeführten 12 ethnischen Minoritäten sind hier zusäzlich die Afghanen genannt, vgl. P63/243 vom 26. Mai 1938, in: RGASPI, f. 17, op. 162, d. 29, 1. 32.

173. Vgl. Pamiat’: Žertvy polititičeskich repressij. Rossijskaja Federacija. Respublika Mordovija. Sost. P. E. Sen’kin, F. P. Saraev, Saransk, 2000, S. 748-749. Eine vom stellvertretenden Volkskommissar des Inneren, Berija, gezeichnete Erläuterung (21.09.1938) zur Durchführung von Prikaz 00606 präzisiert den Personenkreis, der von den Sondertrojki abgeurteilt werden sollte. Angehörige der technischen, militärischen Elite sowie des NKVD fielen nicht in ihre Zuständigkeit. Daneben legte die Direktive fest, daß die Sondertrojki - anders als im Politbürobeschluß vom 15.09.1938 und im Prikaz 00606 dekretiert - auch Lagerstrafen "bis zum 5 Jahren" verhängen dürften, vgl. Ot $\check{C} K$ do FSB. Dokumenty i materialy po istorii organov gosbezopasnosti Tverskogo kraja. 1918-1998. Sost. V. A. Smirnov, A. V. Borisov, M. V. Cvetkova, Tver', 1998, S. 168-170. Die Mitglieder der Sondertrojki bedurften keiner Bestätigung durch das Politbüro. In den knapp zwei Monaten ihres Bestehens verurteilten sie 105.032 Angehörige nationaler Minderheiten (keine Ausländer), darunter 72.254 zum Tode, N. Petrov, A. Roginskij, “"Pol'skaja operacija' NKVD...”, art. cit., S. 30..

174. Tagebucheintrag V. I. Vernadskijs vom 5. November 1938. Vgl. "Dnevnik 1938 goda", Družba narodov, 3, 1991, S. 260

175. Veröffentlicht in: N. Gevorkjan, "Vstrečnye plany...", art. cit., S. 19.

176. Veröffentlicht in: Istoričeslij archiv, 1, 1992, S.125-128. 
Stalin unterzeichnet und den Leitern des NKVD, den Parteisekretären und leitenden Staatsanwälten der Republiken, Regionen, Gebiete, Stadt- und Rajonabteilungen zugestellt: insgesamt also einem Kreis von ca. 14.000 Personen, was angibt, daß die Parteiund Staatsführung der Direktive weite Verbreitung wünschte. Der Textentwurf war von einer durch das Politbüro am 8. Oktober 1938 eingesetzten Kommission ausgearbeitet worden, der Ežov, Berija, Vyšinskij, Malenkov und N. M. Ryčkov, Vorsitzender des Obersten Gerichts der UdSSR, angehörten. ${ }^{177}$ Stalin und Molotov ziehen zunächst eine positive Bilanz der Repressionskampagne gegen die ehemalige Parteiopposition (Trotzkisten-Bucharinisten) und der Massenoperationen gegen Kulaken, Kriminelle und andere sowjetfeindliche "Elemente" sowie gegen die "nationalen konterrevolutionären Kontingente"; sie üben jedoch schärfste Kritik an den vom NKVD und der Staatsanwaltschaft in diesem Kontext gemachten "Fehlern" und verursachten "Enstellungen der revolutionären Gesetzlichkeit", die letztlich auch den Endsieg über die Feinde verhindert hätten. Angeprangert werden Verzicht auf Beschaffung von Beweismaterial zur Überführung der Volksfeinde (durch die agentura), unbegründete und gesetzwidrige Massenverhaftungen und massive Verletzungen elementarster Normen beim Untersuchungsverfahren. Über die 1937/1938 gängige Praxis der Erpressung von Geständnissen durch die Folter hüllt sich die Resolution der Partei- und Staatsführung aus guten Gründen in Schweigen. Nach Stalins und Molotovs Lesart wurden die genannten Exzesse letztendlich durch in den NKVD und die Staatsanwaltschaft eingedrungene Feinde verursacht, ein im stalinistischen Diskurs der dreißiger Jahre immer wieder auftauchender Mechanismus der Schuldzuschreibung. Und diesen sei es auch gelungen, Geheimpolizei und Staatsanwaltschaft der Kontrolle der Partei zu entziehen. Mit dem Verbot, weiterhin Massenverhaftungen und Deportationen durchzuführen, und der Anordnung, die Trojka, die zentrale Repressionsinstitution des Großen Terrors, und gleichzeitig die im Mai 1935 geschaffenen Polizeitrojki aufzulösen, erklärten Partei- und Staatsführung den Großen Terror für beendet. Verhaftungen sollten in Zukunft, so wie in Artikel 127 der Verfassung festgelegt, nur noch auf Beschluß des Gerichts oder mit Genehmigung des Staatsanwalts erfolgen; Strafsachen sollten, entsprechend den gesetzlichen Normen, den ordentlichen Gerichten und dem Osoboe Soveščanie des NKVD übergeben werden; ein langer Katalog von Bestimmungen sollte Verhaftete vor Willkürmaßnahmen der Untersuchungsleiter schützen. Ganz neu waren diese Forderungen nicht; in den im Text genannten Direktiven vom Mai 1933 und Juni 1935 hatten der Vorsitzende des Rats der Volkskommissare (Molotov) und der Erste Sekretär des Zentralkomitees (Stalin) das Ende von Massendeportationen und -verhaftungen verkündet und Verhaftungen an die Genehmigung der Staatsanwaltschaft gebunden. 1937/ 1938 finden sich die Namen beider unter allen Dokumenten, die den Massenterror in Gang setzten. Die dem Text der Resolution immanente Deutung der Ereignisse der Jahre 1937-1938 tendiert dazu, diese Tatsache zu verschleiern und die Führung von Partei und Staat von der Verantwortung für die Massenoperationen zu entlasten; so zum Beispiel für die im Politbürobeschluß vom 2. Juli 1937 initiierte, am 31. Juli sanktio- 
nierte und darauf in Dutzenden von Politbürobeschlüssen gebilligte quotenregulierte Vernichtung von Feinden. Die schon sehr früh für den Großen Terror gebrauchte Bezeichnung "ežovščina" 178 kam dieser Deutung der Ereignisse entgegen. Ihr war ein langes Leben beschieden: Bei Stalinapologeten ${ }^{179}$ wie bei Historikern. ${ }^{180}$ In diesen Kontext paßte es, daß der NKVD-Chef wenige Tage nach der Resolution, am 23. November 1938, dem Politbüro sein Rücktrittsgesuch unterbreitete, das von diesem am 24. November angenommen wurde. In einer langen Erklärung vom 26. November 1938 (Prikaz 00762) übte der neue Volkskommissar des Inneren Berija im Namen seiner Behörde Selbstkritik und versprach, die in der Resolution vom 17. November postulierte Rückkehr in die sowjetische Legalität. Nicht weniger als 18 zwischen Juli 1937 und September 1938 ergangene Befehle, Zirkulare und Verordnungen des NKVD, in denen Repressalien gegen bestimmte Zielgruppen angeordnet und die Modalitäten ihrer Umsetzung geregelt waren, wurden außer Kraft gesetzt bzw. aufgehoben. Darunter auch der Befehl 00447. Ohne Zweifel war jeder dieser "podzakonnye akty" (quasigesetzlichen Akte) durch einen Politbürobeschluß legitimiert worden.

Punkt 16 von Prikaz 00762 forderte, allen operativen Mitarbeitern des NKVD der Zentrale und der Provinz ein Exemplar des Strafgesetzbuches und der Strafprozeßordnung zuzustellen. ${ }^{181}$

Rolf Binner

Iepenplein $80 \mathrm{~b}$

1091 JR Amsterdam

e-mail:nobis@hfd.nl

\author{
Marc Junge \\ Lehrstuhl für Osteuropäische Geschichte \\ Ruhr-Universität - Bochum
}

e-mail:marc.junge@ruhr-uni-bochum.de

178. Tagebucheintrag V. I. Vernadskijs vom 4. Januar 1939: "An allen Orten und im ganzen Land ist offensichtlich, daß der Ruin Folge der ežovščina ist.", vgl. "Dnevnik 1939 goda", Družba narodov, 11-12, 1992, S. 8.

179. Molotov stellt in seinen "Memoiren" einen Zusammenhang zwischen dem Ežov zugeschriebenen System der Repression nach Quoten und seiner Absetzung her: "Man fing an, Ežov zu beschuldigen, er habe den Gebieten Quoten zugeteilt und von den Gebieten ausgehend den Bezirken Ziffern; ein bestimmtes Gebiet hatte nicht weniger als 2.000 Personen zu liquidieren und ein bestimmter Bezirk nicht weniger als $50 \ldots$ Und dafür wurde er erschossen. Eine Kontrolle darüber gab es allerdings bereits nicht mehr." Sto sorok besed s Molotovym. Iz dnevnika F. Čueva, Moskau, 1991, S. 399.

180. Der Petersburger Historiker Boris Starkov strickt an der Legende vom hintergangenen Stalin, wenn er 1993 Ežov nicht als willigen Exekutor der Aufträge Stalins, sondern als eigenmächtigen, autonomen Akteur im Großen Terror zeichnet: "Ezhov's primary crime, however, consisted in the fact that he had not informed Stalin of his actions", vgl. B. A. Starkov, "Narkom Ezhov", art. cit., S. 38.

181. Organy Gosudarstvennoj Bezopasnosti SSSR v Velikoj Otečestvennoj Vojne. Sbornik dokumentov, Bd 1 Nakanune. Kniga pervaja (nojabr' 1938 g. - dekabr' 1940 g.), Moskau, 1995, S. 16-21. 
Tabelle zum Operativen Befehl 00447

\begin{tabular}{|c|c|c|c|c|}
\hline & 1. Kategorie & 2. Kategorie & Insgesamt & \\
\hline \multicolumn{4}{|l|}{ 1. Azerbajdžanische SSR } & $3056978^{2}$ \\
\hline 10. Juli $1937 \mathrm{a}^{3}$ & 1500 & 3900 & 5400 & Anfrage $4 / \mathrm{PB}^{5}$ \\
\hline $\begin{array}{l}\text { Ehem. Kulaken/Kriminelle } \\
\text { Mitglieder aufständischer } \\
\text { Organisationen/ } \\
\text { Angehörige von } \\
\text { Bandengruppenmitgliedern }\end{array}$ & $\begin{array}{r}500 / 500 \\
500\end{array}$ & $\begin{array}{r}300 / 1700 \\
750\end{array}$ & & \\
\hline 30. Juli $1937^{6}$ & 1500 & 3750 & 5250 & Befehl 00447 \\
\hline 31. Januar $1938^{7}$ plus & 2000 & & 2000 & Politbüro $^{8}$ \\
\hline Summe $^{9}$ & 3500 & 3750 & 7250 & $0,24 \% 10$ \\
\hline \multicolumn{4}{|l|}{ 2. Armenische SSR } & 1209253 \\
\hline 11. Juli $1937^{11}$ & 500 & 650 & 1150 & Anfrage/PB \\
\hline Ehem. Kulaken/Kriminelle & $300 / 200$ & $400 / 250$ & & \\
\hline 30. Juli 1937 & 500 & 1000 & 1500 & Befehl 00447 \\
\hline 22. Sep. $1937^{12}$ erhöhen um & 700 & & 700 & Anfrage \\
\hline 24. Sep. $1937^{13}$ erhöht um & 1500 & & 1500 & Politbüro \\
\hline 31. Januar 1938 plus & 1000 & 1000 & 2000 & Politbüro \\
\hline Summe & 3000 & 2000 & 5000 & $0,41 \%$ \\
\hline \multicolumn{4}{|l|}{ 3. Weißrussische SSR } & 5196549 \\
\hline 10. Juli 1937a & 3000 & 9800 & 12800 & Anfrage/PB \\
\hline 30. Juli 1937 & 2000 & 10000 & 12000 & Befehl 00447 \\
\hline 31. Januar 1938 plus & 1500 & & 1500 & Politbüro \\
\hline 17. Juli $1938^{14}$ plus & 2000 & 3000 & 5000 & Anfrage \\
\hline Summe & 5500 & 13000 & 18500 & $0,35 \%$ \\
\hline \multicolumn{4}{|l|}{ 4. Gruzinische SSR } & 3376946 \\
\hline 10. Juli 193715 & 1419 & 1562 & 2981 & Anfrage/PB \\
\hline 30. Juli 1937 & 2000 & 3000 & 5000 & Befehl 00447 \\
\hline 30. Oktober $1937^{16}$ & & & 5236 & verurteilt \\
\hline 31. Januar 1938 plus & 1500 & & 1500 & Politbüro \\
\hline 2. April $1938^{17}$ plus & 1000 & 500 & 1500 & Anfrage/PB \\
\hline Summe & 4500 & 3500 & 8236 & $0,24 \%$ \\
\hline \multicolumn{4}{|l|}{ 5. Kirgizische SSR } & 1369667 \\
\hline 30. Juli 1937 & 250 & 500 & 750 & Befehl 00447 \\
\hline 31. Januar 1938 plus & 500 & & 500 & Politbüro \\
\hline Summe & 750 & 500 & 1250 & $0,09 \%$ \\
\hline \multicolumn{4}{|l|}{ 6. Tadžikische SSR } & 1382168 \\
\hline 10. Juli 1937a & & & 1775 & Anfrage/PB \\
\hline
\end{tabular}




\begin{tabular}{|c|c|c|c|c|}
\hline 30. Juli 1937 & 500 & 1300 & 1800 & Befehl 00447 \\
\hline 31. Januar 1938 plus & 1000 & 500 & 1500 & Politbüro \\
\hline Summe & 1500 & 1800 & 3300 & $0,24 \%$ \\
\hline \multicolumn{4}{|l|}{ 7. Turkmenische SSR } & 1168538 \\
\hline 9. Juli $1937^{18}$ & 500 & 1475 & 1975 & Anfrage \\
\hline Ehem. Kulaken/Kriminelle & $400 / 100$ & $1200 / 275$ & 1975 & \\
\hline 30. Juli 1937 & 500 & 1500 & 2000 & Befehl 00447 \\
\hline Oktober $1937^{19}$ plus & 1100 & 1300 & 2400 & NKVD \\
\hline 19. Aug. - 30. Dez. 193720 & 1824 & 3340 & 5164 & verurteilt \\
\hline 9. Januar $1938^{21}$ plus & 125 & 252 & 377 & NKVD \\
\hline 27. Januar $1938^{22}$ plus & 500 & & 500 & NKVD \\
\hline 31. Januar 1938 plus & 1000 & & 1000 & Politbüro \\
\hline Januar - September $1938^{23}$ & 2213 & 5882 & 8095 & verurteilt \\
\hline Aug. 1937 - Aug. $1938^{24}$ & 3225 & 3052 & 6277 & $0,53 \%$ \\
\hline Inspektion 193925 & 4037 & 9222 & 13259 & $1,13 \%$ \\
\hline \multicolumn{4}{|l|}{ 8. Uzbekische SSR } & 5847448 \\
\hline 11. Juli 1937 & 1489 & 3952 & 5441 & Anfrage/PB \\
\hline 30. Juli 1937 & 750 & 4000 & 4750 & Befehl 00447 \\
\hline 31. Januar 1938 plus & 2000 & 500 & 2500 & Politbüro \\
\hline Summe & 2750 & 4500 & 7250 & $0,12 \%$ \\
\hline \multicolumn{4}{|l|}{ 9. Baškirische ASSR } & 2956778 \\
\hline 30. Juli 1937 & 500 & 1500 & 2000 & Befehl 00447 \\
\hline \multicolumn{4}{|c|}{ 10. Burjato-Mongolische ASSR } & 647575 \\
\hline 30. Juli 1937 & 350 & 1500 & 1850 & Befehl 00447 \\
\hline $21.10 .1937^{26}$ erhöht auf & 1000 & & 1000 & Anfrage/PB \\
\hline 31. Januar 1938 plus & 500 & & 500 & Politbüro \\
\hline 28. Oktober $1938^{27}$ plus & & & 2500 & Anfrage \\
\hline Summe & 1850 & 1500 & 5850 & $0,90 \%$ \\
\hline \multicolumn{4}{|l|}{ 11. Dagestanische ASSR } & 1009884 \\
\hline 10. Juli $1937 \mathrm{a}^{28}$ & 600 & 2485 & 3085 & Anfrage/PB \\
\hline 30. Juli 1937 & 500 & 2500 & 3000 & Befehl 00447 \\
\hline 26. Sept. 193729 erhöht auf & 1200 & 3300 & 4500 & Anfrage/PB \\
\hline 3. Dez. $1937^{30}$ plus & 800 & & 800 & Politbüro \\
\hline Summe & 2000 & 3300 & 5300 & $0,52 \%$ \\
\hline \multicolumn{4}{|l|}{ 12. Karelische ASSR } & 512554 \\
\hline 10. Juli 193731 & 12 & 74 & 86 & Anfrage/PB \\
\hline 30. Juli 1937 & 300 & 700 & 1000 & Befehl 00447 \\
\hline August $1937^{32}$ plus & 250 & & 250 & Anfrage \\
\hline 13. Oktober $1937^{33}$ plus & 1000 & & 1000 & Anfrage/NKVD \\
\hline
\end{tabular}




\begin{tabular}{|c|c|c|c|c|}
\hline 20. November $1937^{34}$ & 1690 & & 1690 & verurteilt \\
\hline 7. Aug. -31. Dez. $1937^{35}$ & 2676 & 684 & 3360 & verurteilt \\
\hline 31. Januar 1938 plus & 500 & 200 & 700 & Politbüro \\
\hline 1. Januar - 15. April $1938^{36}$ & 2021 & 343 & 2364 & verurteilt \\
\hline Ende der Operation & & & & 15. April 1938 \\
\hline Summe $1^{37}$ & 4697 & 1027 & 5724 & $1,12 \%$ \\
\hline Summe $2^{38}$ & 3935 & 950 & 4885 & $0,95 \%$ \\
\hline \multicolumn{4}{|c|}{ 13. Kabardinisch-Balkarische ASSR } & 512554 \\
\hline 10. Juli 1937 & 360 & 467 & 827 & Anfrage/PB \\
\hline Ehem. Kulaken/Kriminelle & $339 / 21$ & $324 / 143$ & & \\
\hline 30. Juli 1937 & 300 & 700 & 1000 & Befehl 00447 \\
\hline \multicolumn{4}{|l|}{ 14. Krim ASSR } & 994798 \\
\hline 10. Juli $1937 \mathrm{a}$ & 143 & 1385 & 1528 & Anfrage/PB \\
\hline Kulaken/Kriminelle & $109 / 34$ & $1103 / 282$ & & \\
\hline 30. Juli 1937 & 300 & 1200 & 1500 & Befehl 00447 \\
\hline \multicolumn{4}{|l|}{ 15. Komi ASSR } & 309314 \\
\hline 10. Juli 1937 & 211 & 221 & 432 & Anfrage/PB \\
\hline Ehem. Kulaken/Kriminelle & $55 / 156$ & $117 / 104$ & & \\
\hline 30. Juli 1937 & 100 & 300 & 400 & Befehl 00447 \\
\hline 28. August $1937^{39}$ & 211 & 221 & 432 & Anfrage/PB \\
\hline Summe & 311 & 521 & 832 & $0,26 \%$ \\
\hline \multicolumn{4}{|l|}{ 16. Kalmykische ASSR } & 194482 \\
\hline 30. Juli 1937 & 100 & 300 & 400 & Befehl 00447 \\
\hline \multicolumn{4}{|l|}{ 17. ASSR der Mari } & 562322 \\
\hline 10. Juli 1937 & 704 & 1439 & 2143 & Anfrage/PB \\
\hline Ehem. Kulaken/Kriminelle & $366 / 338$ & $692 / 747$ & & \\
\hline 30. Juli 1937 & 300 & 1500 & 1800 & Befehl 00447 \\
\hline September $1937^{40}$ plus & & & 500 & Anfrage \\
\hline Summe & & & 2300 & $0,41 \%$ \\
\hline \multicolumn{4}{|l|}{ 18. Mordwinische ASSR } & 1192012 \\
\hline 10. Juli 1937a & 1250 & 2263 & 3513 & Anfrage/PB \\
\hline Ehem. Kulaken/Kriminelle & $930 / 320$ & $1883 / 380$ & & \\
\hline 30. Juli 1937 & 300 & 1500 & 1800 & Befehl 00447 \\
\hline \multicolumn{4}{|l|}{ 19. ASSR der Wolgadeutschen } & 489328 \\
\hline 30. Juli 1937 & 200 & 700 & 900 & Befehl 00447 \\
\hline Aug. 1937 - Feb. $1938^{41}$ & 3027 & 2603 & 5630 & verurteilt \\
\hline Summe & 3027 & 2603 & 5630 & $0,87 \%$ \\
\hline \multicolumn{4}{|l|}{ 20. Nord-Ossetische ASSR } & 309071 \\
\hline 9. Juli 1937 & 169 & 200 & 369 & Anfrage/PB \\
\hline
\end{tabular}




\begin{tabular}{|c|c|c|c|c|}
\hline 30. Juli 1937 & 200 & 500 & 700 & Befehl 00447 \\
\hline 5. September $1937^{42}$ plus & 200 & & 200 & Anfrage/PB \\
\hline Summe & 400 & 500 & 900 & $0,29 \%$ \\
\hline \multicolumn{4}{|l|}{ 21. Tatarische ASSR } & 2735685 \\
\hline 30. Juli 1937 & 500 & 1500 & 2000 & Befehl 00447 \\
\hline \multirow{2}{*}{ 23. Aug. $37-6$. Jan. $38^{43}$} & & & 5350 & Gesamtquote \\
\hline & & & 5362 & verhaftet ${ }^{44}$ \\
\hline \begin{tabular}{|l} 
Ehem. Kulaken \\
Funktionsträger unter dem \\
Zarismus, Weiße \\
Religionsgemeinschaften \\
Kriminelle \\
Sozialrev. u. andere \\
Nationalisten
\end{tabular} & \begin{tabular}{r|}
1218 \\
569 \\
281 \\
350 \\
137 \\
15
\end{tabular} & \begin{tabular}{r|}
1791 \\
474 \\
89 \\
406 \\
13 \\
19
\end{tabular} & $\begin{array}{r}3009 \\
1043 \\
370 \\
756 \\
150 \\
34\end{array}$ & \\
\hline 23. Aug. $1937-6$. Jan. 1938 & 2570 & 2792 & 5362 & verurteilt 45 \\
\hline \begin{tabular}{|l|} 
Januar 1938 \\
\end{tabular} & & & 5000 & $\begin{array}{l}\text { Anfrage/ } \\
\text { abgelehnt }{ }^{46}\end{array}$ \\
\hline Ende der Operation & & & & 6. Jan. 1938 \\
\hline Summe & 2570 & 2792 & 5362 & $0,2 \%$ \\
\hline \multicolumn{4}{|l|}{ 22. Udmurtische ASSR } & 936005 \\
\hline 10. Juli 1937 & 63 & 423 & 486 & Anfrage/PB \\
\hline Ehem. Kulaken/Kriminelle & $49 / 14$ & $365 / 58$ & & \\
\hline 30. Juli 1937 & 200 & 500 & 700 & Befehl 00447 \\
\hline \multicolumn{4}{|c|}{ 23. ASSR der Čečenen und Ingušen } & 659838 \\
\hline 11. Juli 1937 & 1417 & 1256 & 2673 & Anfrage/PB \\
\hline Ehem. Kulaken/Kriminelle & $862 / 555$ & $730 / 526$ & & \\
\hline 30. Juli 1937 & 500 & 1500 & 2000 & Befehl 00447 \\
\hline \multicolumn{5}{|l|}{\begin{tabular}{|l|} 
13. Juli $1938^{47}$ \\
\end{tabular}} \\
\hline Ende der Operation & & & & 15. Feb. 1938 \\
\hline \multicolumn{4}{|l|}{ 24. ASSR der Čuvaši } & 1023958 \\
\hline 9. Juli 1937 & 140 & 877 & 1017 & Anfrage/PB \\
\hline Ehem. Kulaken/Kriminelle & $86 / 54$ & $676 / 201$ & & \\
\hline 30. Juli 1937 & 300 & 1500 & 1800 & Befehl 00447 \\
\hline Summe & 300 & 1500 & 1800 & $1,8 \%$ \\
\hline \multicolumn{4}{|l|}{25 Region Azov-Černomorskij } & 5601759 \\
\hline 10. Juli 1937 & 6644 & 6962 & 13606 & Anfrage/PB \\
\hline Ehem. Kulaken/Kriminelle & $5721 / 923$ & $5914 / 1048$ & & \\
\hline 30. Juli 1937 & 5000 & 8000 & 13000 & Befehl 00447 \\
\hline \multicolumn{5}{|l|}{ Gebiet Rostov $^{48}$} \\
\hline
\end{tabular}




\begin{tabular}{|c|c|c|c|c|}
\hline \multicolumn{5}{|l|}{ 11. November $1937^{49}$} \\
\hline 13. Mai $1938^{50}$ plus & 3500 & 1500 & 5000 & Anfrage/PB \\
\hline \multicolumn{5}{|l|}{ Region Krasnodar } \\
\hline 20. November $1937^{51}$ & & & 1252 & verurteilt \\
\hline Summe & 8500 & 9500 & 19252 & $0,34 \%$ \\
\hline \multicolumn{4}{|l|}{ 26. Fernöstliche Region } & 2441185 \\
\hline 10. Juli 1937a & 3017 & 3681 & 6698 & Anfrage/PB \\
\hline 30. Juli 1937 & 2000 & 4000 & 6000 & Befehl 00447 \\
\hline 31. Januar 1938 plus & 8000 & 2000 & 10000 & Politbüro \\
\hline 31. Juli $1938^{52}$ plus & 15000 & 5000 & 20000 & Anfrage/PB \\
\hline Summe & 25000 & 11000 & 36000 & $1,5 \%$ \\
\hline \multicolumn{4}{|l|}{ 27. West-Sibirische Region } & 6433527 \\
\hline 8. Juli 193753 & 10924 & 15036 & 25960 & registriert \\
\hline Ehem. Kulaken/Kriminelle & $6642 / 4282$ & $8201 / 6835$ & 25960 & \\
\hline 9. Juli 1937 & 10800 & & 10800 & Anfrage/PB \\
\hline Ehem. Kulaken/Kriminelle & $6600 / 4200$ & & & \\
\hline 30. Juli 1937 & 5000 & 12000 & 17000 & Befehl 00447 \\
\hline August 193754 & 3230 & 1504 & 4734 & verurteilt \\
\hline 4. Oktober $1937^{55}$ & & & 25413 & verhaftet \\
\hline $\begin{array}{l}\text { Ehem. Kulaken } \\
\text { Kriminelle } \\
\text { ROVS - Mitglieder } \\
\text { And. konterrev. "Elemente" }\end{array}$ & & & $\begin{array}{r}10541 \\
3436 \\
9689 \\
1747 \\
\end{array}$ & \\
\hline 5. Oktober $1937^{56}$ & $12876^{57}$ & $6093^{58}$ & 18969 & verurteilt \\
\hline $\begin{array}{l}\text { Ehem. Kulaken/Kriminelle } \\
\text { ROVS/Andere }\end{array}$ & $\begin{array}{r}256 / 1294 \\
6437 / 889\end{array}$ & & & \\
\hline \multicolumn{5}{|l|}{ Gebiet Novosibirsk $^{59}$} \\
\hline 31. Januar 1938 plus & 1000 & & 1000 & Politbüro \\
\hline 4. September $1938^{60}$ plus & & & 1000 & Anfrage \\
\hline \multicolumn{5}{|l|}{ Region Altaj } \\
\hline 20. Oktober $1937^{61}$ & 4000 & 4500 & 8500 & Politbüro \\
\hline 31. Januar 1938 plus & 2000 & 1000 & 3000 & Politbüro \\
\hline Summe & 19876 & 11593 & 31469 & $0,49 \%$ \\
\hline \multicolumn{4}{|l|}{ 28. Region Krasnojarsk } & 1828746 \\
\hline 30. Juli 1937 & 750 & 2500 & 3250 & Befehl 00447 \\
\hline Undatiert ${ }^{62}$ plus & 6600 & & 6600 & Stalin/Molotov \\
\hline 31. Januar 1938 plus & 1500 & 500 & 2000 & Politbüro \\
\hline 16. März $1938^{63}$ plus & & & 1500 & Anfrage/PB \\
\hline 28. April $1938^{64}$ plus & 3000 & & 3000 & \\
\hline Summe & 11850 & 3000 & 16350 & $0,89 \%$ \\
\hline
\end{tabular}




\begin{tabular}{|c|c|c|c|c|}
\hline \multicolumn{4}{|l|}{ 29. Region Ordžonikidze } & \multirow{2}{*}{\begin{tabular}{|l}
1635277 \\
Anfrage/PB
\end{tabular}} \\
\hline 11. Juli 1937 & 2461 & 3672 & 6133 & \\
\hline 30. Juli 1937 & 1000 & 4000 & 5000 & Befehl 00447 \\
\hline \multicolumn{4}{|l|}{ 30. Ost-Sibirisches Gebiet } & 1897049 \\
\hline 30. Juli 1937 & 1000 & 4000 & 5000 & Befehl 00447 \\
\hline \multicolumn{5}{|l|}{ Gebiet Čita ${ }^{65}$} \\
\hline 31. Januar 1938 plus & 1500 & 500 & 2000 & Politbüro \\
\hline 16. April $1938^{66}$ plus & & & 3000 & \\
\hline 29. Aug. $1938^{67}$ plus & & & 3000 & Anfrage/PB \\
\hline \multicolumn{5}{|l|}{ Gebiet Irkutsk } \\
\hline 31. Januar 1938 plus & 3000 & 500 & 3500 & Politbüro \\
\hline 29. April $1938^{68}$ plus & 4000 & & 4000 & Anfrage/PB \\
\hline 25. Aug. $1938^{69}$ plus & 5000 & & 5000 & $\begin{array}{l}\text { Anfrage/ } \\
\text { bestätigt }{ }^{70}\end{array}$ \\
\hline Summe & 14500 & 5000 & 25500 & $1,34 \%$ \\
\hline \multicolumn{4}{|l|}{ 31. Gebiet Voronež } & 6086834 \\
\hline 10. Juli 1937 & 850 & 3687 & 4537 & Anfrage/PB \\
\hline Kulaken/Kriminelle & $720 / 130$ & $2368 / 1319$ & & \\
\hline 30. Juli 1937 & 1000 & 3500 & 4500 & Befehl 00447 \\
\hline \multicolumn{4}{|l|}{ 32. Gebiet Gor'kij } & 3683008 \\
\hline 10. Juli 1937 & 2295 & 4285 & 6580 & Anfrage/PB \\
\hline Kulaken/Kriminelle & $1620 / 675$ & $3850 / 435$ & & \\
\hline 30. Juli 1937 & 1000 & 3500 & 4500 & Befehl 00447 \\
\hline 8. Oktober $1937^{71}$ plus & 1000 & & 1000 & Anfrage/PB \\
\hline 4. Februar 1938 & & & 9600 & verurteilt \\
\hline 4. Februar $1938^{72}$ plus & 3000 & 2000 & 5000 & Anfrage \\
\hline Summe & 5000 & 5500 & 14500 & $0,39 \%$ \\
\hline \multicolumn{4}{|l|}{ 33. Westliches Gebiet } & 4693495 \\
\hline 30. Juli 1937 & 1000 & 5000 & 6000 & Befehl 00447 \\
\hline 30. Juli 193773 & 2000 & & & verhaftet \\
\hline 1. Aug. $1937^{74}$ erhöhen auf & 3000 & 6000 & 9000 & Anfrage/NKVD ${ }^{75}$ \\
\hline $\begin{array}{l}\text { Ehem. Kulaken und } \\
\text { konterrev.'Elemente"/ } \\
\text { Kriminelle }\end{array}$ & $\begin{array}{l}2000 \\
1000\end{array}$ & & & \\
\hline \multicolumn{5}{|l|}{ Gebiet Smolensk $^{76}$} \\
\hline \multicolumn{5}{|l|}{ Okt. 1937 - April $1938^{77}$} \\
\hline \multicolumn{4}{|l|}{ 34. Gebiet Ivanovo } & 2519168 \\
\hline 10. Juli 1937 & 342 & 1718 & 2060 & Anfrage/PB \\
\hline Ehem. Kulaken/Kriminelle & $276 / 66$ & $1293 / 425$ & & \\
\hline
\end{tabular}




\begin{tabular}{|c|c|c|c|c|}
\hline 30. Juli 1937 & 750 & 2000 & 2750 & Befehl 00447 \\
\hline \multicolumn{4}{|l|}{ 35. Gebiet Kalinin } & 3220664 \\
\hline 30. Juli 1937 & 1000 & 3000 & 4000 & Befehl 00447 \\
\hline 16. September 193778 plus & 1500 & & 1500 & Anfrage/PB \\
\hline 13. Dezember $1937^{79}$ plus & 700 & 1000 & 1700 & Anfrage/PB \\
\hline 31. Januar 1938 plus & 1500 & 500 & 2000 & Politbüro \\
\hline Zwischensumme & 4700 & 4500 & 9200 & \\
\hline $\begin{array}{l}\text { 1937/193880 } \\
\text { (Aug. 1937/Dez. 1937) } \\
(1.1 .1938-26.3 .1938)\end{array}$ & 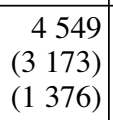 & $\begin{array}{r}5468 \\
(4885) \\
(583)\end{array}$ & $\begin{array}{l}10017 \\
(8058) \\
(1959)\end{array}$ & verhaftet \\
\hline $\begin{array}{l}\text { Ehem. Kulaken 37/38 } \\
\text { (Aug. 1937-Dez. 1937) } \\
(1.1 .1938-26.3 .1938) \\
\end{array}$ & 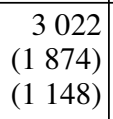 & $\begin{array}{r}3925 \\
(3419) \\
(508)\end{array}$ & $\begin{array}{r}6949 \\
(5293) \\
(1656)\end{array}$ & \\
\hline $\begin{array}{l}\text { Kriminelle 37/38 } \\
\text { (Aug. 1937-Dez. 1937) } \\
(1.1 .1938-26.3 .1938)\end{array}$ & $\begin{array}{r}525 \\
(506) \\
(19)\end{array}$ & $\begin{array}{r}587 \\
(571) \\
(16)\end{array}$ & $\begin{array}{r}1112 \\
\left(\begin{array}{ll}1 & 077) \\
(35)\end{array}\right.\end{array}$ & \\
\hline $\begin{array}{l}\text { Andere konterrev. Elemente } \\
\text { (Aug. 1937-Dez. 1937) } \\
(1.1 .1938-26.3 .1938)\end{array}$ & $\begin{array}{l}1002 \\
(793) \\
(209)\end{array}$ & $\begin{array}{r}954 \\
(895) \\
(59)\end{array}$ & $\begin{array}{r}1956 \\
(1688) \\
(268)\end{array}$ & \\
\hline Aug. 1937 - 26. März $1938^{81}$ & 4587 & 5613 & 10200 & verurteilt \\
\hline Kriminelle & 525 & 588 & 1113 & \\
\hline Ende der Operation & & & & 26. März 1938 \\
\hline Summe & 4587 & 5613 & 10200 & $0,32 \%$ \\
\hline \multicolumn{4}{|l|}{ 36. Gebiet Kursk } & 4166636 \\
\hline \begin{tabular}{|l|}
10. Juli 37 \\
\end{tabular} & 1798 & 2986 & 4784 & Anfrage/PB \\
\hline 30. Juli 1937 & 1000 & 3000 & 4000 & Befehl 00447 \\
\hline \multicolumn{5}{|l|}{ Gebiet Orel ${ }^{82}$} \\
\hline \multicolumn{5}{|l|}{ 13. November $1937^{83}$} \\
\hline \multicolumn{4}{|l|}{ 37. Gebiet Kujbyšev } & 3948246 \\
\hline 10. Juli 1937a & 1881 & 4259 & 6140 & Anfrage/PB \\
\hline 30. Juli 1937 & 1000 & 4000 & 5000 & Befehl 00447 \\
\hline \multicolumn{4}{|l|}{ 38. Gebiet Kirov } & 2380337 \\
\hline 10. Juli 1937 & 368 & 510 & 878 & Anfrage/PB \\
\hline 30. Juli 1937 & 500 & 1500 & 2000 & Befehl 00447 \\
\hline 2. Sep. $1937^{84}$ erhöht auf & 900 & & 900 & Anfrage/PB \\
\hline 25. Oktober $1937^{85}$ plus & 500 & 800 & 1300 & Anfrage/PB \\
\hline Summe & 1400 & 2300 & 3700 & $0,16 \%$ \\
\hline \multicolumn{4}{|l|}{\begin{tabular}{|l|} 
39. Gebiet Leningrad \\
\end{tabular}} & 6831743 \\
\hline 30. Juli 1937 & $4000^{86}$ & 10000 & 14000 & Befehl 00447 \\
\hline \begin{tabular}{|l|} 
November 1937 \\
Dezember 193787
\end{tabular} & \begin{tabular}{ll|}
1201 \\
1701
\end{tabular} & & & $\begin{array}{l}\text { verurteilt } \\
\text { verurteilt }\end{array}$ \\
\hline
\end{tabular}




\begin{tabular}{|c|c|c|c|c|}
\hline $\begin{array}{l}\text { 5.8.1937-31.12.1938 } \\
\text { Kriminelle u. sozial } \\
\text { gefährliche Elemente }\end{array}$ & $\begin{array}{r}2905^{88} \\
(3041)^{89}\end{array}$ & $\begin{array}{r}4209 \\
(3587)\end{array}$ & $\begin{array}{r}7114 \\
(6628)\end{array}$ & verurteilt \\
\hline 31. Januar 1938 plus & 3000 & & 3000 & Politbüro \\
\hline 13. April $1938^{90}$ plus & 1500 & & 1500 & Anfrage/PB \\
\hline Zwischensumme & 8500 & 10000 & 18500 & \\
\hline \multicolumn{5}{|l|}{ Kreis Pskov ${ }^{91}$} \\
\hline 1. Juli 1937 - Mai $1938^{92}$ & & & 3000 & verurteilt \\
\hline Summe & 8500 & 10000 & 18500 & $0,27 \%$ \\
\hline \multicolumn{4}{|l|}{ 40. Gebiet Moskau } & 11971367 \\
\hline 10. Juli 1937 & & & 41305 & registriert $^{93}$ \\
\hline 10. Juli 1937a & 8500 & 32805 & 41305 & Anfrage/PB \\
\hline Ehem. Kulaken/Kriminelle & $2000 / 6500$ & $5869 / 26936$ & 41305 & \\
\hline 30. Juli 1937 & 5000 & 30000 & 35000 & Befehl 00447 \\
\hline 31. Januar 1938 plus & 4000 & & 4000 & Politbüro \\
\hline Operation 00447 & ca. $15000^{94}$ & & & \\
\hline Summe & ca. 15000 & 30000 & 45000 & $0,38 \%$ \\
\hline \multicolumn{5}{|l|}{ Gebiet Tula $^{95}$} \\
\hline Keine Angaben & & & & verurteilt \\
\hline \multicolumn{5}{|l|}{ Gebiet Rjazan } \\
\hline \multicolumn{5}{|l|}{ Keine Angaben } \\
\hline \multicolumn{4}{|l|}{ 41. Gebiet Omsk } & 2330420 \\
\hline 9. Juli 1937 & 479 & 1959 & 2438 & Anfrage/PB \\
\hline 30. Juli 1937 & 1000 & 2500 & 3500 & Befehl 00447 \\
\hline 1. August 193796 & 3008 & & & verhaftet \\
\hline 13. August 1937 & 5444 & & & verhaftet \\
\hline 15. Aug. 193797 erhöht auf & 8000 & & 10500 & Anfrage/Stalin \\
\hline 19. November $1937^{98}$ plus & 1000 & 1500 & 2500 & Politbüro \\
\hline 10. Dezember 193799 & 11050 & 5004 & 16054 & verurteilt \\
\hline 31. Januar 1938 plus & 3000 & 2000 & 5000 & Politbüro \\
\hline 10. Mai $1938^{100}$ & 1000 & & 1000 & Politbüro \\
\hline Juli - Dezember 1937101 & 11091 & 6162 & 17253 & verurteilt \\
\hline Januar-September $1938^{102}$ & 4340 & 2121 & 6461 & verurteilt \\
\hline Ende der Operation ${ }^{103}$ & & & & 13. Sep. 1938 \\
\hline Summe & 15431 & 8283 & 23714 & $1,0 \%$ \\
\hline \multicolumn{4}{|l|}{ 42. Gebiet Orenburg } & 1566010 \\
\hline 11. Juli 1937 & 1720 & 3150 & 4870 & Anfrage/PB \\
\hline Ehem. Kulaken/Kriminelle & $1200 / 520$ & $2390 / 760$ & & \\
\hline 30. Juli 1937 & 1500 & 3000 & 4500 & Befehl 00447 \\
\hline
\end{tabular}




\begin{tabular}{|c|c|c|c|c|}
\hline 28. Aug. $1937^{104}$ erhöht auf & 3500 & & & Anfrage/PB \\
\hline Summe & 3500 & 3000 & 6500 & $0,41 \%$ \\
\hline \multicolumn{4}{|l|}{ 43. Gebiet Saratov } & 1886611 \\
\hline 10. Juli 1937 & 437 & 1586 & 2023 & Anfrage/PB \\
\hline Ehem. Kulaken/Kriminelle & $346 / 91$ & $836 / 750$ & & \\
\hline 30. Juli 1937 & 1000 & 2000 & 3000 & Befehl 00447 \\
\hline \multicolumn{4}{|l|}{ 44. Gebiet Stalingrad } & 2224797 \\
\hline 10. Juli 1937a & 800 & 2200 & 3000 & Anfrage/PB \\
\hline 30. Juli 1937 & 1000 & 3000 & 4000 & Befehl 00447 \\
\hline \multicolumn{4}{|l|}{ 45. Gebiet Sverdlovsk } & 4126450 \\
\hline 10. Juli 1937 & 5000 & 7000 & 12000 & Anfrage/PB \\
\hline Ehem. Kulaken/Kriminelle & $4700 / 300$ & $5800 / 1200$ & & \\
\hline 30. Juli 1937 & 4000 & 6000 & 10000 & Befehl 00447 \\
\hline 31. Januar 1938 plus & 2000 & & 2000 & Politbüro \\
\hline März - Juli $1938^{105}$ & 481 & & & erschossen \\
\hline $\begin{array}{l}\text { Men`̌̌eviki } \\
\text { Mitglieder anderer } \\
\text { oppositioneller Org. }\end{array}$ & $\begin{array}{l}186 \\
295\end{array}$ & & & \\
\hline 5. Mai $1938^{106}$ plus & 1500 & & 1500 & Anfrage/PB \\
\hline 27. September $1938^{107}$ plus & 2000 & 1000 & 3000 & Anfrage/PB \\
\hline Summe & 9500 & 7000 & 16500 & $0,4 \%$ \\
\hline \multicolumn{4}{|l|}{ 46. Nördliches Gebiet ${ }^{108}$} & 2262255 \\
\hline 30. Juli 1937 & 750 & 2000 & 2750 & Befehl 00447 \\
\hline \multicolumn{5}{|l|}{ Gebiet Archangelsk } \\
\hline 20. Oktober 1937109 plus & 400 & 800 & 1200 & Anfrage/PB \\
\hline \multicolumn{5}{|l|}{ Gebiet Vologda 110} \\
\hline Undatiert $^{111}$ & ca. 100 & & & \\
\hline Summe & ca.1 150 & 2800 & ca. 4150 & $0,18 \%$ \\
\hline \multicolumn{4}{|l|}{ 47. Gebiet Čeljabinsk } & 2768565 \\
\hline 10. Juli 1937 & 2552 & 5401 & 7953 & Anfrage/PB \\
\hline 30. Juli 1937 & 1500 & 4500 & 6000 & Befehl 00447 \\
\hline $1937-1938^{112}$ & (8 656) & {$\left[\begin{array}{ll}8 & 130\end{array}\right]$} & $(16786)$ & verurteilt \\
\hline Summe & (8 656) & {$\left[\begin{array}{ll}8 & 130\end{array}\right]$} & $(16786)$ & $(0,61 \%)$ \\
\hline \multicolumn{4}{|l|}{ 48. Gebiet Jaroslavl' } & 2197057 \\
\hline 11. Juli 1937 & 685 & 1265 & 1950 & Anfrage/PB \\
\hline Ehem. Kulaken/Kriminelle & $453 / 232$ & $873 / 392$ & & \\
\hline 30. Juli 1937 & 750 & 1250 & 2000 & Befehl 00447 \\
\hline Aug. 1937 - Jan. $1938^{113}$ & 1708 & 1550 & 3254 & verurteilt \\
\hline
\end{tabular}




\begin{tabular}{|c|c|c|c|c|}
\hline $\begin{array}{l}\text { Kriminelle } \\
\text { Ehem. Kulaken } \\
\text { Religionsgemeinschaften } \\
\text { Aufständische } \\
\text { Terroristen } \\
\text { Ehemalige Sozialrevol. } \\
\text { Saboteure } \\
\text { Konterrevolutionäre } \\
\text { "Elemente" in der Industrie } \\
\text { Trotzkisten } \\
\text { Spione }\end{array}$ & & & $\begin{array}{r}1499 \\
694 \\
558 \\
211 \\
80 \\
66 \\
56 \\
\\
50 \\
32 \\
8\end{array}$ & \\
\hline Aug. 1937 - Mai $1938^{114}$ & 2066 & $?$ & 3616 & verurteilt \\
\hline Ende der Operation ${ }^{115}$ & & & & 19. Mai 1938 \\
\hline Summe & & & & $0,16 \%$ \\
\hline \multicolumn{4}{|l|}{ Ukrainische SSR } & 28387609 \\
\hline 30. Juli 1937 & 8000 & 20800 & 28800 & Befehl 00447 \\
\hline 5. Sep. $1937^{116}$ plus & 4200 & & 4200 & $\begin{array}{l}\text { Anfrage/ } \\
\text { bewilligt }{ }^{117}\end{array}$ \\
\hline 27. Sep. 1937118 & {$\left[\begin{array}{ll}9 & 458\end{array}\right]^{119}$} & 13700 & 23158 & verurteilt \\
\hline 28. September 1937 & & & 39922 & verhaftet \\
\hline 29. Sep. $1937^{120}$ plus & 4500 & 15200 & 19700 & Anfrage/bewilligt \\
\hline 19. Dez. 1937 erhöht auf ${ }^{121}$ & 26150 & 37800 & 63950 & Anfrage/bewilligt \\
\hline $5.8 .1937-31.12 .1937122$ & & & 77813 & verurteilt \\
\hline \begin{tabular}{|l|} 
Ehem. Kulaken \\
Kriminelle \\
Andere kontrev. Elemente
\end{tabular} & & & \begin{tabular}{ll|}
41758 \\
11 & 194 \\
24 & 861
\end{tabular} & \\
\hline 31. Januar 1938 plus & 6000 & & 6000 & Politbüro \\
\hline 17. Februar $1938^{123}$ plus & 15000 & & 15000 & Anfrage \\
\hline 17. Februar $1938^{124}$ plus & & & 30000 & Politbüro \\
\hline Mai 1938 plus & & & $125[35000]$ & Anfrage \\
\hline Mai 1938 erhöht um & & & ${ }^{126}\left[\begin{array}{ll}5 & 000]\end{array}\right.$ & NKVD \\
\hline Summe & & & 113813 & $0,40 \%$ \\
\hline \multicolumn{4}{|l|}{ 1. Gebiet Char'kov } & 505343 \\
\hline 30. Juli 1937 & 1500 & 4000 & 5500 & Befehl 00447 \\
\hline \multicolumn{5}{|l|}{ Gebiet Poltava $^{127}$} \\
\hline \multicolumn{4}{|l|}{ 2. Gebiet Kiev } & 5098241 \\
\hline 30. Juli 1937 & 2000 & 3500 & 5500 & Befehl 00447 \\
\hline \multicolumn{5}{|l|}{ Gebiet Žitomir $^{128}$} \\
\hline \multicolumn{4}{|l|}{ 3. Gebiet Vinnica } & 3918736 \\
\hline 30. Juli 1937 & 1000 & 3000 & 4000 & Befehl 00447 \\
\hline \multicolumn{5}{|l|}{ 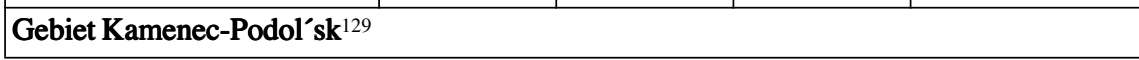 } \\
\hline
\end{tabular}




\begin{tabular}{|c|c|c|c|c|}
\hline \multicolumn{4}{|l|}{ 4. Gebiet Doneck } & \multirow[t]{2}{*}{4578669} \\
\hline 30. Juli 1937 & 1000 & 3000 & 4000 & \\
\hline \multicolumn{5}{|l|}{ 10. März $1938^{130}$} \\
\hline \multicolumn{4}{|l|}{ 5. Gebiet Odessa } & 2925399 \\
\hline 30. Juli 1937 & 1000 & 3500 & 4500 & Befehl 00447 \\
\hline \multicolumn{5}{|l|}{ Gebiet Nikolaevsk $^{131}$} \\
\hline Undatiert $^{132}$ & 2300 & 900 & 3200 & verurteilt \\
\hline \multicolumn{4}{|l|}{ 6. Gebiet Dnepropetrovsk } & 3721228 \\
\hline 30. Juli 1937 & 1000 & 2000 & 3000 & Befehl 00447 \\
\hline \multicolumn{4}{|l|}{ 7. Gebiet Černigov } & 2522371 \\
\hline 9. Juli 1937 & 244 & 1379 & 1623 & Anfrage/PB \\
\hline 30. Juli 1937 & 300 & 1300 & 1600 & Befehl 00447 \\
\hline \multicolumn{4}{|l|}{ 8. Moldauische ASSR } & 569534 \\
\hline 11. Juli 1937 & 11 & 248 & 259 & Anfrage/PB \\
\hline 30. Juli 1937 & 200 & 500 & 700 & Befehl 00447 \\
\hline \multicolumn{4}{|l|}{ Kazachische SSR } & 5120173 \\
\hline 10. Juli 1937 & 2346 & 4403 & 6749 & Anfrage/PB \\
\hline Zwischensumme 30. Juli 1937 & 2500 & 5000 & 7500 & Befehl 00447 \\
\hline 4. Oktober 1937133 plus & 3500 & & 3500 & Anfrage/PB \\
\hline 17. November $1937^{134}$ plus & 2000 & 3000 & 5000 & Anfrage/PB \\
\hline 3. Dezember $1937^{135}$ plus & 600 & 1000 & 1600 & Politbüro \\
\hline 15. Dez. $1937^{136}$ plus & 900 & 3500 & 4400 & Anfrage/PB \\
\hline Ende der Operation & & & & 15. Feb. 1938 \\
\hline Summe & 9500 & 12500 & 22000 & $0,43 \%$ \\
\hline \multicolumn{5}{|l|}{ 1. Nord-Kazachisches Gebiet } \\
\hline 10. Juli 1937a & 658 & 310 & 968 & Anfrage/PB \\
\hline 30. Juli 1937 & 650 & 300 & 950 & Befehl 00447 \\
\hline \multicolumn{5}{|l|}{ 2. Süd-Kazachisches Gebiet } \\
\hline 30. Juli 1937 & 350 & 600 & 950 & Befehl 00447 \\
\hline \multicolumn{5}{|l|}{ 3. West-Kazachisches Gebiet } \\
\hline 30. Juli 1937 & 100 & 200 & 300 & Befehl 00447 \\
\hline \multicolumn{5}{|l|}{ 4. Gebiet Kustanaj } \\
\hline 11. Juli 1937 & 145 & 354 & 499 & Anfrage/PB \\
\hline 30. Juli 1937 & 150 & 450 & 600 & Befehl 00447 \\
\hline \multicolumn{5}{|l|}{ 5. Ost-Kazachisches Gebiet } \\
\hline 30. Juli 1937 & 300 & 1050 & 1350 & Befehl 00447 \\
\hline \multicolumn{5}{|l|}{ 6. Gebiet Aktjubinsk } \\
\hline 30. Juli 1937 & 350 & 1000 & 1350 & Befehl 00447 \\
\hline
\end{tabular}




\begin{tabular}{|c|c|c|c|c|}
\hline \multicolumn{5}{|l|}{ 7. Gebiet Karaganda } \\
\hline 30. Juli 1937 & 400 & 600 & 1000 & Befehl 00447 \\
\hline \multicolumn{5}{|l|}{ 8. Gebiet Alma-Ata } \\
\hline 30. Juli 1937 & 200 & 800 & 1000 & Befehl 00447 \\
\hline \multicolumn{5}{|l|}{ Lager des NKVD } \\
\hline 30. Juli 1937 & 10000 & & 10000 & Befehl 00447 \\
\hline $25.10 .1937^{137}$ plus & 3600 & & 3600 & NKVD \\
\hline \multicolumn{5}{|l|}{ Siblag } \\
\hline 4. Oktober $1937^{138}$ & 803 & & 803 & verurteilt \\
\hline \multicolumn{5}{|l|}{ Fernöstliche Region } \\
\hline 1. Februar $1938^{139}$ & 12000 & & 12000 & Anfrage/PB \\
\hline \multicolumn{5}{|l|}{ Uchtinsko-Pečorskij ITL } \\
\hline Okt. 1937 - Mai $1938^{140}$ & 2755 & & 2755 & verurteilt \\
\hline \multicolumn{5}{|l|}{ Belbaltlag } \\
\hline 5. August $1937^{141}$ & 800 & & 800 & NKVD \\
\hline $\begin{array}{l}\text { 17. Aug. } 1937-10 . \text { Nov. } \\
\text { 1938 }\end{array}$ & 3000 & & 3000 & verurteilt \\
\hline \multicolumn{5}{|l|}{ Volgolag } \\
\hline Aug. 1937 - Jan. $1938^{143}$ & 272 & & 272 & verurteilt \\
\hline Aug. 1937 - Nov. $1938^{144}$ & 30178 & & 30178 & verurteilt \\
\hline \multicolumn{5}{|l|}{ Gefängnisse des GUGB } \\
\hline \multicolumn{5}{|l|}{ Solovki ${ }^{145}$} \\
\hline $\begin{array}{l}\text { 9.10.14. Okt./ 10.25. Nov. } \\
\text { 1937/ 14. Feb. } 1938\end{array}$ & 1825 & & 1825 & verurteilt \\
\hline \multicolumn{5}{|l|}{ Jaroslavskaja tjur'ma } \\
\hline Aug. $1937-$ Jan. $1938^{146}$ & 45 & & 45 & verurteilt \\
\hline \multicolumn{4}{|l|}{ Endrechnung ${ }^{147}$} & $161754970^{148}$ \\
\hline 30. Juli 1937 & 75950 & 193000 & 268950 & Befehl 00447 \\
\hline $\begin{array}{l}\text { Vom Politbüro bestätigte } \\
\text { Erhöhungen der Quoten } \\
\text { Aug. } 1937 \text { - Nov. } 1938\end{array}$ & 150500 & {$\left[\begin{array}{ll}33 & 250\end{array}\right]$} & $183750^{149}$ & \\
\hline $\begin{array}{l}\text { Insgesamt vom Politbüro } \\
\text { bestätigt (Befehl plus } \\
\text { Erhöhungen) }\end{array}$ & 226450 & {$\left[\begin{array}{lll}226 & 250\end{array}\right]$} & 452700 & \\
\hline \begin{tabular}{|l|} 
Nur von der NKVD- \\
Zentrale bestätigte \\
Erhöhungen der Quoten \\
Aug. 1937 - Nov. 1938
\end{tabular} & {$\left[\begin{array}{lll}129 & 655\end{array}\right]$} & {$\left[\begin{array}{lll}170 & 960\end{array}\right]$} & $\begin{array}{r}300000^{150} \\
{[300615]}\end{array}$ & \\
\hline $\begin{array}{l}\text { Vom PB/NKVD bestätigte } \\
\text { Quoten insgesamt }{ }^{151}\end{array}$ & 356105 & [397 210] & 753315 & \\
\hline
\end{tabular}




\begin{tabular}{|l|r|r|r|l|}
\hline $\begin{array}{l}\text { Verurteilungen ohne } \\
\text { Genehmigung durch } \\
\text { PB/NKVD }\end{array}$ & & & $14082^{152}$ & verurteilt \\
\hline Anzahl der Verhaftungen ${ }^{153}$ & & & 699929 & \\
\hline Anzahl der Verhaftungen ${ }^{154}$ & 386798 & {$[380599]$} & 767397 & \\
\hline Anzahl der Verhaftungen & & & & \\
\hline $\begin{array}{l}\text { Verhältnis zur } \\
\text { Bevölkerungszahl }{ }^{156}\end{array}$ & 350000 & 450000 & 800000 & \\
\hline
\end{tabular}

1. Die Tabelle enthält Angaben über die Repression nach Befehl 00447 in den Republiken, Regionen und Gebieten im Zeitraum Juli 1937 bis November 1938. Im Vordergrund steht die Interaktion zwischen Politbüro/NKVD-Zentrale und den regionalen Partei- und NKVD Leitungen bei der Festsetzung der Opferkontingente für die erste (Erschießung) und zweite Kategorie (Lagerhaft bzw. Gefängnis von 8 bis 10 Jahren). Aufgenommen sind: 1.) Angaben über die Vorbereitung des Befehls von Anfang bis Ende Juli 1937. 2.) Die Zahlen des Befehls vom 30. Juli 1937. 3.) Angaben über die Erhöhung der Obergrenzen zwischen dem 30. Juli 1937 und Anfang Januar 1938. 4.) Angaben zur Erhöhung der Kontingente am 31. Januar 1938 durch das Politbüro. 5.) Angaben für den Zeitraum vom 1. Februar 1938 bis zum 15. November 1938. In vielen Fällen konnten die Angaben zusätzlich nach den verschiedenen Zielgruppen aufgeschlüsselt werden. Die Tabelle gibt zusätzlich als Vergleichswert die Bevölkerungszahl und das prozentuale Verhältnis von Bevölkerungs- und Opferzahl (d.h. den Repressionsgrad) an. In der Spalte "Summe" werden die vorhandenen Angaben dann zusammengezählt. Es handelt sich zum größten Teil um vorläufige Zahlen. Wir freuen uns über jede Kritik, noch mehr über Vorschläge zur Verbesserung oder Ergänzung! (Marc.Junge @ruhr-uni-bochum.de)

2. Die Bevölkerungszahlen sind übernommen von V. B. Žiromskaja, I. N. Kiselev, Ju. A. Poljakov, Polveka pod grifom sekretno. Vsesojuznaja perepis' naselenija $1937 \mathrm{~g}$., Moskau, 1996.

3. Postanovlenie Politbjuro CK P[rotokoll]51/[Tagesordnungspunkt]206, in: RGASPI, f. 17, op. 162, d. 21, 11. 98-99. Jede folgende Erwähnung des Datums 10. Juli 1937 a bezieht sich, soweit nicht anders angemerkt, auf diese Quelle, die dann nicht mehr angegeben wird.

4. "Anfrage" aus den Republiken, Regionen und Gebieten.

5. Anfrage/PB bedeutet, daß aus den Republiken, Regionen und Gebieten die Anfragen über die Limite an das Politbüro gestellt wurden und das PB (= Politbüro) diese dann bestätigt hat.

6. Der Text von prikaz 00447 ist veröffentlicht in: Kniga pamjati žertv političeskich repressij. Memorial'noe izdanie, [U1'janovskaja oblast']. Sost. Ju. M. Zlotnikov, Ul'janovsk, 1996, S. 766-780 bzw. in: GULAG (Glavnoe upravlenie lagerei). 1917-1960. Sost. A. I. Kokurin, N. V. Petrov, Moskau, 2000, S. 96-104. Die Liste der den Gebieten, Regionen und Republiken zugeteilten Quoten findet sich auf S. 768 770 bzw. S. 98-99. Jede folgende Erwähnung des Datums 30. Juli 1937 bezieht sich auf diese Quelle, die dann nicht mehr angegeben wird.

7. Der Politbürobeschluß vom 31. Januar 1938 ist als Faksimileabdruck publiziert in: Ju. Feofanov, "Rasstrel po 1-j kategorii”, Izvestija, 3. April 1996, S. 1, 5. Jede folgende Erwähnung des Datums 31. Januar 1938 bezieht sich auf diese Quelle, die nicht mehr angegeben wird.

8. Der Hinweis "Politbüro" bedeutet, daß dieses Organ die Zahlen festgelegt bzw. nach einer Anfrage aus den Republiken, Gebieten und Regionen bestätigt hat.

9. Die Spalte "Summe" gibt immer die Zahl an, die der Endrechnung zugrunde liegt.

10. Verhältnis von Opfer- zu Bevölkerungszahl (Repressionsgrad).

11. P51/212, in: RGASPI,f. 17, op. 162, d. 21,1.99. Jede folgende Erwähnung des Datums 11. Juli 1937 bezieht sich, soweit nicht anders angemerkt, auf diese Quelle, die dann nicht mehr angegeben wird.

12. N. Gevorkjan, "Vstrečnye plany po uničtoženiju sobstvennogo naroda", Moskovskie novosti, 25, 21. Juni 1992, S. 19.

13. Ebenda

14. Ju. Feofanov, art. cit., S. 1,5. 
15. P51/199, in: RGASPI, f. 17, op. 162, d. 21, 11. 96-97. Jede folgende Erwähnung des Datums 10. Juli 1937 bezieht sich, soweit nicht anders angemerkt, auf diese Quelle, die dann nicht mehr angegeben wird.

16. M. Vylcan, "Garantiruetsja vysšaja mera”, Trud, 2. August 1997, S. 5.

17. Ebenda; P69/62, in: RGANI, f. 89, op. 73, d. 133,1.1.

18. P51/187, in: RGASPI, f. 17, op. 162, d. 21, 1. 95. Jede folgende Erwähnung des Datums 9. Juli 1937 bezieht sich, soweit nicht anders angemerkt, auf diese Quelle, die dann nicht mehr angegeben wird.

19. O. Hlevnjuk, "Les mécanismes de la 'Grande Terreur' des années 1937-1938 au Turkménistan", Cahiers du Monde russe, 39, 1-2, 1998, S. 200.

20. Es handelt sich um Zahlen, die bei einer Inspektion des NKVD 1939 durch die Moskauer Zentrale ermittelt wurden. Bemerkenswert ist, daß diese Angaben die Zahlen, die ursprünglich vom turkmenischen NKVD kurz nach der Beendigung der Operation an Moskau gemeldet wurden, um mehr als 100\% überschreiten. Diese hohe Abweichung ist möglicherweise darauf zurückzuführen, daß der turkmenische NKVD vor Ort mit der Durchführung der Operation 00447 personell überlastet war und keine ordnungsgemäße Addierung aller Opfer vorgenommen hat. Chlevnjuk führt die hohe Abweichung der Zahlenangaben auch auf die "gewöhnliche sowjetische Unordnung" in den Behörden zurück (persönliche Mitteilung an Verfasser).

21. O. Hlevnjuk, art. cit., S. 202.

22. Ebenda.

23. Ebenda.

24. Es handelt sich hierbei um die Zahlen, die vom NKVD Turkmeniens offiziell an die Moskauer Zentrale weitergeleitet wurden. Vgl., O. W. Chlewnjuk, Das Politbüro. Mechanismen der politischen Macht in der Sowjetunion der dreißiger Jahre, Hamburg, 1998, S. 275.

25. O. Hlevnjuk, "Les mécanismes ...", art. cit., S. 204.

26. P54/393, in: RGANI, f. 89, op. 73, d. 105,1.1.

27. M. Vylcan, art. cit., S. 5.

28. N. Gevorkjan, art. cit., S. 19.

29. Ebenda.

30. Ju. Feofanov, art. cit., S. 5.

31. I. Čuchin, Karelija-37: Ideologija i praktika terrora, Petrozavodsk, 1999, S. 152 (Faksimile).

32. L. Takala, "Nacional'nye operacii OGPU/NKVD v Karelii", in: V sem'e edinoj. Nacional'naja politika partii bol'ševikov i ee osuščestvlenie na Severo-Zapade Rossii v 1920-1950-e gody. (Pod redak. T. Vichavajnena i I. Takala), Petrozavodsk, 1998, S.188.

33. Ebenda.

34. Ebenda.

35. Errechnet anhand der Angaben bei I. Čuchin, op. cit., S. 146-147.

36. Ebenda.

37. Ebenda, S. $145-147$

38. L. Takala, art. cit., S. 194-196

39. P51/781, in: RGANI, f. 89, op. 73, d. 73,1.1.

40. Tragedija naroda. Kniga pamjati žertv političeskich repressij Respubliki Marij El. Bd 1, Joškar-Ola, 1996, S. 30; K. Sanukov, "Stalinist terror in the Mari Republic. The attack on 'Finno-Ugrian bourgeois nationalism"”, The Slavonic and East-European Review, 4, 1996, S. 675.

41.N. Ochotin, A. Roginskij, "Iz istorii 'nemeckoj operacii' NKVD 1937-1938 gg." in: I. L. Ščerbakova (Hrsg.), Nakazannyj narod. Repressii protiv rossijskich nemcev, Moskau, 1999, S. 67.

42. P51/920, in: RGANI, f. 89, op. 73, d. 77,1. 1 .

43. A. Stepanov,"Rasstrel po limitu”, Volja, 6-7, 1997, S. 106. 
44. A. F. Stepanov, Rasstrel po limitu. Iz istorii političeskich repressij v TASSR v gody "ežovščiny", Kazan, 1999, S. 86.

45. Ebenda.

46. Ebenda, S. 117.

47. Am 13. Juli 1938 ersuchte F. P. Bykov, Erster Sekretär des Gebietskomitees der Republik, das Zentralkomitee in Moskau, "der Einrichtung einer besonderen Trojka mit Sondervollmachten für 4-5 Monate, nach dem Beispiel der zuvor durchgeführten Operation, zuzustimmen." Zapiska Bykova (Čečeno-Ingušskij obkom partii) ob organizacii trojki v Čečeno-Ingušskoj ASSR ot 13 ijulja 1938 g., in: RGANI, f. 89, op. 73, d. 147,1.7.

48. Am 13. September 1937 wird die Region Azovo-Černomorskij aufgeteilt in das Gebiet Rostov und die Region Krasnodar.

49. Am 11. November wurde die entsprechende Trojka vom Politbüro bestätigt, vgl. RGANI, f. 89, op. 73, d. $142,1.1$.

50. P61/149, in: RGANI, f. 89, op. 73, d. 144,1.1.

51.S. Kropačev, Chronika kommunističeskogo terrora. Tragičeskie fragmenty novejšej istorii Otečestva. Sobytija. Masštaby. Kommentary, Bd 1, 1917-1940, Krasnodar, 1995, S. 47 (nach: Kubanskie novosti, 20. Februar 1992).

52. P63/40, in: RGANI, f. 89, op. 73, d. 149,1.1.

53. Bericht S. N. Mironovs an Ežov, 8. Juli 1937, vgl. M. Vylcan, art. cit., S. 5.

54. A. T. Tepljakov, "Personal i povsednevnost' Novosibirskogo UNKVD v 1936-1946 gg.", Minuvšee, 21, Moskau, 1997, S. 254.

55. Wir gehen davon aus, daß die wegen ihrer Mitgliedschaft im ROVS (Rossijskij Obščevoinskij Sojuz/Russische militärische Vereinigung) verhafteten Personen im Rahmen des Befehls 00447 abgeurteilt wurden. Es handelte sich dabei um 9689 Personen.

56. D. Shearer, "Crime and social disorder in Stalins's Russia. A reassesment of the Great Retreat and the origins of mass repression", Cahiers du Monde russe, 1-2, 1998, S. 140-141.

57. Bei A. T. Tepljakov, art. cit., S. 254; D. Shearer, art. cit., S. 141.

58. Vgl. D. Shearer, art. cit., S. 141.

59. Mit einer Anordnung des CIK wurde die West-Sibirische Region am 28. September 1937 in das Gebiet Novosibirsk und die Region Altaj aufgeteilt.

60. RGANI, f. 89 , op. 73 , d. $152,1.3$.

61. P54/369, in: RGANI, f. 89, op. 73, d. 103,1.1.

62. M. Vylcan, art. cit., S. 5 (Faksimile). Diese handschriftliche Notiz Stalins ("Der Region Krasnojarsk ist zusätzlich ein Limit von 6600 Menschen für die erste Kategorie zuzuteilen. Dafür Iosif Stalin, V. Molotov") wurde der ersten Repressionsphase (August bis Ende Dezember 1937) zugeordnet, da es hinter dem Politbürobeschluß zur Umbesetzung der Trojka der Region Krasnojarsk vom 16. August 1937 abgeheftet war. Vgl. P51/684, in: RGANI, f. 89, op. 73, d. 67,1.2.

63. P. 59/190, in: RGANI, f. 89, op. 73, d. 31,1.1.

64. P61/19, in: RGANI, f. 89, op. 73, d. 139,1.1.

65. Am 26. September 1937 wird das Ost-Sibirische Gebiet aufgeteilt in Gebiet Čita und Gebiet Irkutsk.

66. P60/136, in: RGANI, f. 89, op. 73, d. 137,1. 1.

67. N. Petrov, "Tod nach Plansoll. Der operative NKVD-Befehl Nr. 00447": Arbeitstagung "Stalinistischer Terror, Massenrepressalien, Gulag”, Hamburg 21.-22. Februar 1998, S. 12-13. (Quelle: P68/168, in: RGANI, f. 89, op. 73, d. 151,1.1).

68. P61/56), in: RGANI, f. 89, op. 73, d. 140,1.1.

69. Ju. Feofanov, art. cit., S. 5.

70. Daß die Anfrage positiv entschieden wurde, ergibt sich aus der Tatsache, daß in Irkutsk die Trojka (im Rahmen von Befehl 00447) im September 1938 noch mehrmals zusammentrat und wahrscheinlich 
erst im Oktober ihre Arbeit einstellte, vgl. Žertvy političeskich repressij Irkutskoj oblasti: pamjat' i predupreždenie buduščemu. Tom 1: A-B. Sost. P. P Bochanov u.a., Irkutsk, 1998, S. 99, 145-148, 150, 153 , 249,259 .

71. P54/212., in: RGANI, f. 89, op. 73, d. 99,1.1.

72. Ju. Feofanov, art. cit., S. 5.

73. Zu diesem Zeitpunkt waren bereits 2000 für die erste Kategorie vorgesehene ehemalige Kulaken verhaftet, vgl. R. Manning, "Massovaja operacija protiv 'kulakov i prestupnych elementov': apogej Velikoj Čistki na Smolenščine", in: Stalinizm v rossijskoj provincii. Smolenskie archivnye dokumenty v pročtenii zarubežnych i rossijskich istorikov, Smolensk, 1999, S. 239.

74. Ebenda, S. 239-241.

75. Laut Manning bestätigt durch die NKVD-Zentrale, ebenda, S. 241. Wahrscheinlich stimmte auch Stalin zu, vgl. Ežovs Brief vom 11. August 1937 an ihn, in: "Doklad Komissii CK KPSS Prezidiumu CK KPSS po ustanovleniju pričin massovych repressij [...], 9 fevralja 1956g”, in: Reabilitacija: Kak eto bylo. Dokumenty Prezidiuma CK KPSS i drugie materialy. T. 1: Mart 1953-fevral' 1956. Sost. A. N. Artizov, Ju. V. Sigačev, V. G. Chlopov, u.a., Moskau, 2000, S. 320.

76. Ab dem 27. September 1937 wird das Westliche Gebiet unter Einbeziehung des größten Teils seines Teritoriums umbenannt in Gebiet Smolensk.

77. Zwischen Oktober 1937 und Frühjahr 1938 verurteilte die Smolensker Trojka im Rahmen des operativen Befehls 00447 zum Tode oder zu 8 bis 10 Jahre ITL. Vgl. z. B. Iz bezdny nebytija. Kniga pamjati repressirovannych Kalužan, Kaluga, 1994, Bd. 2, S. 15, 95, 234. Genauere Angaben liegen nicht vor.

78. P53/71, in: RGANI, f. 89, op. 73, d. 86,1.1.

79. P56/19, in: RGANI, f. 89 , op. 73 , d. $120,1.1$.

80. Ot $\check{C} K$ do FSB. Dokumenty i materialy po istorii organov gosbezopasnosti Tverskogo kraja. 19181998. Sost. V. A Smirnov, A. V Borisov, M. V. Cvetkova, Tver', 1998, S. 158.

81. Kniga pamjati žertv političeskich repressii Kalininskoj oblasti. Martirolog 1937-1938 gg., T. 1. Sost. E. I. Kravcova, Tver', 1999, S. 26-27.

82. Am 27. September 1937 wurde vom Gebiet Kursk das Gebiet Orel abgespalten.

83. Die Trojka war hier ab dem 7. Oktober 1937 tätig. P54/202, in: RGANI, f. 89, op. 73, d. 98, 1.1; P55/ 202, in: RGANI, f. 89, op. 73, d. 113, 1. 1; Iz bezdny nebytija..., op . cit., Bd 2, S. 15, 151.

84. P51/867, in: RGANI,f. 89, op. 73, d. 75,1.1.

85. P54/487, in: RGANI, f. 89, op. 73, d. 105,1.1.

86. Nach Leningradskij martirolog [= LM], Bd 1, S. 50 war das Kontingent für die erste Kategorie bereits im September 1937 "aufgebraucht". Da im November 19371213 und im Dezember 1701 Personen von der Trojka zum Tode durch Erschießen verurteilt wurden, dürfte Ende September oder im Oktober die Planziffer für die erste Kategorie erhöht worden sein. Vgl. "Statističeskie svedenija o graždanach rasstreljannych v Leningrade v nojabre 1937 g. i vposledstvii reabilitirovannych", in: LM 1937-1938, Tom 3 Nojabr' 1937 goda, St.-Petersburg, 1998, S. 589; Tom 41937 god, St.-Petersburg, 1999, S. 688.

87. Wahrscheinlich waren alle auf Grund von Artikel 58. verurteilt.

88. LM 1937-1938, Bd. 4, S. 576. Hier ist noch eine andere, nur wenig abweichende Zahl für die von der Trojka verurteilten Kriminellen und "social'no opasnye elementy" angegeben.

89. LM 1937-1938, Bd. 4, S. 576-577.

90. P60/115, in: RGANI, f. 89, op. 73, d. 136,1.1.

91. Pskov gehörte 1937/1938 zum Gebiet Leningrad.

92. Ne predat’ zabveniju. Kniga pamjati žertv političeskich repressij, Bd. 1, Pskov, 1996, S. 33.

93. Brief von N. S. Chruščev an das ZK und den Genossen Stalin vom 10. Juli 1937, in: Trud, 4. Juni 1992, S. 1.

94. Rasstrel'nye spiski, Moskva, 1937-1941. "Komunarka”, Butovo. Kniga pamjati žertv političeskich repressij. Sost. L. S. Eremina, A. B. Roginskij, Moskau, 2000, S. 493. 
95. Tula gehörte ebenso wie Rjazan bis zum 26. September 1937 zum Gebiet Moskau. Im Gebiet Tula war eine Trojka eingesetzt worden, vgl. Iz bezdny nebytija..., op. cit., Bd. 2, S. 36, 228 (Verurteilungen im Dezember 1937).

96. A. A. Petrušin, “My ne znaem poščady...” Izvestnye, maloizvestnye i neizvestnye sobytija iz istorii Tjumenskogo kraja po materialam VČK-GPU-NKVD-KGB, Tjumen', 1999, S. 137.

97. Ju. Feofanov, art. cit., S. 5 .

98. P55/261, in: RGANI, f. 89, op. 73, d. 116,1.1.

99. R. Gol’dberg, “Slovo i delo po-sovetski. Poslednyj iz NKVD”, Rodina, 9, 1998 S. 87.

100. P61/128, in: RGANI, f. 89, op. 73, d. 41,1.11.

101. V. M. Samosudov, Bol'šoj terror v Omskom priirtyše 1937-1938, Omsk, 1998.

102. Ebenda. Die letzte Trojka-Sitzung im Rahmen des Befehls 00447 fand am 13. September 1938 statt. Danach handelt es sich, wie aus den Protokollen zu erkennen ist, um die Osobaja Trojka, die die nationalen Minoritäten verurteilte.

103. Ebenda, S. 241.

104. N. Gevorkjan, art. cit., S. 19.

105. V. V. Čevardin, "Esero-menševistskaja operacija NKVD”, in: V. M. Kirillov, Žertvy repressii. Nižnyj Tagil 1920-1980-e gody, Ekaterinburg, 1999, S. 104-105.

106. P61/84, in: RGANI, f. 89, op. 73, d. 141,1. 1.

107. RGANI, f. 89, op. 73 , d. $155,11.1-2$.

108. Am 23. September 1937 wurde das Nördliche Gebiet aufgeteilt in Gebiet Archangel'sk und Gebiet Vologda. Angaben über eine Zuweisung von Kontingenten liegen nur bei Archangel'sk vor.

109. P54/364, in: RGANI, f. 89, op. 73, d. 102,1.1.

110. Sitzungen der Trojka sind bis 16.02.1938 dokumentiert, vgl. Pomorskij memorial. Kniga pamjati Žertv političeskich repressij. T. 1: A-K. Otv. red. Ju. M. Šperling, Archangel’sk, 1999, S. 165, 197, 569.

111. Vgl. A. J. Vyšinskij - I. V. Stalinu, V. M. Molotovu ot 1.2.1939 g., in: Sovetskoe rukovodstvo. Perepiska 1928-1941, Moskau, 1999, S. 398-400.

112. Diese Angaben finden sich in der "spravka o repressijach v 1937-38 godach na territorii Čeljabinskoj oblasti”, die im Januar 1956 im Auftrag einer CK-Kommission erstellt wurde, vgl. Reabilitacija: Kak eto byl..., op. cit., T.1, S. 303. Wahrscheinlich sind in der Endzahl auch die über 2.000 von der Osobaja trojka im September-November 1938 Verurteilten inbegriffen.

113. Archiv FSB Jaroslavskoj oblasti, f. 22, op. 4, d. 3, 11. 1-18.

114. Es liegen hier nur die Angaben über die Zahl der Erschießungen vor. Vgl.: Archiv FSB Jaroslavskoj oblasti.

115. Am 19. Mai 1938 fand die letzte Trojka-Sitzung im Rahmen des Befehls 00447 statt. Vgl., Archiv FSB Jaroslavskoj oblasti.

116. Ju. Šapoval, V. Pristajko, V. Zolotar'ov, $\check{C} K-G P U-N K V D$ v Ukraini. Osoby, fakty, dokumenty, Kyiv, 1997, S. 167: Die Angaben beruhen auf einem Brief des ukrainischen Volkskommisars für Inneres I. M. Leplevskij an Ežov von Ende (29.?) September 1937.

117. Ebenda. Es wird im Text nicht deutlich, wer die Erhöhung bewilligt hat.

118. Ebenda.

119. Ebenda. Im Text steht hier 5458, offensichtlich ein Fehler.

120. Ebenda.

121. Ebenda, S. 168; S. Bilokin, Mechanizm bol`̌̌sevickogo nasilija. Konspekt issledovanija, Kiev, 2000, S. 105-106.

122. B. Nikol'skyj, "Statystyka polityčnych represij 1937 r. v Ukraïns'kij RSR”, Z archiviv VUČKGPU-NKVD-KGB, 2-4, 2000, S. 111-112.

123. S. Bilokin, op. cit., S. 105-106; Brief des neu ernannten ukrainischen Volkskommissars des Inneren A. I. Uspenskij an Ežov vom 17. Februar 1938. 
124. Mitteilung des Sekretärs des ZK (Stalin) an Frinovskij vom 17. Februar 1938: Das Politbüro erlaubt dem NKVD der Ukraine, das Kontingent um 30000 zu erhöhen, vgl.: Ju. Feofanov, art. cit., S. 5.

125. S. Bilokin, op. cit., S. 106-107. Die Zahl 35000 erscheint uns zu hoch und zu unsicher. Sie wurde bei der Addition aus den folgenden Gründen nicht berïcksichtigt: 1.) Bilokin gibt keine Quelle an. Möglich wäre, daß das Limit vom 17. Februar von 30000 um 5000 erhöht wurde, aber auch dafür gibt es keinen zuverlässigen Beleg (siehe folgende Anmerkung.) 2.) Die Operation 00447 wurde in einigen Gebieten der Ukraine bereits im Mai 1938 beendet: Im Gebiet Vinnica fand die letzte Sitzung des in den ukrainischen Quellen "sudtrojka" (sudebnaja trojka) genannten Tribunals am 10. Mai statt, vgl. O. Lošyc'kyj, “'Laboratorija'. Novi dokumenty i svidčennja pro masovi represiï 1937-1938 rokiv na Vinnyččyni”, Z archiviv VUČK-GPU-NKVD-KGB, 1-2, 1998, S. 183-227, hier S. 197-198. Auch für Poltava ist ähnliches anzunehemen. Dem Gebiet Poltava wurde um den 26. Februar 1938 ein Vernichtungskontingent von 500 Personen zugewiesen, das am 1. März nochmals um 2000 erhöht wurde. In dem entsprechenden Telegramm Uspenskijs war angekündigt, "für die erste Kategorie wird es keine weiteren Sollziffern mehr geben.” Im Tätigkeitsbericht des UNKVD für den Zeitraum 1.1.-1.8.1938 sind 3100 Urteile der Trojka des Gebiets Poltava registriert, ausschließlich Todesurteile, keine einzige Lager- oder Gefängniseinweisung. Wir nehmen an, daß die Trojka im Januar/Februar 600 und nach dem 26. Februar entsprechend Uspenskijs Telegramm nochmal 2500 Todesurteile verhängte. O. Lošyc'kyj, "Laboratorija' - 2: Poltava. Dokumental'ni materialy pro masovi represiï v Poltavs'koj oblasti u 1937-1938 rr.", Z archiviv VUCK-GPU-NKVD-KGB, 2/4, 2000, S. 148, 175-176.

126. Im Zuge der Vorbereitung des Prozesses gegen Ežov sagte Uspenskij aus, der Volkskommissar habe ihm "das Limit für die Ukraine um fünftausend Menschen erhöht." Ezov konnte sich an nichts erinnern, da es bei einem Trinkgelage gewesen sei, vgl. Die Erinnerungen des die Voruntersuchung leitenden Staatsanwalts N. P. Afanas'ev in: S. Ju. Ušakov, A. A. Stukalov, Front voennych prokurov, Moskau, 2000, S. 67. Die Zahl wurde bei der Addition nicht berücksichtigt.

127. Am 22. September 1937 wurde aus dem Gebiet Charkov, das Gebiet Poltava ausgegliedert.

128. Am 22. September 1937 wurde hauptsächlich aus dem Kiever Gebiet das Gebiet Žitomir ausgegliedert.

129. Am 22. September 1937 wurde aus dem Gebiet Vinnica, das Gebiet Kamenec-Podol'sk ausgegliedert.

130. Das Politbüro entschied, auf Anfrage des Gebietskomitees der VKP(b) von Doneck, daß die Trojka in der oblast' ihre Arbeit fortsetzen solle. Vgl., P59/22, in: RGANI, f. 89, op. 73, d. 130,1.1.

131. Am 22. September 1937 entstand durch eine Teilung des Gebiets Odessa das Gebiet Nikolaevsk.

132. M. M. Šytjuk, "Masovi represiï na teritoriï Mykolaïvščyny (30-ti rr. XX ct.)”, Ukraïns’kyj istoryčnyj žurnal, 1, 1998, S. 95.

133. P54/72, in: RGANI, f. 89, op. 73, d. 95,1. 1.

134. P55/249, in: RGANI, f. 89 , op. 73 , d. $115,1.1$.

135. Ju. Feofanov, art. cit., S. 5 .

136. P56/39, in: RGANI, f. 89, op. 73, d. 121,1.1.

137. "Doklad Komissii CK KPSS Prezidiumu CK KPSS po ustanovleniju pričin massovych repressij", in: Reabilitacija: Kak eto bylo..., op. cit., S. 320.

138. A. T. Tepljakov, art. cit., S. 254.

139. P57/61, in: RGANI, f. 89, op. 73, d. 124, 1. 2; J. Arch Getty, O. V. Naumov, The road to terror. Stalin and the self-destruction of the Bolsheviks, 1932-1939, New Haven, 1999, S. 520.

140. S. Kuz'min, "Lagerniki. Gulag bez retuši", Molodaja gvardija, 4, 1993, S. 211. Vgl. auch V. M. Poleščikov, "Massovyj terror v GULAGe", in: Pokajanie: Komi respublikanskij martirolog žertv massovych političeskich repressiij. T. 1. Sost. G. V. Nevskij, Syktyvkar, 1998, S. 530-550.

141. I. Čuchin, op. cit., S. 160.

142. Ebenda, S. 125

143. Archiv Jaroslavskoj oblasti, f. 22, op. 4, d. 3, 11. 1-18.

144. S. Kuz'min, art. cit., S. 211. Der Autor beruft sich auf Quellen aus NKVD-Archiven, gibt allerdings keine Fundstelle an. Auf der Hamburger Arbeitstagung "Staatlicher Terror, Massenrepressalien, Gulag" 
vom 21.-22. Februar 1998 gab N. Ochotin (Memorial) an, daß ca. 30000 Lagerhäftlinge im Zuge des Befehls 00447 zum Tode verurteilt worden seien.

145. M. Roženko, E. Bogac'ka, Sosni Bukivni svidčat'. Zloči proti ljudstva, Kiïv, 1999, S. 565 ff (Dokumente).

146. Archiv Jaroslavskoj oblasti, f. 22, op. 4, d. 3, 11. 1-18.

147. Wir haben auf eine Hochrechnung der Zahlen unserer Tabelle verzichtet, da wir einige Politbüroprotokolle nicht einsehen konnten.

148. Bevölkerungszahl 1937 gesamt, abzüglich des Gebiets Jakutien (284500), das nicht an der Operation 00447 teilgenommen hat.

149. Laut Petrov (S. 9) erhöhte das Politbüro auf Antrag aus der Provinz die im Befehl 00447 zugewiesenen Repressionskontingente in dem angegebenen Zeitraum um 183750 Personen (1. Kategorie 150500). Petrov gibt keine Zahl für die zweite Kategorie an, wir haben die vermutlichen Ziffern in eckige Klammern gesetzt. N. Petrov, “Tod nach Plansoll...”, op. cit.

150. Ebenda, S. 9 . Petrov gibt nur die Zahl 300000 an.

151. Ebenda, S. 18.

152. 767397 minus 753315 vgl. vorausgehende Anmerkung.

153. S. V. Kudrjavcev, "Partijnye organizacii i organy NKVD v period massovych politicheskich repressij 1930-ch godov (na materialach oblastej Verchnego Povolž 'ia)," Diss... kand. ist. nauk, Jaroslavl', 2000, S. 165. Diese Angabe beruht auf CA FSB RF, f. 100, op. 5, por. 2, 11. 63, 78-83. Der Verfasser verweist darauf, daß die Angaben unvollständig sind, da die Daten für die Fernöstliche Region und für zwei dem DTO (Dorožno-transportnyj otdel) GUGB NKVD unterstehende Bahnlinien fehlen. Bei Kudrjavcevs Ausführungen bleibt auch undeutlich, auf welchen Zeitraum sich die Ziffer der Verhaftungen bezieht, auf August 1937 bis Juli oder bis November 1938

154. Die Gesamtzahl der nach Befehl 00447 verurteilten Personen liegt laut Petrov bei 767397, von denen 386798 erschossen worden seien. Petrov gibt nur diese beiden Zahlen an. Die Ziffer der nach der zweiten Kategorie Verurteilten müßte demnach 767397 minus $386798=380599$ sein. Vgl. ebenda, S. 9 und S. 18. Die Angabe für die erste Kategorie deckt sich in etwa mit Daten aus anderen Quellen: Nach dem im Februar 1963 dem Zentralkomitee übergebenen Bericht der Svernikkommission wurden 1937 1938 "nach nicht vollständigen Angaben" 631897 Personen von außergerichtlichen Organen (Trojki/ Dvojki) zum Tode durch Erschießen verurteilt, vgl. Vestnik, 1, 1995, S. 120. Die Zahl der von den Dvojki (Komissii NKVD i Prokuratury SSSR) 1937-1938 ausgesprochenen Urteile wird mit 335513 angegeben, darunter 247157 Todesstrafen (vgl. N. Petrov, A. Roginskij, "'Pol'skaja operacija' NKVD 1937-1938”, in: Repressii protiv poljakov i pol'skich graždan, Moskau, 1997, S. 33), das ergäbe 631897 minus $247157=384740$ Todesurteile der Trojki. Petrovs Zahlenreihe 386798 (erste Kategorie), 380599 (zweite Kategorie), 767397 (Gesamtzahl der Verurteilten) wirft jedoch noch ein Problem auf: Petrov hat mehrfach behauptet, daß die Relation Todesstrafen / Haftstrafen in der Operation $0044749,3 \%$ zu 50,7 gewesen sei, vgl. ebenda, S. 33. Ausgehend von der Gesamtziffer 767397 ergäbe das 378327 für die erste Kategorie und 389070 für die zweite.

155. M. Vylcan, art. cit., S. 5 ; M. Vylcan, V. Danilov, "Primenenie VMN "nami garantiruetsja", Nauka i Žizn', 9, 1997, S. 71; R. Manning, art. cit., S. 230-254. Die Verfasser geben nicht an, welche Daten ihren Berechungen zugrunde liegen.

156. Dieser Rechnung liegen die Zahlen der tatsächlich verurteilten, d. h. 767397 (1. Kategorie 386798, 2. Kategorie 380599) zugrunde. 